\title{
Organisation and Self-Concept in Year 6 and Year 7 Mathematics
}

By

Rebecca Blackwood

Thesis submitted to the Victoria University of Wellington in partial fulfillment of the requirements for the degree of Masters of Education

Victoria University

2013 


\begin{abstract}
In New Zealand, schools use the term "tracking", "ability grouping", "setting" or "streaming" to define their class grouping and organisation for mathematics. This organisation of grouping may hinder students' development of mathematical concepts in their primary and secondary school years. To group or not to group seems to be an important question facing many mathematical educators today. The aim of this study was to investigate if class organisation in regards to grouping affects female students' mathematical self-concept.
\end{abstract}

The research looks at possible factors affecting mathematical self-concept of students in a comparative study of their Year 6 and Year 7 mathematics learning by focusing on their attitudes to grouping in mathematics over a one-year period spanning two year levels. The Year 6 class organisation was mixed ability (within-class ability grouping for number strategies). The same cohort of girls was followed into Year 7 where three classes were taught using whole class teaching, with a cross-class ability grouping approach.

This research draws from data collected from a purposive sample of one school in the Wellington area. Qualitative and quantitative methods were used in order to explore whether class organisation (cross-class or mixed ability grouping) affected students' self-concept in relation to their mathematical learning. The underlying research paradigm was social constructivist, chosen in order to gain knowledge from students' experiences and perceptions.

Thirty-one questionnaires and nine one-to-one semi-structured interviews were used. The questionnaire answers were put into three categories of strategy groupings based on the expectations for Number from the New Zealand Curriculum (Ministry of Education, 2003a) in order to explore the responses from students of a broad range of abilities. Each semi-structured interview was recorded and transcribed in full for analysis.

This study indicates that students are aware of their mathematical ability whether being taught in a small group or whole class situation. Year 6 students preferred learning within a small group ability approach. They felt that this way of organisation fostered an inclusive environment which allowed for individual differentiation, encouraged risk 
taking, collaboration, helping of others, and feeling confident to discuss ideas, strategies, and ask questions without feeling judged by their peers.

Whole class contribution, test scores, and assessment was found to affect the Year 7 students' mathematical self-concept negatively and positively. The students felt that learning within a whole class approach which was broadly ability grouped was a positive experience as all students could hear everyone's questions, ideas, strategies, and points of view.

Implications from this research include that more exploration is needed in New Zealand schools into the effects of class organisation on students' mathematical self-concept in order to inform teacher practices of differentiation in relation to the organisation of small group and whole class situations. This and other such research can also inform professional development for teachers on effective ways to create inclusive mathematics learning community environments. 


\section{Acknowledgements}

I would like to acknowledge the following people for all their help and support. My supervisor Dr Robin Averill has been of tremendous support for me over the years providing encouragement and a positive spirit to keep me going. This thesis would not have been possible without her understanding, advice, and knowledge.

My family has offered continual encouragement and support throughout the time that I have spent on this thesis, allowing me the opportunity to write and to focus on the research process, especially after the birth of my son.

The school that allowed me to trial and carry out my research and those who took part in the final study must be acknowledged. Their support of education research shows that as teachers we are continually trying to listen to and improve our teaching for our students learning. 


\section{Contents}

Abstract

Acknowledgements............................................................

List of Tables.................................................................. 4

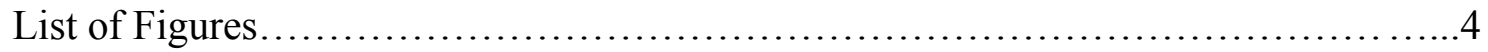

List of Appendices........................................................... 5

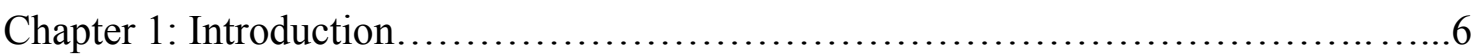

1.1: Background.........................................................

1.2: New Zealand Education System........................................... 8

1.3: Self-concept and Mathematics...........................................11

1.4: Summary and Research Question..................................... 12

1.5: Thesis Outline........................................................ 13

Chapter 2: Literature Review............................................. 14

2.1: Classroom Organisation............................................. 14

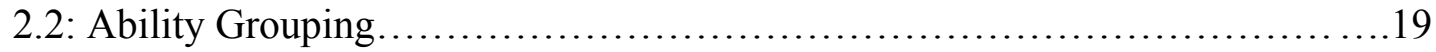

2.3: Self-Concept and mathematics.......................................24

2.3.1: Self-Concept and Ability Grouping................................25

2.3.2: Transition and Self-Concept....................................26

3.3.3: Gender and Mathematical Self-Concept..............................27

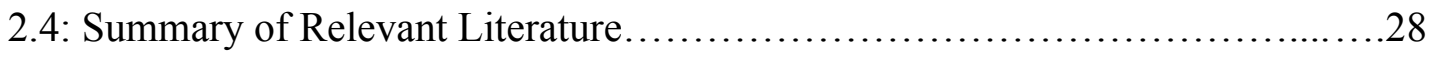

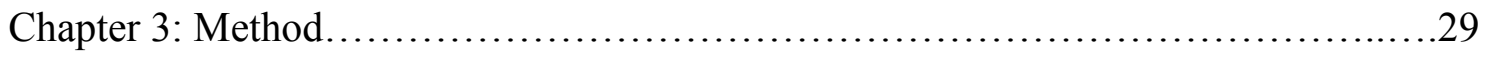

3.1: Methodological Approach...................................................29

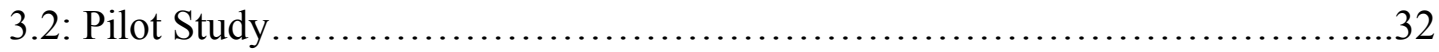

3.3: Research Participants................................................33

3.3.1: Choice of School......................................................

3.3.2: Students..................................................... 34

3.3.3: Teachers....................................................... 34

3.4: Ethics................................................................

3.5: Data Collection Process...................................................... 36

3.6: Analysis Techniques................................................ 37

3.7: Summary ...................................................... 38

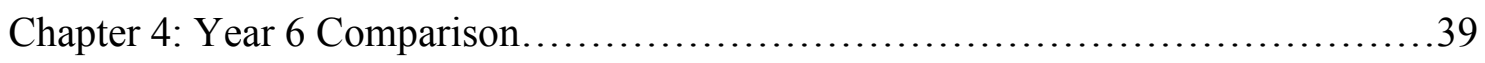

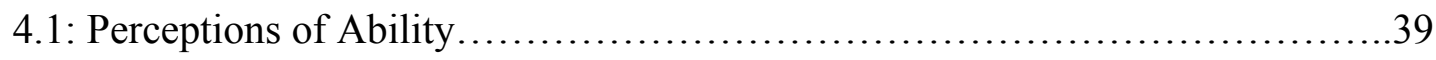




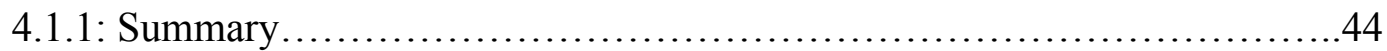

4.2: Grouping and Students' Preferences for Organisation of Grouping.............44

4.2.1: Summary...................................................... 47

4.3: Ways of Learning.................................................47

4.3.1: Summary.................................................... 52

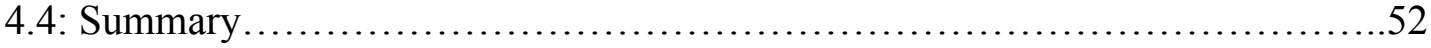

Chapter 5: Year 7 Comparison..............................................53

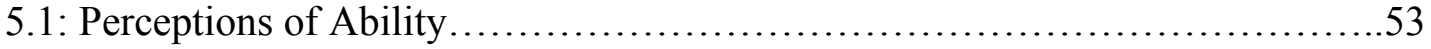

5.1.1: Summary..................................................... 58

5.2: Grouping and Students' Preferences for Organisation of Grouping.............59

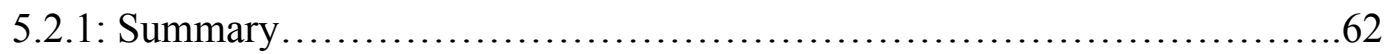

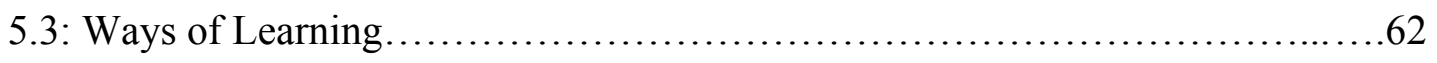

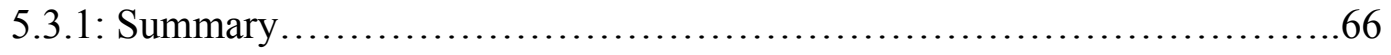

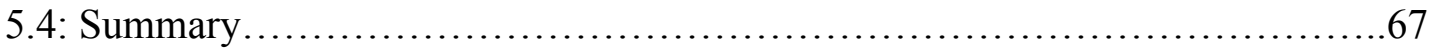

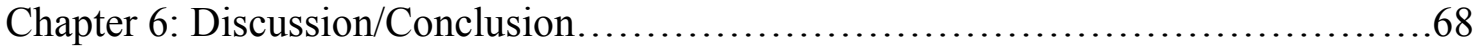

6.1: Perceptions of ability..................................................68

6.2: Grouping and Students' Preferences for Organisation of Grouping.............71

6.3: Ways of Learning................................................... 73

6.4: Conclusion.......................................................76

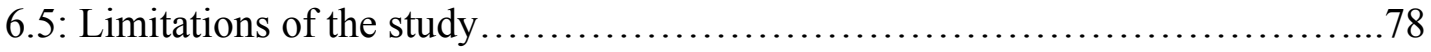

6.6: Further questions promoted by the study................................79

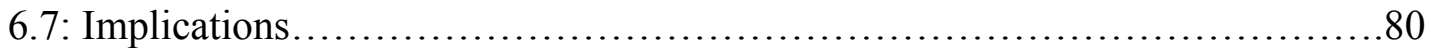

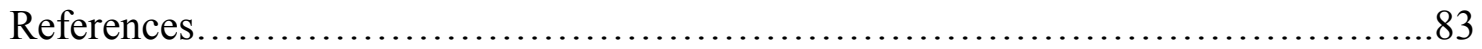




\section{List of Tables}

Table 1.1: New Zealand Curriculum Mathematical Numeracy Standards

Table 2.1. Types of ability grouping

Table: 3.1: Timetable of collecting data

Table 3.2 : The breakdown of the questionnaire questions in this study into analysis categories

p. 38

Table 3.3 : The breakdown of the semi-structured interview questions in this study into analysis categories

Table 4.1: Student pseudonyms and ability stages

Table 4.2: Students' responses regarding how they and others perceive their mathematical ability

Table 4.3: Students' responses to asking questions in mathematics

p. 48

Table 5.1: Students' responses regarding how they and others perceive their mathematical ability

p. 54

Table 5.2: Students' responses to asking questions in mathematics

p. 64

Table 5.3: Students' responses to asking questions in mathematics

p. 64

\section{List of Figures}

Figure 4.1: Students' responses in relation to how students like mathematics by students' Numeracy Stage

Figure 4.2: Students' responses in relation to how good students think they are at mathematics by students' Numeracy Stage

Figure 4.3: Students' responses in relation to if they ask question in a whole class situation in mathematics by Numeracy Stage

Figure 4.4: Students' responses in relation to asking questions in small groups in mathematics by Numeracy Stage

Figure 4.5: Students' responses in relation to if they ask the teacher questions one-on-one in mathematics by Numeracy Stage

Figure 4.6: Students' responses in relation to if they ask the teacher for help in mathematics by Numeracy Stage 
Figure 5.2: Students' responses in relation to how good students think they are at mathematics by Students' Numeracy Stage

Figure 5.3: Students' responses in relation to if they ask question in a whole class situation in mathematics by Numeracy Stage

Figure 5.4: Students' responses in relation to asking questions in small groups in mathematics by Numeracy Stage

Figure 5.5: Students' responses in relation to if they ask the teacher questions one-on-one in mathematics by Numeracy Stage

Figure 5.6: Students' responses in relation to if they ask the teacher for help in mathematics by Numeracy Stage

Figure 6.1: A comparison of students' Numeracy Stages from Year 6 to Year 7 student responses in relation to how good students think they are at mathematics

Figure 6.2: A comparison of students' Numeracy Stages from Year 6 to Year 7 student responses in relation to how students like mathematics

Figure 6.3: A comparison of students' Numeracy Stages from Year 6 to Year 7 student responses in relation to asking questions in small groups in mathematics

Figure 6.4: A comparison of students' Numeracy Stages from Year 6 to Year 7 p.75 student responses in relation to if they ask question in a whole class situation in mathematics

Figure 6.5: A comparison of students' Numeracy Stages from Year 6 to Year 7 student responses in relation to if they ask the teacher questions one-on-one in mathematics

Figure 6.6: A comparison of students' Numeracy Stages from Year 6 to Year 7 student responses in relation to if they ask the teacher for help in mathematics

\section{List of Appendices}

Appendix 1: Questionnaire for Year 6 and Year 7

Appendix 2: Semi-Structured Interviews for Year 6 and Year 7

Appendix 3: Information Letters

p. 95

Appendix 4: Consent Forms

p. 98 


\section{Chapter 1: Introduction}

The way in which a classroom is organised has been studied in many ways and from many perspectives. This thesis explains one of the aspects least often explored: group organisation in primary school classrooms and how this may affect students' mathematical self-concept. In this study the context is the year before and the year after the transition from a primary school to a middle school, both within the same school environment. Students' views of their class organisation for mathematics instruction in each year will be compared. This chapter will outline the researcher's background, provide an overview of the study context, describe the rationale for undertaking this research, and introduce the research questions, which are given at the end of the chapter.

In New Zealand, as in many countries, students will experience different ways of classroom organisation through their schooling. Ability grouping or differentiation is the practice of dividing students for instruction on the basis of their perceived capacities for learning. Two forms of ability grouping used in New Zealand primary schools are within-class and cross-class grouping. In mathematics, cross-class grouping is often used to address content differentiation or acceleration for high ability students. Students in classes grouped by ability are relatively homogeneously grouped (grouping students according to ability) and students in mixed-ability classes are organised heterogeneously.

The differences between the ways students are grouped for mathematics learning in New Zealand classrooms is the focus for this research. Schools and teachers have different ways of structuring classroom organisation. In New Zealand primary schools, students are generally grouped into year levels and have a classroom teacher who teaches all or most of the subjects of the curriculum. Students will generally stay with this teacher for most of the day. When New Zealand students leave the primary school (Years 1 to 6) many transition into an intermediate school setting (Years 7 to 8) often with a similar way of grouping. In some places, students move into a middle school (Years 7 to 10). New Zealand middle schools tend to follow a secondary school type structure. In a New Zealand secondary school, students often have a form teacher who takes most of the responsibility for their school-based pastoral care, and who may or may not teach the students for one subject. Secondary school students are generally taught by a variety of different subject specialist teachers throughout the day. 


\subsection{Background}

The stimulus for carrying out this study has come from my own personal experiences as a child and now as an education professional. I was never placed in the advanced class and I felt that I was never good enough when it came to mathematics. Finally, over time I knew that I would be placed in the "lower set", the "dummies class". I believe that this placement contributed to a mental block understanding mathematical concepts easily throughout my primary and secondary school years.

In my role in charge of Junior School mathematics in a New Zealand primary school I have become increasingly aware that a large number of our school students have an aversion to mathematics. I have wondered if these feelings could be intensified by the fact that students are grouped by ability. As a primary school teacher I enjoy teaching mathematics and I am very passionate about my programme delivery. I want my students to enjoy mathematical lessons, be challenged and be successful, to have confidence in their learning and to feel positive about mathematics, regardless of their ability. Throughout these experiences I have questioned how class organisation benefits students academically as well as emotionally and wanted to know to what extent grouping inhibits students' mathematical self-concept.

To group or not to group seems to be an important question facing many mathematical educators today. In 2003 the Ministry of Education established the Best Evidence Synthesis Iterative (BES) project to deepen understanding of what works best for learners in mathematical education (Anthony \& Walshaw, 2007). The project involved examining research and practice aimed at maximising desirable outcomes for the diverse learners in the New Zealand education system. Findings showed that 'engaging students in mathematical thinking through a variety of organisational structures' (p. 18) was the best way forward for students' learning. The BES identified that the New Zealand Numeracy Development Project (NDP) supported this variety of classroom organisation, offering a 'teaching model that encourages both whole-class and small group teaching' (p. 66). Group participation is known to develop students' sense of self-concept therefore using the NDP's teaching model should help support development of positive self-concept in mathematics (Diezmann \& Watters, 2001). 
Self-concept is the idea or mental image of oneself that includes weaknesses and strengths of an individual. A study carried out in 2003 by the Programme for International Student Assessment (PISA) surveyed 15-year-old students from 41 countries including 4500 students from New Zealand (Ministry of Education, 2009a). The participants were surveyed about their mathematical attitude, interest, enjoyment, motivation, and sense of belonging, anxiety, strategies, self-efficacy, and self-concept. The results showed that about a third of students (33\%) saw themselves at being 'just no good' at mathematics, but over two-thirds of students (71\%) saw themselves getting good marks, and over half of all students (56\%) saw themselves learning mathematics quickly. The research showed that New Zealand students had highly mixed views about their own abilities in mathematics. The study also showed that boys had a stronger sense of self-concept than girls (Ministry of Education, 2009a). However, it was not clear that the girls did not have mathematical ability and the results indicated that differences between genders were more about how students saw their own ability.

Through this study, whether or not class organisation affects this low self-concept among girls was explored. My reasons for choosing to focus only on female participants included the small scale of the study, and wanting to focus on the context that is current and relevant to my own work teaching in an all-girls' school.

\subsection{New Zealand Education System}

The National Education Guidelines (NEGs) and The National Administration Guidelines (NAGs) are at the heart of New Zealand education (Ministry of Education, 2008). The NAGs provide teaching and learning programmes which incorporate The National Curriculum as expressed in The New Zealand Curriculum 2007 (Ministry of Education, 2007). Boards of Trustees within schools have the responsibility of fostering achievement of their students by providing the learning from the Curriculum and assessing students' learning against the National Standards (Ministry of Education, 2009b). The National Education Goals (NEGs) identify that education is at the core of New Zealand's nation and that the Government sets goals for the education system of New Zealand. 
The previous New Zealand Mathematics Curriculum (Ministry of Education, 1992) identified that some lower ability students needed to have the opportunity to experience a range of mathematics that was suitable for their age, interests and capabilities. Students with exceptional ability need to be extended and the curriculum advocated that improving students' participation rate in mathematics through real life problem solving experiences would encourage student confidence and independence. In order for problem solving to occur, students needed opportunities to work co-operatively as a group to express ideas and to listen and respond to others. However, it was not clearly stated how this classroom organisation was best applied.

The New Zealand Ministry of Education introduced a new curriculum into New Zealand in 2007 (Ministry of Education, 2007), stating that students need to be given learning situations to impact students and to have the ability to take risks, to discuss with others, and to listen actively within a mixed class approach. However, there has been little explanation as to how the students perceive themselves as mathematical learners and I see this as an issue that needs inquiry; in order to adhere to students' needs it is imperative that educators are aware of how students feel and see themselves as mathematicians in a given learning situation. If education professionals are to have more direction regarding which methods are most beneficial for their students' selfconcept and achievement, more research is needed. There is a gap within New Zealand research, and schools would benefit from greater awareness of how practised approaches impact students within New Zealand Primary Schools.

In a comparative study in 2000, the Education Review Office reported finding that New Zealand primary school mathematics students are likely to be taught in small groups, which are organised by ability. The report identified two issues regarding teaching mathematics that need further understanding and exploration in New Zealand classrooms: preferred teaching styles and classroom organisation. The Ministry of Education (2009b) specifies in its Mathematics Standards that students need to be given opportunities to gain confidence and to have the ability to take risks, to discuss with others, and to listen actively.

Existing research examining the student's point of view about ability grouping is limited, particularly within New Zealand. The Education Review Office (2000) states 
that in New Zealand schools, students are generally grouped according to ability, to match ideas and learning with the teaching strategy. Research into the transition from a primary to a secondary school setting found that the structure of the schooling (e.g. different teachers for different subjects) decreased students' motivation (Cocklin, 1999 cited in Matheson, 2009). Matheson's 2009 New Zealand study into mathematics teaching before and after the Year 8/9 transition found fewer opportunities for the students to make decisions in secondary school lessons, as activities set were less personal and were more likely to be whole class tasks than in primary school mathematics lessons.

The National Standards provide a national means of responding to New Zealand students' progress and achievement in years 1-8 (Ministry of Education, 2009b). The standards assist with teacher judgments about their students' progress and work alongside the student and families to set the next learning goals. The purpose of the National Standards is to promote quality teaching and learning of mathematics in every New Zealand classroom. The Ministry of Education (2009b) clearly stipulates that the curriculum and the standards work together, the curriculum driving the teaching and the standards supporting the teachers with the student assessment. Table 1.1 shows this link between the New Zealand Curriculum, the National Standards and the Numeracy Project Stages. Research findings from the Numeracy Development Projects (NDP) ratify the importance of quality programmes in mathematics (Ministry of Education, 2009b).

\section{Table 1.1}

New Zealand Curriculum Mathematical Numeracy Standards (Adapted from Expectations for Number - the New Zealand Curriculum and the Mathematics Standards http://nzmaths.co.nz/expectations-number?parent node)

\begin{tabular}{|l|l|l|l|l|l|}
\hline \multicolumn{2}{|c|}{ Curriculum Level 2 } & \multicolumn{2}{c|}{ Curriculum Level 3 } & \multicolumn{2}{c|}{ Curriculum Level 4 } \\
\hline $\begin{array}{l}\text { Standard at the } \\
\text { end of year 3 }\end{array}$ & $\begin{array}{l}\text { Standard at the } \\
\text { end of year 4 }\end{array}$ & $\begin{array}{l}\text { Standard at the } \\
\text { end of year 5 }\end{array}$ & $\begin{array}{l}\text { Standard at the } \\
\text { end of year 6 }\end{array}$ & $\begin{array}{l}\text { Standard at the } \\
\text { end of year 7 }\end{array}$ & $\begin{array}{l}\text { Standard at the } \\
\text { end of year 8 }\end{array}$ \\
\hline \multicolumn{2}{|c|}{ Numeracy Stage 5 } & \multicolumn{2}{|c|}{ Numeracy Stage 6 } & \multicolumn{2}{c|}{ Numeracy stage 7 } \\
\hline
\end{tabular}

The Numeracy Professional Development Project provides several ways of managing and organising students for mathematics, putting students together from close strategy stages and cross-grouping between classes for a few students at the extreme ends of the strategy stage (Ministry of Education, 2003b). However, other factors can be taken into 
consideration when forming instructional groups including ability to work collaboratively, friendship and heterogeneous grouping (Ministry of Education, 2003b).

Some New Zealand schools use a curriculum in line with the International Baccalaureate (IB) (International Baccalaureate Organisation, 2009). The perspective of the International Baccalaureate (IB) is on "inclusivity, not only are all students engaged in the programme, but all students are engaged with each other in constructing meaning, and in doing so learning to accommodate the range of abilities and perspectives that will inevitably exist in a heterogeneous classroom" (International Baccalaureate Organisation, 2009, p. 18). However, the Primary Years Programme (PYP) does stipulate that between-class grouping can allow for short-term grouping based on ability. The PYP states that ability grouping for very high achievers in mathematics can be positive for students and it clearly recognises that both approaches can be useful. It is unclear, however, to what extent each approach impacts upon students' mathematical self-concept.

\subsection{Self-Concept and Mathematics}

Self-concept is a significant factor underpinning levels of motivation for academic performance. Self-concept can be broadly defined as a student's personal perception of him or herself (Shaverlson \& Bolus, 1981). These perceptions can be formed and influenced through one's experiences and their environment. Through experiences of teaching the lower-ability class, I have observed some bleak perceptions as a classroom educator. The motivation, self-esteem and learning expectations were low from a Year 4 class, saying that they 'can't do the work' and they are 'no good at mathematics'. Students in the low-ability groups have lower self-concept than those students in higherability groups (MacIntyre \& Ireson, 2002).

Self-concept is a multidimensional construct that refers to a person's perceptions of self in terms of both academic and nonacademic aspects (Bong \& Clark, 1999). Academic self-concept refers to a person's "perception of self with respect to achievement in school" (Reyes, 1984, p. 559). In particular a person's self-concept refers to the perception or belief in their ability to do well. According to Wong (1992) mathematics achievement is closely related to self-concept and attitudes towards mathematics. Findings from Davis (1994) clearly suggest that mathematical self-concept is closely 
related to mathematical achievement, which implies that actual changes in mathematics education should address the student's self-concept as well (Davis, 1994). Walker and Debus (1991) argue that judgments of self-concept are based on social and selfcomparisons within the individual's context. Nevertheless, when Ireson and Hallam (2005) measured self-concept of students from year 9, they found a positive relationship between prior and current self-concept. Being in a mixed ability school, rather than an ability grouped school, had a positive impact on students' self-concept. From the research it is evident that there is a lack of conclusive findings of academic performance and self-concept. The research reviewed helps demonstrate that research of students' self-concept of mathematics in a New Zealand context will add to our understanding of students' mathematics learning and will be useful for informing teacher practice and teacher education.

\subsection{Summary and Research Question}

In order to improve the understanding of what occurs in New Zealand classrooms, and to understand how classrooms are organised during mathematics and effects of class organisation, this study was designed to explore class grouping in mathematics in Year 6 and Year 7 classrooms within one school. Through a comparative research process this study aimed to identify differences and similarities between how students were grouped and how they felt about that grouping across the two-year levels, to explore self-concept of female students in the way that they perceive their own mathematics learning and achievement.

The study is situated at the researcher's own school and focused on female students in Years 6 and 7. The aim of this research was to investigate female students' self-concept within mathematics by answering the following question:

- To what extent does class organisation in mathematics affect female students' mathematical self-concept?

This question will be answered by collecting data and identifying, categorizing and analyzing student responses. 


\subsection{Thesis Outline}

Chapter 1 has provided an introduction as to why I wanted to learn more about classroom organisation in mathematics and how students perceive themselves within that grouping. Chapter 2 will outline previous international and New Zealand research in the areas of ability grouping, class organisation, differentiation, gender, and selfconcept of students within mathematics. The underlying methodology of the data collection and analysis and how the study was conducted is described in Chapter 3. The analysis of data is compared from year to year and is described in Chapters 4 and 5. The conclusions from the research, how the results of this study add to the field of knowledge in this area, and the significance of the research for teaching mathematics at Years 6 and 7 are the focus of the final chapter, Chapter 6. 


\section{Chapter 2: Literature Review}

This review is the starting point for my investigation into how class organisation, such as different types of ability grouping, affects a female student's mathematical selfconcept. In order to frame the study this chapter is split into four sections. Section 2.1 deals with how New Zealand schools organise mathematical classrooms, the impacts on students, and explores the pros and cons of small group and whole class organisation. This section also looks at differentiation and why it is an important consideration in a mathematical programme.

Ability grouping is the practice of dividing students for instruction on the basis of teachers' perceptions of students' academic progress. There are several terms relating to grouping for ability used by schools to define class grouping for mathematics (Table 2.1), which will be used in the following discussion.

Table 2.1

Types of ability grouping (Adapted from Ireson \& Hallam, 2001)

\begin{tabular}{|l|l|}
\hline Types of ability grouping \\
\hline Banding & $\begin{array}{l}\text { Students are placed in two, three, or four bands on the basis of a test of their general ability. Each band } \\
\text { contains a number of classes and pupils may be regrouped within the band for some subjects. }\end{array}$ \\
\hline Setting (regrouping) & Students are grouped according to their attainment in a subject. \\
\hline Streaming (tracking) & Students are placed in classes on the basis of a test of their general ability. \\
\hline $\begin{array}{l}\text { Within class ability } \\
\text { grouping }\end{array}$ & Students are grouped within the class on the basis of ability in the subject. \\
\hline $\begin{array}{l}\text { Mixed ability } \\
\text { (heterogeneous } \\
\text { grouping) }\end{array}$ & $\begin{array}{l}\text { Students may be grouped with others of a range of abilities within class. Other factors, such as social } \\
\text { relationships, gender or ethnic composition, may form the basis for grouping. }\end{array}$ \\
\hline
\end{tabular}

Section 2.2 deals with what the research says about ability grouping and explores different types of ability grouping. This section will discuss what is said in the literature that indicates whether heterogeneous or homogenous grouping is suitable for New Zealand schools.

What happens in the classroom that can alter a student's mathematical self-concept is the focus of Section 2.3. The discussion will focus on how ability grouping and the transition of students from primary to secondary school in New Zealand affects a student's self-concept. Other research dealing with gender (especially for girls) and the effects of gender on mathematical self-concept will be presented. 


\subsection{Classroom Organisation}

Class organisation is managed in different ways in order to establish an effective environment where all students can achieve and have the opportunity to maximize their learning experiences. In mathematics, effective mathematics organisation promotes active learning as students manipulate materials to investigate, discuss and construct concepts within a range of mathematics experiences (Booker, Bond, Sparrow \& Swan, 2004).

In New Zealand the backbone of class organisation in mathematics is the Numeracy Development Project (NDP). This project gives guidelines for class organisation, assessment information, and developing classroom programmes. The classroom mathematics planning should also meet the achievement objectives of the mathematics and statistics learning area of the New Zealand Curriculum (Ministry of Education, Book 3, 2003b). There are three clear steps to organise the class programme:

(a) analysis of knowledge hot spots,

(b) assigning stages to students, and

(c) grouping for instruction (Ministry of Education, 2003b, p.10).

Teachers, according to their perceptions of individual or class needs, identify the "hot spots'. These are problematic areas of knowledge that need addressing and are generally taught as a warm up in a whole class situation. Assigning strategy stages is also organised using individual ability, taking into account gaps of learning and strengths. Membership in these groups is intended to be flexible depending on individual needs and what is being taught and learnt at the time. Grouping for instruction is developed for students to be actively engaged in small group discussion by asking and answering questions of others (Ministry of Education, 2003b). Grouping students by their strategy stages makes it easier for the teacher to pose problems that are broadly in the students' "zone of proximal development" (Vygotsky, 1978 cited in Ministry of Education, $2003 \mathrm{~b}, \mathrm{p} .11)$. The characteristics advocated for teachers forming these groups are friendship, ability and co-operation opportunities. Most mathematics classes have students at a wide range of strategy stages. These can be managed in many ways, including:

(a) putting together students from close strategy stages,

(b) cross-grouping between classes for a few students at the extreme ends of the range, and 
(c) using parent or teacher aide help to monitor group or independent work (Ministry of Education, 2003b, p.11).

The Numeracy Development Project (NDP) advocates that there are benefits for using a range of organisational methods when grouping students, depending on the situation, such as class and individual needs. Grouping students by ability allows individuals to work on problems that match their prior learning, providing intense situations for dialogue and new learning, and increasing students' potential for success (Ministry of Education, 2003b). Implementing ability grouping successfully is advocated as the key to promoting high student expectations of themselves. Therefore good routines and habits of students need to be established: "Using mixed ability grouping may be created on a social basis that allows compatible students to work together" (Ministry of Education, 2007, p12). This type of grouping allows for students of differing abilities to learn from one another through questioning and explaining (Slavin, 1990). Last of all, working individually allows students the opportunity to reflect on their own personal confidence and their ability to recall knowledge or use strategies (Ministry of Education, 2003b). Schools that have taken part in the NDP tend to focus on grouping students based on the strategy stages of the students and these groups are often flexible. The groupings depend on the planned learning outcomes, the strand of the national curriculum taught, and the teachers' assessment of students.

Organising students into small groups and having them work in pairs allows for caring relationships between teacher and students, and between students (Ministry of Education, 2003b). Acknowledging student voice and student needs, and letting students know they are valued, are also seen as a way to improve attitudes, with students knowing what is expected of them, and sharing ownership of the learning process (Ministry of Education, 2003b). In this way students can take risks, be more involved in discussions and group work, and be free from the negative preconceptions of others toward them. An advantage of using small groups is that students can work cooperatively together in small cooperative learning groups. Cohen (1994) differentiates cooperative group work from students interacting while sitting together working on individual tasks. She defines cooperating as "students working together in a group small enough that everyone can participate on a collective task" (Cohen, 1994, p3). 
Whole class teaching as well as students working individually were classroom organisation approaches used by a higher proportion of teachers of mathematics in 1998 than in 1994 (Ministry of Education, 2002). Research has found that low achievers are only minimally involved in whole class lessons and students may appear distracted as other students explain their thinking (Baxter, Woodward \& Olson, 2001). This may be because low achievers have limited opportunities to speak and participate within whole class discussions.

In 1994, findings from New Zealand's participation in TIMSS-98/99 at the Year 9 level found that two levels of grouping were being implemented during lessons in the main, which included working individually with assistance from the teacher (63\%) and working together as a class with the teacher teaching the whole class (51\%) (Ministry of Education, 2002). In 1998, these approaches were used but were more likely to be used in every lesson than was the case in 1994. While some teachers still used working in pairs or small groups, this organisation of grouping tended to be used less often than was the case in 1994 (Ministry of Education, 2002). The findings showed that:

Teachers of mixed ability groups deviated from the pattern. For example, 'whole class' teaching was not used to the same extent in mixed ability classes - just six percent of students in mixed ability classes were taught mathematics in a whole class setting 'every lesson' (more than $20 \%$ in other groups). However, working in pairs or groups with assistance from the teachers was the approach more frequently used for students in these classes ( $23 \%$ most lessons compared with $18 \%$ or less for students in other groupings). Working individually with assistance from the teacher was actually more prevalent 'every lesson' for more than a quarter of students in lower ability and average ability classes. (Ministry of Education, 2002, p. 67)

When organising a mathematics class, research has identified that students' learning is improved when there are "strong and supportive relationships amongst students and teachers and a positive tone in the school that supports the learning of all students" (Education Review Office, 2007, p.31). It is clear from different forms of research that valuing students' contributions is vital for influencing the way in which students view their relationship with mathematics (Anthony \& Walshaw, 2007). However, Bartholomew (2003 sited in Anthony \& Walshaw, 2007) found that teachers do not always value student contribution and therefore may add to a student's low 
mathematical self-concept. Other ways of building a student's self-concept involve using self and peer assessment, which are tools for promoting student thoughtfulness and self-management: "Teaching students the skills to take charge of their learning is a vital part of preparing them to be lifelong learners" (Education Review Office, 2007, p28).

Bossert (1979), in a landmark study of social relationships in classrooms, found that task and activity structure determined student relationships and interactions with each other. The study showed that the teacher's programme and the rationale for group organisation were directly linked to the students' friendship patterns, peer status and grouping. However, when "single task large group formats prevailed, fixed academic hierarchies formed influencing friendship patterns and academic status shaped by the teacher's public evaluations. Students became more competitive and less inclined to help, or associate with, many other class members" (Bossert, 1979).

However, an international review of task context use in mathematics education found that whole class discussion following individual or group work improves student achievement. Individual or pair grouping work can give students the opportunity to scaffold their own learning through preparing, reflecting on, and/or practising a task before risking public participation. In addition, whole class discussion enables key ideas from individual or group work to be brought to the surface (Grouws \& Cebulla, 2000). In contrast, when working with a partner, the low-achieving students were engaged in the task, touching materials and talking with their partners, but often the roles of the partners were quite different. The low-achieving students usually assumed a nonmathematical task, such as managing materials, while their average- or high-achieving partners made mathematical decisions. When two low achievers worked together, they were slow to begin work and were easily distracted. They also tended to need additional help from the teacher or an aide to understand the task and begin work (Baxter, et al, 2001).

In the classroom, differentiated learning is a process, which is intended to enable teachers to enhance learning for all students regardless of ability. Differentiating students is an approach that focuses on the needs of groups of students or individuals in order to assist with them achieving and feeling success and confidence. Differentiation 
permits all students to access the same classroom curriculum by providing entry points, learning tasks and outcomes that are adapted to the needs of the student (Hall, Strangman, \& Meyer, 2003). A teacher may differentiate based on several factors or any combination of factors, such as grouping preferences (i.e., individual, small group, or large group), learning style (i.e., a visual, auditory, tactile, or kinesthetic learner), or environmental preferences (i.e., lots of space or a quiet area to work) (Tomlinson, 1999). A meta-analysis by Kulik \& Kulik (1982) of the effects on achievement of grouping programmes showed that programmes which offer the same basic curriculum have little or no effect on achievement, but that programmes differentiated for the aptitude of the group are beneficial for pupils of all ability levels.

\subsection{Ability Grouping}

Ability grouping in education has long been the subject of debate. Two forms of ability grouping used in New Zealand schools are within-class (grouped by ability in the class) and cross-class (grouping across classes by ability) grouping. Students grouped by ability are homogeneously grouped (grouping students according to ability). Students in mixed-ability classes are heterogeneously grouped. The advantages and disadvantages of grouping students by ability have been debated for many years (Bartholomew, 2003) with mixed research findings regarding the effects of ability grouping. The discussion is particularly relevant to middle and secondary mathematics education, as mathematics, more than any other subject, tends to be taught in homogeneously grouped classes (Loveless, 1998; Boaler, William \& Brown, 2000). Many studies of ability grouping have focused on questions of equity, and the negative effects on children who are taught in low-ability classes (Slavin 1990; Oaks, 1995). Other studies have found that some grouping systems have benefits for learners (Kulik \& Kulik, 1982).

The Education Review Office carried out research in 2008 in a New Zealand School that focused on providing for gifted students and implemented a study using mixed ability classes. Parents and the school community struggled with the perception of mixed ability classes. The principal, with board support, convinced the community this would be good for their children and presented evidence through research and current theories. The principal said, "A benefit of mixed ability classes was that all teachers had a stronger awareness of what was meant by gifted and talented. Teachers planned and 
implemented differentiated learning programmes to suit students, particularly gifted and talented students" (Education Review Office, 2008, p. 15). The school created a substantially inclusive culture with gifted and talented students being highly valued and respected by the school community. The principal attributed this lack of tall poppy syndrome to the use of mixed ability classes:

There was no nerds' class anymore and this used to be very apparent. Now the children are learning about life, how to deal with people, how to understand other people's struggles. (Education Review Office, 2008, p. 18)

A survey has shown that students felt they were being bullied and asked for better monitoring when organised in mixed ability classes. New strategies were implemented and through a subsequent survey students felt happy, excited and engaged (Education Review Office, 2008). In this study, the school was seen as more enjoyable as the students were allowed to make choices and decisions. Students felt challenged and were given leadership opportunities. Year 8 students acknowledged that their self-esteem had grown hugely between the start of Year 7 and the end of Year 8. The students were engaged, focused and motivated, saying, "It's okay to succeed at this school" (Education Review Office, 2008). The Education Review Office identified that effective gathering and use of assessment data had a strong influence on students' achievement. When teachers and school managers used the information appropriately, it is believed that students' motivation and self-esteem will also be enhanced (Ministry of Education, 2007).

Findings from New Zealand's participation in TIMSS-98/99 at the Year 9 level found that in almost all instances classes for mathematics were grouped based on ability (Ministry of Education, 2002). More than 80 percent of students were in schools where some form of grouping by ability was used for teaching mathematics. However, there was considerable variation in how schools grouped students for mathematics, for example, 'within class ability' grouping and 'mixed ability grouping'. Some schools' classes were described as 'mixed ability' and there were classes for 'remedial' students and very high ability (or accelerated) students (Ministry of Education, 2002).

Many studies have shown that ability grouping arrangements can bring about increased learning for students (e.g., Becker \& Foletta, 2003; Holloway, 2001). In the UK and the 
USA, grouping by 'ability' has had a long tradition as a practice founded upon the idea that "students have relatively fixed levels of ability and need to be taught accordingly" (Boaler, William \& Brown, 2000, p. 632). In the first half of the $20^{\text {th }}$ century, intelligence tests were used to measure ability, whereas in the 1960s education was more child-centered and questions were being raised about the effects of streaming in primary schools (Jackson, 1964). In the meantime, the United Kingdom proposed that streaming students would improve National Curriculum scores. Boaler, et al (2000), amongst others, claim that existing research has tended to report the effects of ability grouping practices rather than proving detailed insights into the way that tracking and setting impact upon students' learning of mathematics. They suggest that this is partly because the majority of studies use quantitative research methods "with no analysis of the mechanisms by which tracking influences learning” (Boaler, et al, 2000, p. 633).

Hollifield (2000) identifies that one of the main arguments against using cross-class ability grouping is that low achievers can be deprived of the example and learning provided by higher achievers. Labeling students by ability and assigning some to a low achievement group may also communicate self-fulfilling low expectations for these students, affecting their self-concept. The self and self-beliefs are increasingly being seen as factors underpinning levels of motivation for academic performance and perceptions of ability are formed as individuals attempt and complete tasks. Pajares and Schunk (2001) highlight these ideas by declaring that in educational settings, the perceptions students create of themselves and their learning are vital forces in their success or failure in school. In turn, students' sense of their academic selves will have a substantial bearing on how they approach their studies. Studies of Bankston and Zhou (2002), Lockett and Harrell (2003), Ross and Broh (2000), Schmidt and Padilla (2003), and Verkuyten and Brug (2002) all found that academic achievement and one's selfconcept are positively correlated.

Diezmann and Watters (2001) provide evidence that shows that putting students in small homogenous groups to complete group tasks significantly enhances knowledge construction, claiming that the positive effects of homogenous grouping for gifted students outweigh those offered through heterogeneous groups. Many studies show that ability grouping arrangements can bring about increased learning and achievement for students (e.g. Holloway, 2001). It can be easier for teachers to teach and manage 
homogenous classes, and low-achieving students may feel more comfortable and participate more when working with students of a similar ability.

In addition, reasons for grouping students by ability can be viewed through improving test scores and providing differential work for individuals (Foote, 2006). This aspect can be seen in a positive way: grouping students in small groups by ability allows for differentiated, concentrated learning to occur in a focused, safe environment. Smith and Sutherland (2003) identified in their study that perceived advantages of cross-class ability grouping (setting) could be seen, such as:

- encouragement of teamwork and collaboration with colleagues in primary schools;

- the creation of a different ethos: in particular, attention was focused and work became more purposeful;

- easier preparation and 'set management' for the teacher; and

- more whole class teaching could take place.

However, the study did identify disadvantages of grouping by ability such as:

- difficulty motivating pupils in the slower sets;

- sets were often fairly rigid and inflexible; and

- moving pupils from one set to another.

Holloway (2003) declares that heterogeneous grouping is best for students' learning as students bring different experiences and different abilities to the group. Lower achieving students are more likely to make gains with their learning when they interact with higher achievers. Similarly, the impact on higher achieving students is positive because of the consolidation of concepts that takes place through discussion and sharing of ideas:

Quality teaching for heterogeneous groups of students, whether by ethnicity, socioeconomic status of the student's homes, special educational needs, language background, gender or other differences, is a fundamental challenge for New Zealand schooling. For each individual student the intersection of social class, ethnicity and gender can markedly influence cultural practices, preferences and prior experiences (Smith \& Sutherland, 2003, p.5). 
Research has shown that collaboration of peers benefits gifted students, as well as low attainers. Having mixed ability groups can lead to greater success for all group members rather than other types of grouping (Adams, Carlson, \& Hamm, 1990; Bennett \& Cass, 1998; Kutnick, 1994). Lower achieving students are more likely to make gains with their learning when they interact with higher achievers. This is because of the levels of interactions that take place in the group process. Similarly, the impact on higher achieving students is positive because of the consolidation of concepts that takes place through discussion and sharing of ideas.

Gardner (2001, cited in Foote 2006) characterized mixed ability grouping as being the best for all students. Students have the opportunity to become good role models when working with others. Students have high expectations of them and are motivated to push themselves. The students have a better understanding of their peers and provide support through developing co-operation (Foote, 2006).

Despite a lack of research and evidence to favour setting as the most effective organisational method, many schools in Scotland have changed their organisational procedures (Smith \& Sutherland, 2003). There is, therefore, a contradiction apparent with policy makers in that 'setting' continues to be implemented, although research for this type of grouping is limited. Schools are then caught between these two conflicting messages (Smith \& Sutherland, 2003) about which method is beneficial for students:

As neither setting nor mixed ability organisation appears to offer great advantages in terms of raising standards, decisions about the best way to group pupils should be based on other considerations. It is time for a reassessment of the organisation of pupils to achieve a better alignment between grouping, pedagogy and learning outcomes. Social outcomes should also be considered (Ireson, Hallam \& Hurley 2002, p. 12).

Research has focused on the motivation of students and acknowledged difficulties in both mixed ability and set grouping. It has been perceived as being easier to motivate pupils who work more slowly than others through mixed ability grouping; however, the motivation of 'more able pupils' was found to be more difficult to achieve within mixed ability classes (Smith and Sutherland, 2003). By cross-class grouping students it is easier for teacher planning and class management. However, with mixed ability 
arrangements it takes a great deal more effort to plan and organise than other methods of organisation (Smith \& Sutherland, 2003).

In contrast, from a homogenous approach, schools using mixed ability direct teaching are less dependent on whole class sessions. Small group and one-on-one teaching are then implemented more than whole class teaching. Two ways of maximising direct teaching opportunities are: the encouragement and facilitation of independent learning by pupils, and teachers being aware of the range of abilities within their classes and catering for diversity (Smith and Sutherland, 2003). Smith and Sutherland (2003) identified the advantages they found from their study, such as:

- a lower likelihood of pupil stigmatisation;

- ease of maintaining the motivation of those pupils working at a slower rate;

- greater flexibility for pupils to progress at their own rates; and

- pupils benefitting from peer support.

Smith and Sutherland identified the disadvantages of mixed ability grouping as including:

- a good deal - sometimes inordinate amounts - of organisation and preparation for staff;

- difficulty providing appropriate challenges for the most able pupils; and

- difficulty undertaking whole class lessons because of the range of abilities in the class.

\subsection{Self-Concept and Mathematics}

For the purpose of this research mathematical self-concept refers to an individual's perception or belief in their ability to do well in mathematics. These perceptions are formed and influenced within the environment that a student is exposed to. Studies have shown that "individuals are capable of forming biased (optimistic or pessimistic) appraisals of their competence" (Martin \& Debus, 1998, p. 518) and therefore the selfconcept of one's abilities in mathematics contains subjective knowledge about various strong and weak points, themes and topics, and about their individual level of mathematical understanding and mastery. The positives may be associated with positive emotions such as pride and satisfaction, whereas the negatives can be linked with 
emotions such as shame and dissatisfaction. Therefore, it is vital for educators to be aware of identifying strengths and weaknesses in students' mathematical learning and allowing students to do the same, as self-concept is an important construct in education because of its linkage to academic achievement (Valentine, Dubois, \& Cooper, 2004 cited in Wang, 2007).

From the humanist perspective, self-concept is the focal point of an individual's personality (Rogers, 1982), which shapes and adjusts the behaviour of students including academic achievement (Coms \& Snygg, 1959). The association between selfconcept and students' academic achievement in schools has been a focus of research for many years (Hamachek, 1995). The majority of these studies have supported the belief that there is an important relationship between self-concept and academic achievement. In a study, Brookover, Erikson and Joiner, as cited in Hamachek (1995), looked into the relationship between self-concept of ability and academic performance of more than 1000 male and female students over a four-year period. The findings indicated that selfconcept was a major factor in achievement at each year level. Academic self-concept in mathematics is an individual's self-perceived belief and feelings about themselves as well as their confidence about their competence within their own learning environment. Educators need to be aware of the environment as experienced by their students and take this into consideration when organising grouping within the class. Research has shown that students do become aware of their knowledge more when working with others than they do when working independently. Providing collaborative groups that offer feedback from teachers and peers can help to create a positive self-concept within students. These results are reinforced by Boaler's (1999) study that found that a predictor of a positive self-concept in mathematics is a group climate where students work together and feel support from teachers and peers. It is clear that students who work independently do not have the same opportunity to get positive feedback on their reasoning as students who interact with teachers and peers (Boaler, 1999).

\subsubsection{Self-Concept and Ability Grouping}

Boaler, et al (2000) studied the effects on students' perceptions of mathematics as they moved from a Year 8 to a Year 9 class. They found that students in lower ability group classes had fewer instructional opportunities to learn than those in higher ability classes. 
Brooks and Brooks (1993 cited in Anthony and Walshaw, 2007) observed that a student's unwillingness to answer teacher questions was due to confidence, and whether the student felt confident enough that they knew the answer: "When asking students questions, most teachers seek not to enable students to think through intricate issues, but to discover whether students know the 'right' answers" (Anthony and Walshaw, 2007, p.59). It is clear that having a positive student teacher relationship is important for building self-concept and perceptions in mathematics.

Braddock \& Slavin (1995) cite several studies that show negative effects of ability grouping, especially on students in low-ability groups who are frequently taught by less able teachers, cover less content than higher ability classes, and suffer from loss of motivation and self-image. They found that in ability-grouped classes, overall selfconcept diminished slightly for above average students, but improved for low-ability students. Ireson, Hallam \& Plewis (2001) studied 45 English secondary schools, and found that overall self-concept was higher in schools with moderate levels of ability grouping than in tightly streamed or un-streamed schools. They found that mathematical self-concept was not related to ability grouping in mathematics. Even some opponents of streaming agree that gifted children (the most able three to five percent of students) benefit from grouping in programmes designed to accelerate their learning (Rogers, 1991; Braddock \& Slavin, 1995).

\subsubsection{Transition and Self-concept}

In recent years, a few Year 7 and Year 8 classes from primary and intermediate schools have been reorganised into middle schools or as part of secondary schools. International and New Zealand literature has identified differences between primary and secondary schools and argued that these can be major causes of anxieties for students transferring between the institutions (Pollard, 1984 sited in Ministry of Education, 2003c). On the other hand, there is no conclusive evidence about whether any negative effects last over time. Primary schools are often seen as a more nurturing experience for students than secondary schools, as they are largely centered round a homeroom environment (Ministry of Education, 2003c), with secondary schools implementing a more specialised approach where teachers teach separate subjects (Ward, 2000). A longitudinal study of relevance to New Zealand was the 12 to 18 Projects in Australia (Yates, 1999). The project built up biographies of students in several schools based 
upon their transition experiences from primary to secondary schooling and their thinking about themselves as they went through school. The biographies showed that most primary students viewed their own upcoming transition to secondary school more positively than negatively. What students thought about a subject was dictated by what they thought about its teacher, which is a reminder for education about teacher impact on students' learning and affect (Ministry of Education, 2003c).

\subsubsection{Gender and Mathematical Self-concept}

Gender is a concept to take into consideration when focusing on mathematics and selfconcept as many girls see mathematics as difficult (Fouad, 2008). Fouad (2008) identifies that confidence and interest are closely related and that if a student feels they can do it then that will feed their interest.

A study implemented in Castrop-Rauxel in Germany with 10 participating teachers (7 female, 3 male), 159 girls and 152 boys aged 8 and 9 years found that girls and boys did not differ in their general ability; however, they found that girls relied upon the teacher's perceptions to evaluate their own ability, whereas boys identified their ability from mathematical performance (Dickhauser \& Meyer, 2006). Stipek and Gralinski (1991) found that girls have lower expectations of themselves in mathematics than boys do. They identified that some girls believe that they do not have mathematical ability. Manger and Eikeland (1998) in their study of the effect of mathematics self-concept on girls' and boys' mathematical achievement found that Norwegian elementary schoolboys showed significantly higher mathematics self-concept than girls.

In summary, numerous studies have explained gender differences in self-concept. Males are typically found to have higher self-concept in mathematics than females (Marsh \& Yeung, 1998). Such gender differences in academic self-concept at least partially explain gender differences in career-related choices (Nagy, Trautwein, Koller, Baumert \& Garrett (2006); Nagy, Garrett, Trautwein, Cortina, Baumert \& Eccles, 2008). In an early study, Fennema and Sherman (1978) suggested that boys had a higher self-concept as they were more confident in their mathematical skills. However, recent findings suggest that boys and girls have equal confidence during primary school but, by middle and secondary school, boys have grown more confident (Pintrich \& De Groot, 1990). 


\subsection{Summary of Relevant Literature}

This chapter has discussed what is said in the literature regarding grouping, indicating that ability grouping is used in many countries for organising students in mathematics, whether it is done using in-class ability grouping or cross-class organisation. Studies have shown that there are pros and cons for low and high achievers for the different ways in which schools and teachers can implement class organisation. An inclusive environment is needed for students to develop a good perception of their own mathematical ability, especially when it comes to female students. Whether or not classroom organisation in mathematics affects student self-concept is important to explore and is the focus for this study. The research methodology that has been conducted in this study is outlined in Chapter 3. 


\section{Chapter 3: Method}

This chapter outlines the methodological approach for the study and its rationale (Section 3.1) and how the research was conducted. Aspects of the research school and participants are described in Section 3.2. Details of the selection process for participants in this research and the involvement of participants in the interview are included in Section 3.3. The process used for data collection, collation and analysis is elaborated in Section 3.4.

\subsection{Methodological Approach}

The basis of the research is a comparison study between the views of the same group of students across two different year levels in order to examine two different approaches to classroom organisation in mathematics. In researching the questions, qualitative and quantitative methods were chosen in order to explore whether class organisation (crossclass or mixed ability grouping) affected students' self-concept in relation to their mathematical learning. The underlying research paradigm is a social constructivist one (Cohen, Manion, \& Morrison, 2000) which was chosen in order to gain knowledge from students' experiences and perceptions. It is qualitative in that the data sought through interviews and qualitative questioning within the questionnaires extracted student thinking about particular situations.

Qualitative methods were chosen predominantly for the research in order to formulate hypotheses based on the participants' conceptual ideas, and to discover their main concerns: in this case, how students felt about the way in which they learn within different approaches to grouping. Selecting this method gave a voice to the participants in order to represent their views as accurately as possible (Creswell \& Clarke, 2007). Taking a qualitative tactic allowed the researcher to identify existing patterns using participants' views. This methodology provided the researcher with control over the study to generate and form new theories. The reason behind collecting both qualitative and quantitative data was to bring together the strengths of both forms of research and to be able to compare and validate results (Creswell \& Clark, 2007) towards answering the research question.

The underlying study used two data gathering methods: a survey by student questionnaire, and semi-structured interviews carried out with the students and teachers. 
Survey by questionnaire is a helpful way of extracting personal opinion. The questionnaire (Appendix 1) was designed to obtain both qualitative and quantitative data from the participants, with the objective of discovering and exploring the students' self-concept in relation to their mathematics learning, and how they felt about their grouping within the class organisation. In order to achieve reliability in the data set, the questions needed to be manageable in both the allocated time and for the data analysis. The constructed questions needed to be straightforward, cover enough information, and be brief enough for the students to answer, with no presumptions, use of jargon or leading questions (Denscombe, 2007). To ensure the questionnaires would be manageable and fit for purpose to find out how students felt about class organised for mathematics, all questions were piloted (Section 3.2).

The questionnaire is the most used, descriptive method in education (Creswell \& Clark, 2007). The questionnaire (Appendix 1) was administered by the researcher, in order to ensure that the classroom teachers did not have access to completed questionnaires. It was explained within the ethics and consent procedures and when giving out the questionnaires to the participants that only the researcher and supervisor would see the responses. Quantitative data was collected using Likert scales in the questionnaires (Appendix 1). The questionnaire included eight closed items each using a 'six point Likert scale' and two open items. The use of a six point Likert scale encouraged participants to choose how they felt about mathematics without sitting in the middle of the scale. Respondents would then be forced to show a preference for their perceptions and opinions on how the lessons were organised using open-ended questions in the questionnaire and interviews.

The study design included semi-structured interviews, Year 6 (Appendix 2) and Year 7 (Appendix 3), which were used to enable the researcher to collect comparable in depth data across a number of participants (Bogdan \& Biklen, 1998). The interviews comprised open-ended questions enabling the respondents to demonstrate their unique way of looking at the world (Silverman, 1993), and to openly discuss their self-concept in relation to mathematics. For the semi-structured interviews, participants were selected using purposive sampling. The participants were handpicked by the researcher using knowledge of individuals (Cohen et al., 2000) based on the following factors. 
The selection for the individual interviews was chosen on the basis of their questionnaire responses, in order to gather further data around the patterns that emerged from the questionnaire results. The questionnaires were put into three categories of strategy grouping, based on the Expectations for Number from the New Zealand Curriculum (Ministry of Education, 2003b) and the mathematical standards (Ministry of Education, 2009b) (Chapter 1, Table 1.1). This was in order to get a broad range of responses from each of the strategy stages; Stage 5 being below the standard for the end of year 6 , Stage 6 being at the standard and Stage 7 being above the standard. In order to select students from each of three stages, the researcher used consultation with the classroom teacher. The strategy results were taken from numeracy snapshots taken for Number throughout the year. Further factors considered when selecting participants for interviewing consisted of ensuring a range of participants in terms of ethnicity, strategy ability stage, and self-concepts would be included. Each interview lasted approximately 30 minutes and was recorded and transcribed in full for analysis in order for the researcher to focus on the actual details of the responses (Silverman, 2005).

Drafts of the questionnaires and interview questions were made by drawing from research relating to organisation of the classroom in mathematics and self-concept (Chapter 2). Questions about how well the participants liked mathematics, and why, describing their lessons and asking if they would like to be taught mathematics differently were included. These questions were designed to find out how students feel about mathematics and in which ways they like to learn.

Triangulation is a technique used by qualitative researchers to improve internal and external validity of a study by checking the consistency of data collected from a range of sources (Burns, 1994), and is a powerful means of demonstrating concurrent and predictive validity, particularly in qualitative research (Campbell \& Fiske, 1957). The study used triangulation design in which different but complementary data was collected on the same topic using semi-structured interviews and questionnaires. Concurrent validity occurred in this case through the questionnaire and the interviews being used within a short timeframe. In order to maximize comparability of study conditions, the questionnaires were administered to all participants in the first year of the study when the participants were in Year 6, at the same time of the day, in the same room. The interviews for the chosen participants were implemented just days apart, 
which is acceptable timing for concurrent validity (Campbell \& Fiske, 1957). In the second year of the study the same questionnaires were administered to the Year 7 participants, at the same time of the day, in the same room. Again, the interviews for the same participants as in the first year of the study were implemented just days apart.

\subsection{Pilot Study}

Prior to starting the research, the study tools were piloted to help refine the tools and thereby maximising the reliability of the study data. The trial occurred in September 2010. The pilot was carried out with eight Year 7 students that had been Year 6 students at the study school in 2009. These students were chosen as they had been exposed to different forms of class organisation in mathematics, and in order to maximise the effectiveness of trialing the questions by linking to the target group (age and general nature of students at the school).

The eight students participating in the pilot study were asked to complete the questionnaire and four were individually interviewed. The pilot participants were asked if they had any queries about the questions being asked and to record these thoughts on the questionnaire sheet as well as their responses. This allowed for researcher reflection and improvement of the data gathering tools. The pilot enabled improvements to be made to the data gathering tools without using the students who were to be part of the actual study. The pilot students' responses showed that the participants tended to focus in their responses on teaching styles as opposed to how the class was structured and organised for teaching. There was an emphasis in the pilot responses on the way in which the teacher taught, which was not the researcher's focus for this study.

In the pilot questionnaire the purpose was worded as followed:

"The purpose of this questionnaire will assist in finding out how you feel about the group you are in for mathematics"

After reflection on the data gathered from the pilot questionnaire, the meaning of the word 'group' needed to be clarified in the questionnaire in order to focus on data collection on class organisation. Once definitions had been explained orally the questions were clearer and understood by the piloting participants. As a result, two questionnaires (one for Year 6 and one for Year 7) were created in order to identify the two different ways of organisation and to give participants a clearer understanding of 
the way the word 'group' was being used in the data gathering. The purpose of the questionnaire was explained in detail both orally and in written form to all participants within the two years of study. This was done to help ensure the participants would focus on how they felt about the way in which there were grouped rather than other aspects of the way they were taught. It therefore led to the following instructions and purpose on each year group questionnaire:

1. Year 6 Purpose: "The purpose of the questionnaire is to find out how you feel about how the class is organised into groups for mathematics. The meaning of 'group' is class organisation of small group teaching."

2. Year 7 Purpose: "The purpose of this questionnaire is to find out how you feel about how the class is organised into groups for mathematics. The meaning of 'group' is class organisation with whole class group teaching. In comparison, when you were in year 6 you were taught in a mixed classroom in small groups."

The Likert scales in the pilot questionnaire used a 4-point scale. Even though the instruction to circle only one number was clearly stated, two participants in the pilot study circled more than one number. In order to help avoid this problem happening in the study, changes to the Likert scale were made from a 4-point to a 6-point scale (Appendix 1). Expanding the Likert scale allowed the participants greater flexibility for their choice: 1 being "Not at all" and 6 being "Yes definitely". Furthermore, the pilot helped identify that there were no adverse affects found from the participants from being involved in the study. The pilot indicated that on the whole the questionnaire and interview questions were pitched appropriately and were fit for purpose.

\subsection{Research Participants}

\subsubsection{Choice of School}

The participants were selected from one all-girls school in the Wellington area. The study was designed to inform practice at the school. The intent of this research was not to generalize but to focus in one school on two-year groups, Year 6 and Year 7 
mathematics classrooms. The reason behind limiting the study to one school was the size of the research project. This kept the study to a small scale with enough data being collected to determine informed findings.

\subsubsection{Students}

In the first year of the study the Year 6 participants were grouped for mathematical learning within their form class by strategy stages stipulated from the Numeracy Development Project (Ministry of Education, 2009b) (Chapter 1, Table 1.1). In the second year of the study the Year 7 participants were grouped into four mathematics classes. Three of these classes were form classes, which were mixed ability. The other class held students that were deemed to require extra mathematical help in order for students to raise their level of achievement. This class was established to include the students who gained the lowest scores on the PAT (Progression Achievement Testing) results from the beginning of Term 1 .

The entire cohort of Year 6 students for 2010 (two Year 6 classes) was selected as participants for the first year and second year of the study, to maximize the sample size and reduce the effects on the study of losing students who may move schools during the study, and those for whom consent may not be gained. All Year 6 students were given information letters (Appendix 4) and consent forms (Appendix 5) and invited to participate. The students' Year 6 and Year 7 teachers were also interviewed to determine how they organised their mathematical lessons and their reasons for their class organisation decisions.

In the study school, Year 6 teaching follows the Primary Years Programme (PYP) Curriculum (International Baccalaureate Organisation, 2009), as well as the New Zealand curriculum, focusing on the Numeracy Project (Ministry of Education, 2003b) and the National Standards (Ministry of Education, 2009b), and Year 7 focuses on the Middle Years Programme (MYP) Curriculum (International Baccalaureate Organisation, 2010) and the National Standards (Ministry of Education, 2009b).

\subsubsection{Teachers}

The two teachers involved in the first year of the study indicated that they used a variety of methods for grouping their students including methods such as small group ability 
grouping, whole class, and mixed ability grouping. The teachers, all trained as primary school teachers, taught their form class, with one teacher having an extra support teacher for mathematics, taking the extension group out of the classroom for instruction. Both form teachers identified that when teaching Number they grouped their students in relation to the students' placement in terms of the Numeracy Project number strategy stages (Chapter 3). The four teachers involved in the second year of the study are mathematics teachers who were trained as secondary school teachers.

\subsection{Ethics}

This research was conducted following the ethical guidelines laid out by the New Zealand Association for Research in Education (NZARE) (New Zealand Association for Research in Education, 1998). Full ethical approval for this study was given by the Human Ethics Committee of Victoria University of Wellington's Faculty of Education. Informed consent (Kvale, 1996) from the Principal of the study school was given for carrying out the research. All participants were given a clear description of what the research involved and how it would be reported (New Zealand Association for Research in Education, 1998) (Appendix 3). When working with children informed consent must also be sought from their parents/guardians. The consent form stated that the participants would be able to withdraw at any stage until the data has been collected.

The participants took home the letters of consent to discuss with their parents/guardians. There were three questions from one parent who asked at what time during the day the 40 minute questionnaire and 30 minute interview would be completed during the lunch break. They also asked whether the theme of the study involved some or all students being organised within the class ("class organisation") in some manner that would be different from how the class would be organised in the absence of the research or if the child did not participate in the study; and if there was some difference, what would that be? The researcher replied via email stating that collection of the data would take place at a time that was convenient for the classroom teacher (first year of study) and the mathematics teacher (second year of study). Also stipulated was that the students would be grouped for mathematics in the ways that their usual class teacher would normally be grouping them. Their mathematics learning would continue as normal throughout the research and that it was not part of the research to regroup the class, merely to explore how the grouping styles used may affect students' feelings about learning mathematics. 


\subsection{Data Collection Process}

The collection of the data from the 31 participants occurred over a two-year period. A timetable was established (Table 3.1) in order to manage collection of the data. The questionnaires for the first year of the study were completed by the end of November 2010, Term 4 of the academic school year. The time of the year was selected as the students had experience within in-class organisation for the whole year and had an awareness of the way mathematics was organised with Year 6 . The time needed for the completion of the questionnaire was 45 minutes and the interviews lasted around 30 minutes.

Table: 3.1

Timetable of collecting data

\begin{tabular}{|c|l|l|l|}
\hline $\begin{array}{c}\text { Participants } \\
\text { of the study }\end{array}$ & \multicolumn{1}{|c|}{ Trialling Tools 2010 } & \multicolumn{1}{c|}{$\begin{array}{c}\text { Collecting Data 2010 } \\
\text { (Year 6) }\end{array}$} & \multicolumn{1}{c|}{$\begin{array}{c}\text { Collecting Data 2011 } \\
\text { (Year 7) }\end{array}$} \\
\hline $\begin{array}{c}\text { Participating } \\
\text { Teachers }\end{array}$ & & $\begin{array}{l}\text { Data was collected by two } \\
\text { participating teachers through a a } \\
\text { short interview }\end{array}$ & $\begin{array}{l}\text { Data was collected by four } \\
\text { participating teachers through a } \\
\text { short interview }\end{array}$ \\
\hline Participating & $\begin{array}{l}\text { Questionnaire and } \\
\text { Interviews were trialled } \\
\text { with current Year 7 (2010) } \\
\text { students and completed by } \\
\text { September. }\end{array}$ & $\begin{array}{l}\text { First collection of data } \\
\text { completed by November } \\
\text { Questionnaires by all students } \\
\text { Individual Interviews taken }\end{array}$ & $\begin{array}{l}\text { Second collection of data } \\
\text { completed by May } \\
\text { Questionnaires by all students } \\
\text { Individual Interviews taken }\end{array}$ \\
\hline
\end{tabular}

The second set of data was collection in 2011 at the end of May. The rationale behind this timing was so that the students would be able to make a comparison between organisation styles experienced in Year 6 and Year 7.

The questionnaire was handed out to individuals and the instructions were clearly given. All names were recorded on the questionnaires and were kept confidential and were not used in the write-up of the research. Having the names of the students with their questionnaire responses enabled comparison of the data gained from the questionnaire and the interview, analysis of the data of students in different strategy, peer, and cultural groups, and allowed comparison of results from individuals from the first study year to the second.

The chosen students were interviewed one week after the first questionnaire was administered. The timing was not immediate, to allow for the first informal analysis of the questionnaire responses and reflection on these to inform the researcher about possible probe areas for the interview questions, but was soon enough after the 
questionnaires that the concepts being explored in the questionnaires were still relatively fresh in the participants' minds. The same nine students were selected to be interviewed the second year to show a comparison with students' perspectives. Each participant was interviewed individually and this method was chosen to allow students to discuss their thoughts freely and to give the researcher an opportunity to ask any extra questions to help extract information that could be of use to answer the research question.

\subsection{Analysis Techniques}

The analysis involved collating the responses from the participants' questionnaire and interviews from Year 6 (Chapter 4) and Year 7 (Chapter 5). Next a comparison was made of the Year 6 and Year 7 questionnaire and interview responses to examine the views of students across the two-year groups (Chapter 6).

From the research question, the key words were class organisation in mathematics. Ability perception, grouping and learning were further words that were needed to categorise the answers from the questionnaire and the semi-structured interview. During the analysis of the survey results and semi-structured interviews, three main categories emerged from the data: perceptions of ability, organisation of grouping, and ways of learning. Each question from the questionnaire and the semi-structured interview was then placed within one of the identified categories (Tables 4.1 and 4.2). Perceptions of ability included discussion of whether students like mathematics, are good at maths, if their friends, parents and teacher think they are good at maths. Organisation of grouping included aspects relating to small group, whole class and social aspects, and Ways of learning referred to questioning, discussions and one-on-one instructions. These categories and their relationships are explored further within Chapters 4, 5, and 6 where the data from the questionnaires and the semi-structured interviews are compared and analysed. Analysis of the quantitative data from the questionnaire is presented as numerical data (Creswell \& Clarke, 2007). 
Table 3.2

The breakdown of the questionnaire questions in this study into analysis categories

\begin{tabular}{|c|c|c|}
\hline Perceptions of Ability & Organisation of Grouping & Ways of Learning \\
\hline $\begin{array}{l}\text { Are you are good at maths? } \\
\text { Do you think your friends think you } \\
\text { are good at maths? } \\
\text { Do you think your parents think you } \\
\text { are good at maths? } \\
\text { Do you think your teacher thinks you } \\
\text { are good at maths? }\end{array}$ & $\begin{array}{l}\text { Describe the group you are taught maths } \\
\text { in } \\
\text { Describe how you feel being taught in } \\
\text { this group. } \\
\text { Are you happy to learn in this group? } \\
\text { Give reasons for why or why not. }\end{array}$ & $\begin{array}{l}\text { Do you ask questions in whole class } \\
\text { discussions? } \\
\text { Do you ask questions in small group } \\
\text { discussions? } \\
\text { Do you ask questions one-on-one with } \\
\text { the teacher? } \\
\text { Do you ask your teacher for help when } \\
\text { you need it? } \\
\text { Is there a way you would prefer to } \\
\text { learn? Explain why and how. }\end{array}$ \\
\hline
\end{tabular}

Table 3.3

The breakdown of the semi-structured interview questions in this study into analysis categories

\begin{tabular}{|l|l|l|}
\hline \multicolumn{1}{|c|}{ Perceptions of Ability } & \multicolumn{1}{c|}{ Organisation of Grouping } & \multicolumn{1}{c|}{ Ways of Learning } \\
\hline $\begin{array}{l}\text { Is maths a favourite subject of yours? } \\
\text { Explain why or why not. }\end{array}$ & $\begin{array}{l}\text { Do you like the maths group you are in? } \\
\text { Explain why/why not. }\end{array}$ & $\begin{array}{l}\text { Do you answer questions during class? } \\
\text { Explain why/why not. }\end{array}$ \\
$\begin{array}{l}\text { Describe how you feel about maths. } \\
\begin{array}{l}\text { Do you think that you are good at } \\
\text { maths? Explain why/why not. }\end{array}\end{array}$ & $\begin{array}{l}\text { Do you ask your teacher for help when } \\
\text { you need it? Explain why/why not. }\end{array}$ \\
\end{tabular}

\subsection{Summary}

Qualitative and quantitative methods were used in this small-scale study with the intention of informing mathematical practice of girls in Year 6 and Year 7. Thirty-one students were followed over a two-year period to explore the organisation of mixed ability and cross-class ability grouping in mathematics. The findings from the questionnaires and semi-structured interviews will be analysed in Chapters 4 and 5 . 


\section{Chapter 4: Year 6 Comparison}

Findings from qualitative data from the open-ended questions in the questionnaire (Appendix 1) were analysed by coding the responses for content categories. Data from the semi-structured interviews (Appendix 2) and open-ended questions from the questionnaire were analysed by categories that emerged from the researcher's reflections on reading and re-reading the data (Section 3.5). The participants were grouped into three categories relating to their ability, taken from results of assessment of their achievement against the New Zealand Mathematical Numeracy Standards (Chapter 1), (Table 1.1). This categorisation has been used to explore any relationship between ability grouping of individuals and how they perceive their own ability, the way in which they are organised into groups, and how they learn within mathematics. Pseudonyms are used for data from the semi-structured interviews (Table 4.1). Statements drawn from the questionnaires are indicated using students' year group.

Table 4.1

Student pseudonyms and ability stages

\begin{tabular}{|c|c|c|}
\hline Stage 5 & Stage 6 & Stage 7 \\
\hline Louise & Megan & Helen \\
Lucy & Mia & Hannah \\
Lara & Michelle & Heidi \\
\hline
\end{tabular}

Section 4.1 analyses students' perceptions of their own ability, and their parents', friends' and teachers' perceptions of their ability. In Section 4.2 how students felt about the preferences of grouping and organisation of mathematics are described. The final sections of this chapter discuss the different ways of learning in mathematics that students prefer (Section 4.3) and summarises the key ideas of the chapter (Section 4.4).

\subsection{Perceptions of Ability}

Five questions from the questionnaire were identified as relating particularly closely to students' perceptions of their mathematical ability. The five questions were:

Do you like maths?

Are you good at maths?

Do you think your friends think you are good at maths?

Do you think your parents think you are good at maths?

Do you think your teacher thinks you are good at maths? 
From analysing the answers from the semi-structured interviews, responses to three open-ended questions in particular indicated that the majority of respondents felt that they were good at mathematics. The three open-ended questions were:

Is maths a favourite subject of yours? Explain why or why not.

Describe how you feel about maths.

Do you think that you are good at maths? Explain why/why not.

In the analysis category of perception of ability, two themes emerged: whether students knew they were ability grouped, and how they felt about the placement. The results have been broken down into two areas: ability and learning. Each of these analysis categories will be discussed in turn.

The results for the five questions from the questionnaire are presented in Table 4.2. The table shows how students perceived their own mathematical ability and how they believed people around them (friends, family, and their teacher) perceived their mathematical ability. The results were that $98 \%$ of respondents believe that they were good at mathematics with $59 \%$ of respondents liking mathematics. Respondents indicated that their friends $(93 \%)$ and teacher $(98 \%)$ believe that they are good or extremely good at mathematics. All students recognised that their parents believed them to be good or definitely good at mathematics, with only a small number of respondents identifying that their teacher $(3 \%)$ or friends $(6 \%)$ did not think them to be good at mathematics.

Table 4.2

Students' responses regarding how they and others perceive their mathematical ability (Questionnaire Questions 1, 5, 6, 7 and 8)

\begin{tabular}{|l|c|c|c|}
\hline \multicolumn{1}{|c|}{ Perceptions of Ability } & \multicolumn{2}{|c|}{ Frequency } \\
\cline { 2 - 4 } & $\begin{array}{c}\text { Rank 1 and 2 } \\
\text { (Not at all) }\end{array}$ & $\begin{array}{c}\text { Rank 3 and 4 } \\
\text { (Moderate) }\end{array}$ & $\begin{array}{c}\text { Rank 5 and 6 } \\
\text { (Yes definitely) }\end{array}$ \\
\hline Do you like maths? (1) & $13(41 \%)$ & $16(50 \%)$ & $3(9 \%)$ \\
\hline Are you good at maths? (5) & $1(3 \%)$ & $21(66 \%)$ & $10(32 \%)$ \\
\hline $\begin{array}{l}\text { Do you think your friends think you } \\
\text { are good at maths? (6) }\end{array}$ & $2(6 \%)$ & $18(56 \%)$ & $12(37 \%)$ \\
\hline $\begin{array}{l}\text { Do you think your parents think you } \\
\text { are good at maths? (7) }\end{array}$ & - & $17(53 \%)$ & $15(47 \%)$ \\
\hline $\begin{array}{l}\text { Do you think your teacher thinks } \\
\text { you are good at maths? (8) }\end{array}$ & $1(3 \%)$ & $21(66 \%)$ & $10(32 \%)$ \\
\hline
\end{tabular}

However, even though the respondents believed that they have a good ability (98\%), $41 \%$ of respondents did not like mathematics and it is a concern that only $9 \%$ definitely liked mathematics. This is a worry particularly for female students as research has 
shown that girls can have a lower expectation of themselves in mathematics. Therefore, it was important to create a further break down of the students into ability groups and identify if there was any correlation to organised ability groups in mathematics, whether girls liked mathematics, and how the girls perceived their own ability.

The responses have been categorised using students' progress against the New Zealand Mathematical Numeracy stages (see Table 1.1 in Section 1.2). Graphs were used to further understand if perceived ability was related to whether students liked or disliked mathematics and if the Numeracy Stages that they were placed in were related to how they perceived their own ability (Figures 4.1 and 4.2).

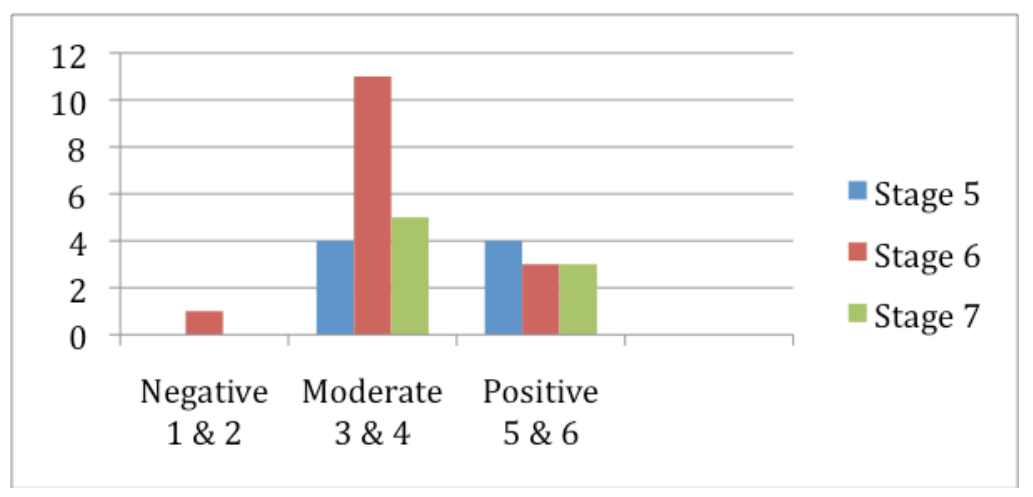

Figure 4.1. Students' responses in relation to how students like mathematics by students' Numeracy Stage (Questionnaire Question 1)

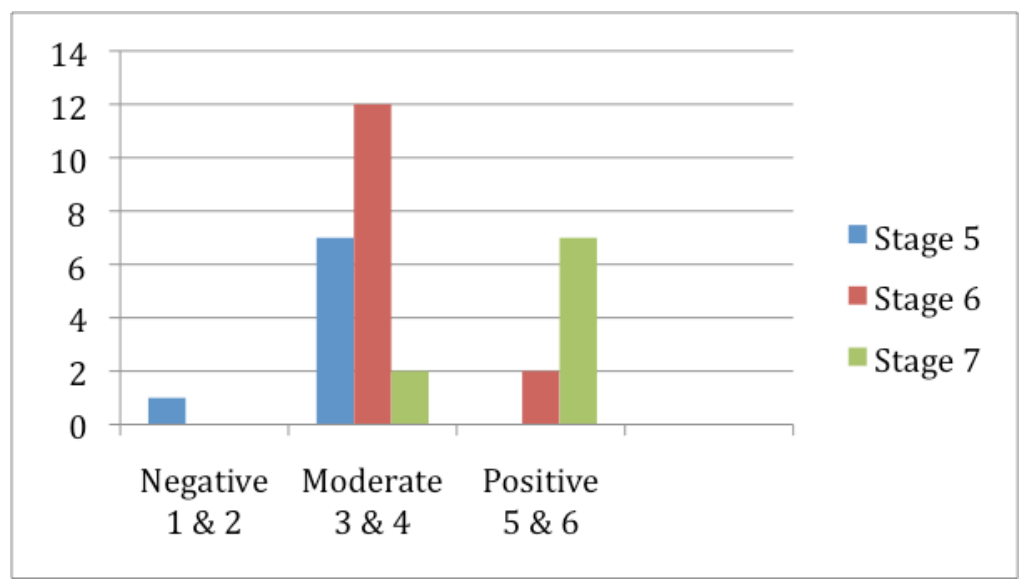

Figure 4.2. Students' responses in relation to how good students think they are at mathematics by students' Numeracy Stage (Questionnaire Question 5)

Further analysis of the data showed that eight students working at stage 5 responded that they liked mathematics and perceived themselves as being 'good' at mathematics. Only one student responded that they felt that they were 'not good' at mathematics. Fifteen students working at stage 6 perceived themselves as being good at mathematics. Fourteen students like mathematics and only one student responded that she did not. All 
eight students working at stage 7 liked mathematics and perceived themselves as being 'good' or 'extremely good' at mathematics. Therefore, the results show that regardless of the ability of the individual students, 30 students out of 31 liked mathematics and perceived themselves as being good at mathematics.

All nine respondents from the semi-structured interview were asked whether mathematics was a favourite subject of theirs and were asked to explain why or why not. From the nine students interviewed, four students identified 'yes', three identified 'no', and two said 'sometimes'. The students who identified as 'yes' commented that:

It is a favourite because we use maths every day and it is important in our lives. We need to know maths. I enjoy the way that we are working when we work in small groups, individually or in partners as we can help each other. (Louise)

Yes, maths is a favourite because it helps me with other things that I do. It is a fun way we do it in the groups that helps. (Megan)

Yes, because it can help me develop in other subjects as well. (Mia)

It is this year because it is different and it gets explained to us. (Michelle)

The students that said 'yes' highlighted that mathematics is used in everyday life and is important to people, that they enjoyed working in small groups, individually or with partners, and that it helped them to develop their strategy knowledge. Two of the respondents who commented 'no' and the two respondents who said 'sometimes' identified that it wasn't that maths wasn't their favourite subject even though it was 'fun'; their feelings were related to the content of what was being taught at the time:

It's sort of in the middle. It sometimes can be fun and sometimes it can be boring. (Lucy)

No, not really. I do enjoy it but it mostly depends on what we are doing. (Hannah)

It's fun. But it's not really my favourite subject. So I can't call it that. (Heidi)

I think it is because there are some aspects of which I enjoy doing. I do find some aspects enjoyable and some quite easy. (Helen)

Only one of the respondents identified that they have never been good at maths and that it is hard for them:

No, it's not my favourite subject because I have never really been good at it. Ever since I have started maths it has been hard. (Lara)

Four students indicated that it could take them a while to grasp new concepts and recognised that they had weaknesses and areas they needed to work on. Five respondents stated that the group they were in affected the way in which they perceived their ability. Two respondents commented that they didn't feel proud of the group they were placed within and commented that ability played a part of the group they were placed within: 
In my group I don't like my group. I don't feel proud to be in my group. In my group we are not really good at maths. We are not really smart. (Megan)

Most of the people in my group are in the middle. Good but not really good but not really dumb. (Michelle)

These results indicate that the students were aware of what the other students were doing in class and they are aware of the work and abilities of different students.

Even though some students saw ability grouping as a negative aspect of their learning there are students, particularly those working at Stage 6, who saw the grouping as positive for their learning:

I feel that we are all around the same level. I am glad that I'm in the average maths group. (Year 6)

My group is the middle group. I think this is a good group for me to be in because it is not too hard for me or too easy. (Year 6)

I am in the middle group, so I am taught maths at a medium level. A level that I understand and can work a good pace at. (Year 6)

Students have expectations when working in a small group. Two students stated:

You can learn how to consolidate your strategies with confidence and find it easy to work with people who have the same strengths. (Year 6)

I can learn new strategies in a small group from the people that I work with. Which helps me through my maths learning. (Year 6)

The data suggests that students' self-perception of their mathematical ability may be related to their prior mathematical performance. This data shows that students are aware of the way in which they are grouped and receive messages about their ability through this organisation. Respondents identified the names of the groups in their class (circles, squares and triangles) were a factor for perceptions of mathematical ability.

From the semi-structured interviews, students mentioned working at a good pace within their group, signifying that within the small group it included students who can feel confident with the strategies they work on. Students identified that the groups were ability based and had an understanding why the groups were organised this way. Students saw these small groups as places they could work co-operatively with their peers, help each other, learn from their mistakes, discuss their work, and have the opportunity to work independently. 


\subsubsection{Summary}

Regardless of Numeracy Strategy stages, students perceived themselves as being good at mathematics. Students saw that their friends, peers and parents also perceived them to be good at mathematics. What was interesting was that even though there was positive perception only $57 \%$ actually liked mathematics. The data showed that students are aware of their ability grouping and receive messages about their ability through classroom organisation. It doesn't matter how a small group is named, the students are aware of a group's strengths and weaknesses. Students preferred working in small ability groups where they could work co-operatively together, help each other, learn from their mistakes and discuss work in a safe environment.

\subsection{Grouping and Students' Preferences for Organisation of Grouping}

Three open-ended questions from the questionnaire (Questions, 10, 11 and 12) were identified in relation to how students felt about the organisation of grouping within mathematics. The three questions were:

Describe the group you are taught maths in.

Describe how you feel being taught in this group.

Are you happy to learn in this group? Give reasons why or why not.

One open-ended question used in the semi-structured interview related to the category of organisation of grouping in mathematics was:

Do you like the maths group you are in? Explain why/why not.

In the category of perception of ability two themes emerged: grouping and learning (small group and whole class), and grouping versus perception of ability.

From the open-ended question (Question 10) within the questionnaire 'Describe the group you are taught in', 24 students indicated that the groups they work within are small groups with 4 to 5 people. Seventeen respondents believed that they are ability based, making comments such as: 'my group is in the middle', 'not above' and 'not below', 'lowest group', 'taught in abilities', 'advanced', 'smart', 'extension', and 'an average group':

There are three groups, triangles are the highest, and squares are a good kind of group and circles are not good at maths. Since I'm in the lowest group people don't think that I am very good at maths. (Lara) 
In contrast, thirteen students used various statements to explain how their group was organised in mathematics. Students described the group they were taught in as follows: working in pairs, through discussions, explanations occurring, using learning intentions, working together, working independently and working within a small group.

When asked to describe how students felt about being taught as part of a group there was some positive discussion about working in pairs:

Ifeel that when we do small group maths that I learn new things all the time. (Year 6)

There was discussion from some respondents about the positive aspects they saw of working together in a small group, and the advantages that small groups bring to individuals and how they feel about mathematics:

I think that it is good that we can all help each other understand. (Year 6)

It feels really good because others can help me and explain to me. (Year 6)

I enjoy being taught in a group because you get to share your thoughts and have support from others. (Year 6)

You get to hear other peoples' explanation and you can learn new ways to do things also, in groups you get to ask questions and get lots of different answers for different ways of doing it. (Year 6)

I feel good because I have lots of people to help me when I don't understand something and when I don't understand something it doesn't make me feel alone. (Year 6)

There were also examples of responses where students were concerned about being at the bottom of the small group and feeling scared and uncomfortable:

At first I felt uncomfortable because I was scared I would be at the bottom of the group. Now I have relaxed. I prefer to work in a small group to working as a class because I learn more and feel more relaxed with working with others. (Year 6)

I feel like I'm not the smartest in the group. (Year 6)

I don't like it because I don't like feeling that I'm the lowest in the group. (Year 6)

In the semi-structured interview, the nine participants were asked if they liked the mathematics group they worked in. Two responded 'no' and seven replied 'yes'. Three of the respondents who replied 'yes' to agreeing that they liked the group they worked in, commented on how the groups provided for individual ability and group needs:

I can work with the people that I'm surrounded with. I can work at that level. It's not too easy or too hard. It keeps me working at a good pace. (Mia) 
It's based around the people of the same ability as me. Being in a smaller group there's more time to have things explained to us. (Michelle)

As a group I can work with people at the same level as me. If we are all at the same level we can find it easier to learn. We have the same strengths and weaknesses as each other. (Helen)

Two students commented that by working in a small group there was no pressure and it was good to be able to work together:

If I'm at a question and I'm struggling we help each other. The group doesn't rush off to another question. (Louise)

It's easy to expand on. No pressure for right or wrong answers. It's good to explain to someone else in the group who doesn't understand the question. (Hannah)

This example indicates some girls liked the collaboration and camaraderie of working with and helping their peers. One student felt that working within the group they were placed in wasn't too easy or too hard for them:

It's a good level for me. It's not too hard or too easy. (Lucy)

One student talked about being in the highest group and being challenged, which made her enjoy mathematics more:

I like the challenge the higher maths group has. (Heidi)

However, one respondent who said 'no' commented that she would prefer to be in a group of mixed ability so that all students could learn from each other. She commented that having a group of mixed ability would work better, believing that:

That way no one would feel bad at maths. (Lara)

This student felt that working with students in a small group with mixed abilities could help all within the group learn from each other and help with the teaching of concepts.

On the other hand, one student recognised that working within a whole class situation could make students feel under pressure that their peers could race ahead and finish their work and that other students could be left behind. She felt that this couldn't leave students with the opportunity to check their work and discuss their answers with other students and “you wouldn't get as much attention as you would need". Students indicated that their class would start off with whole class teaching and then break into small groups for strategy work. The data showed that the students preferred small group work to whole class teaching, as it allowed for discussion. However, this can lead to too much discussion and too many different ways of working things out, that people would 
be talking over each other. Students saw small group work as providing valuable time to learn at the level individuals were at, acknowledging that with a whole class you would have to have a variety of questions to suit all abilities.

\subsubsection{Summary}

Students perceived small group organisation to be a positive experience as it allowed for discussion at an individual's level. It creates a focused atmosphere of being able to ask and answer questions, share ideas and strategies, and where individuals can recognise their own progress and be able to develop mathematical confidence. Overall, students saw whole class teaching as comparatively pressurised and competitive. Students felt that individuals could be left behind and there could be less individual attention from the teacher. Students felt less confident asking and answering questions for the fear of being judged and laughed at.

\subsection{Ways of Learning}

To examine how participants felt about learning and questioning in mathematics, questionnaire and interview questions were grouped into the category of: Questioning (within a whole class and small group situation, a one-on-one basis and whether or not students asked their teacher for help). Five questions from the questionnaire were identified in relation to if and when students ask questions in mathematics:

Do you ask questions in whole class discussions?

Do you ask questions in small group discussions?

Do you ask questions one-on-one with the teacher?

Do you ask your teacher for help when you need it?

Is there any way you would prefer to learn maths? If so please explain why and how.

The two open-ended questions from the semi-structured interview related to the category of organisation of grouping in mathematics:

Do you answer questions during class? Explain why/why not.

Do you ask your teacher for help when you need it? Explain why/why not.

The results for the questionnaire questions are presented in Table 4.3. The table in different ways shows the extent to which students ask questions when they are grouped in different ways. When asked about asking questions within a whole class situation 
$41 \%$ responded 'not at all', however $34 \%$ felt comfortable to do so, showing mixed views of feeling confident to put up their hand. The data showed that only $3 \%$ definitely did not ask questions within a whole class group. However, this could be due to the nature of the class organisation with there being limited whole class teaching occurring. The students seemed more likely to ask questions when they worked in a small group (56\%) than in whole class discussions (47\%) and one-on-one with the teacher $(41 \%)$. This data links to the results from the open-ended questions from the questionnaire when students commented that:

I like being taught in a small group as I find it easier to ask questions.

I find that you can ask questions to the other people in the group and you can work together. (Year 6)

Table 4.3

Students' responses to asking questions in mathematics (Questionnaire Questions 2, 3, 4 and 9)

\begin{tabular}{|l|c|c|c|}
\hline \multicolumn{1}{|c|}{ Ways of learning } & \multicolumn{2}{c|}{ Frequency } \\
\cline { 2 - 4 } & $\begin{array}{c}\text { Rank 1 and 2 } \\
\text { (Not at all) }\end{array}$ & $\begin{array}{c}\text { Rank 3 and 4 } \\
\text { (Moderate) }\end{array}$ & $\begin{array}{c}\text { Rank 5 and 6 } \\
\text { (Yes definitely) }\end{array}$ \\
\hline $\begin{array}{l}\text { Do you ask questions in whole class } \\
\text { discussions? (2) }\end{array}$ & $13(41 \%)$ & $15(47 \%)$ & $3(9 \%)$ \\
\hline $\begin{array}{l}\text { Do you ask questions in small group } \\
\text { discussions? (3) }\end{array}$ & $6(18 \%)$ & $18(56 \%)$ & $8(25 \%)$ \\
\hline $\begin{array}{l}\text { Do you ask questions one-on-one } \\
\text { with the teacher? (4) }\end{array}$ & $15(47 \%)$ & $13(41 \%)$ & $4(12 \%)$ \\
\hline $\begin{array}{l}\text { Do you ask your teacher for help } \\
\text { when you need it? (9) }\end{array}$ & $6(18 \%)$ & $13(41 \%)$ & $13(41 \%)$ \\
\hline
\end{tabular}

Several students stated that they felt they would get the answers to questions wrong and would therefore not answer questions posed to a group. One student responded by saying that she didn't answer questions because she thought that someone would get angry at her if they were thinking something else. The results showed that confidence was a factor when answering questions and suggested that some students would only answer questions if they were sure that they would get the answer correct. A couple of students responded by saying they would sometimes. One student commented that:

Sometimes I don't want to answer questions as it makes me look like a know-it-all and I don't like that feeling. (Year 6)

The data revealed that the students were anxious about answering questions for the fear of being judged by their peers. There was no mention of the teacher being a contributing factor to their anxiety and when analysing the results in Table 4.3 , it is clear that there was a low percentage of students who feel comfortable asking questions in a whole class $(9 \%)$, small group (25\%) or within a one-on-one (12\%) situation. 
The majority of students identified a preference for working in a small group, as it helped individuals to ask more questions about strategy work. One student recognised that by making the groups even smaller this would allow for the students to work quietly and to stay focused on set tasks, while some students saw learning to ask more questions about strategy work, sharing strategies, and seeing how others work beneficial for their progress and confidence. On the other hand some students indicated that they would prefer to work individually or as a whole class so they could work with new people:

Researcher: How would you feel being taught in a large group?

Helen: I feel that in a larger group it could be hard to work with people who are at a different level. Because you might find the work you are doing too easy or too hard.

In contrast, one student preferred be organised into small groups rather than a whole class to assist with her learning:

Hannah: I think that a small group situation is a good way. If we had one big class it might get confusing. People might speak over each other. Also people who are weaker they might ask questions that are not relevant to your question and it could be a waste of time.

Researcher: Can you explain what you mean?

Hannah: You could get frustrated because you already know the answer. I would be happy to help people that are a little bit weaker in other areas. I could explain things to them.

Researcher: Do you think you can learn better in a small group? Explain

Hannah: Yes I think we do. It helps us to answer questions and discuss things as a smaller group. It helps us feel less guilty or wrong as to how to answer questions.

To aid the analysis process the categories were then analysed into strategy stages based on the New Zealand Numeracy Stages (Table 1.1 in Section 1.2). The responses have been categorised into the Numeracy Stages to have a further look into whether ability grouping is related to the way in which students learn and ask questions. These results are shown in Figures 4.3, 4.4, 4.5 and 4.6. 


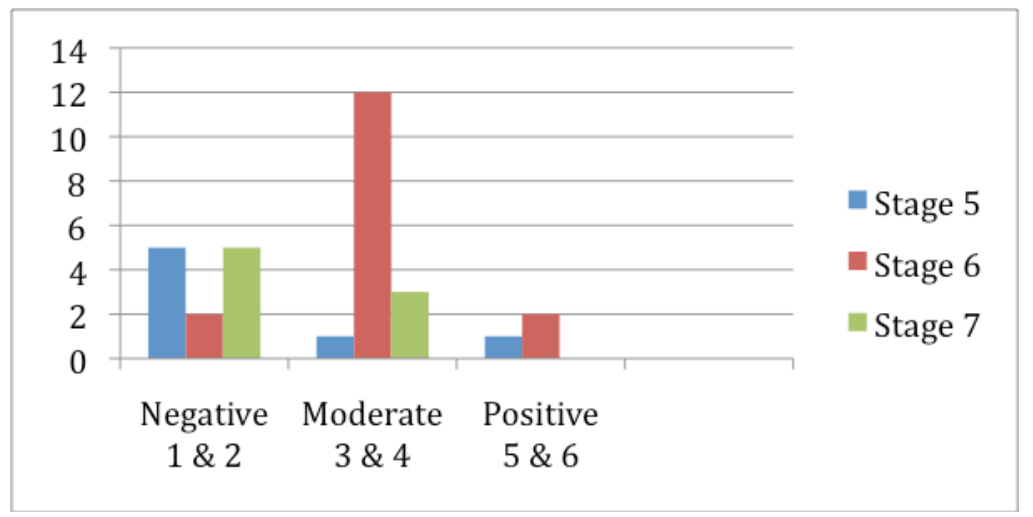

Figure 4.3. Students' responses in relation to if they ask question in a whole class situation in mathematics by Numeracy Stage (Questionnaire Question 2)

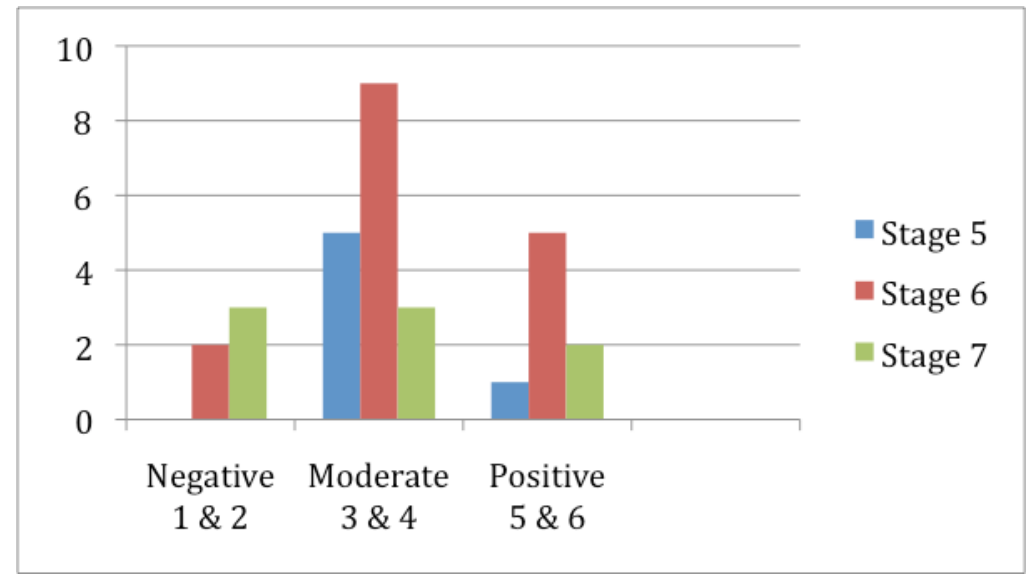

Figure 4.4. Students' responses in relation to asking questions in small groups in mathematics by Numeracy Stage (Questionnaire Question 3)

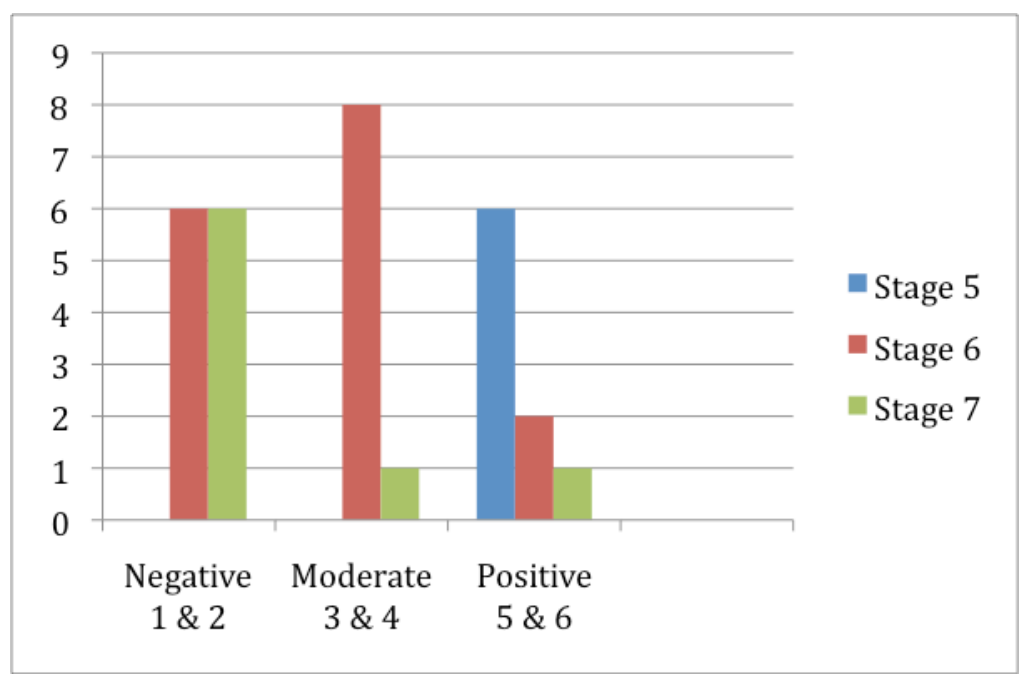

Figure 4.5. Students' responses in relation to if they ask the teacher questions one-on-one in mathematics by Numeracy Stage (Questionnaire Question 4) 


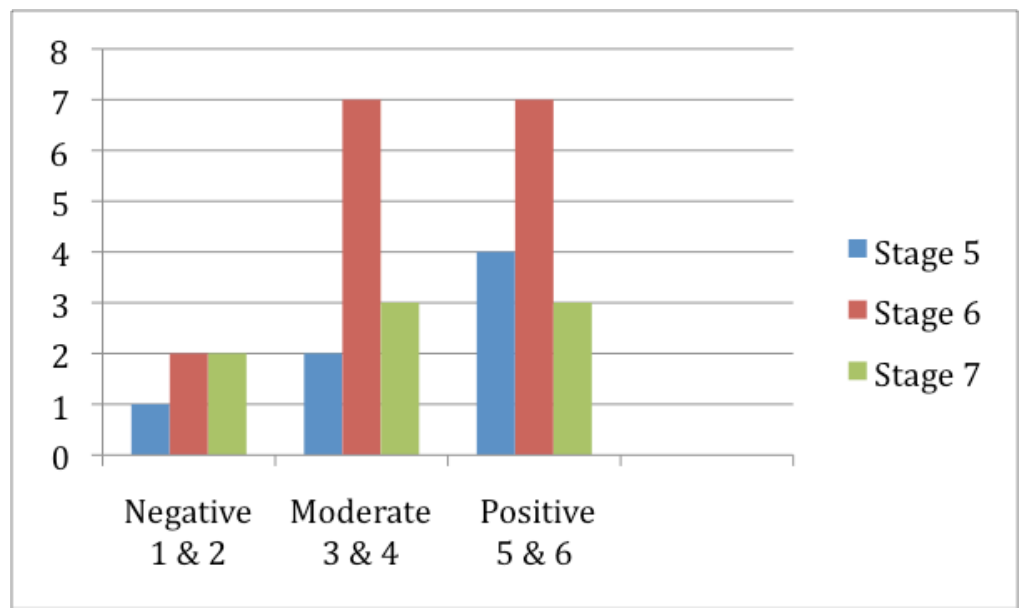

Figure 4.6. Students' responses in relation to if they ask the teacher for help in mathematics by Numeracy Stage (Questionnaire Question 9)

The results show that Stage 5 and Stage 7 participants did not feel as comfortable with answering questions in a whole group situation as stage 6 participants. Five out of eight stage 7 participants and five out of seven Stage 5 participants replied 'not at all', compared to two out of 16 participants at stage 6. Stage 5 participants appeared a lot more confident in asking questions in a small group situation and with the teacher oneon-one. Six out of seven responded to asking the teacher for help. Stage 6 participants appeared similar to that of Stage 5, however six respondents did not ask the teacher for help and were less likely to 'definitely' ask the teacher questions, with six identifying 'not at all'.

Students appeared to be positive about working in small groups based on ability. However, one student indicated that by working all together on the same mathematical strategies in groups of three of mixed ability, or as a whole class, nobody would know if you were bad at mathematics or not. Another student recognised that being taught in a large class could be hard with people of different abilities, as students could find the work either too easy or too hard and that there could be too much pressure on individuals. When the researcher asked what kind of pressure the student responded:

If you're seeing a friend finish their work and they're playing a maths game. Then you kind of feel left behind and want to get work finished faster. You then wouldn't check over all your answers and pay as much attention as you normally would. (Michelle)

When asked if there is another way in which individuals would like to learn and if so, how, one replied:

Researcher: How would you like the class to be organised and why? 
Heidi: I like large groups because you then have an opportunity to help others of different abilities.

Researcher: By helping others from a different ability does this help your learning? Explain.

Heidi: Yes. Because if you all learn with another person you may have different strategies that you can learn and build on to be better. Both of you can benefit from this.

Asking questions for mathematical clarification may seem like a daunting task for a student. It can adhere to students' perceived views of their own inabilities or confidence. Facilitating an environment which encourages questioning to assist with clarification of problems and strategies helps students monitor their own learning and stimulate interest and curiosity.

\subsubsection{Summary}

The data showed that the majority of students preferred to work in a small group based on ability, as it helped individuals to ask more questions about strategy work. Students felt anxious about answering questions for the fear of being judged by their peers. Students felt that it was important to have confidence when answering questions and identified that students would only answer questions if they were sure that they would get the correct answer.

\subsection{Summary}

In this research, the Year 6 students perceived small group learning to be a positive way of organising the mathematics class. Students felt that small group work created a focused atmosphere for students to feel confident to ask and answer questions, and share ideas and mathematical strategies. The students were aware of their strengths and weaknesses in relation to the organisation of grouping, demonstrating a good sense of mathematical self-concept within small group organisation regardless of their strategy stage. In contrast, the students felt that whole class teaching was pressurised and competitive for individuals. The students felt more anxious when answering questions for the fear of being judged by their peers and the feeling of being left behind regardless of their strategy stage. The comparison of the same students in Year 7 will be discussed in Chapter 5. 


\section{Chapter 5: Year 7 Comparison}

Chapter 5 focuses on the findings from qualitative data from the open-ended questions in the questionnaire (Appendix 3) and the data from the semi-structured interviews (Appendix 4). The data from the open-ended questions in the questionnaire were analysed by coding the responses for content categories. Data from the semi-structured interviews and open-ended questions from the questionnaire were analysed by categories that emerged from the researcher's reflections on reading and re-reading the data (Section 3.5). Pseudonyms for the participants of the semistructured interview have been used (Table 4.1 Chapter 4). Statements drawn from the questionnaires are indicated using students' year group.

Section 5.1 analyses students' perceptions of their own ability and their parents', friends' and teachers' perceptions of their ability. In Section 5.2 the preferences of grouping and organisation of mathematics are described. The final sections of this chapter discuss the different ways of learning in mathematics that students prefer (Section 5.3) and summarises the key ideas of the chapter (Section 5.4).

\subsection{Perceptions of Ability}

Five questions from the questionnaire were identified in relation to students' perception of their mathematical ability. The five questions were:

Do you like maths?

Are you good at maths?

Do you think your friends think you are good at maths?

Do you think your parents think you are good at maths?

Do you think your teacher thinks you are good at maths?

From analysing the answers from the semi-structured interviews, responses to three open-ended questions indicated the differences in mathematics from Year 6 to Year 7. The three open-ended questions were:

What are the main differences students see from Year 6 to Year 7?

How do you feel about the differences in grouping for maths?

Do you think the way you have been grouped has affected how good you think you are at maths?

In the analysis category of perception of ability, two themes emerged: whether students knew they were ability grouped, and how they felt about the placement. The results 
have been broken down into two areas: ability, and learning. Each of these areas will be discussed in turn.

The results for the five questions are presented in Table 5.1. The table shows how students perceived their own mathematical ability and how they believed people around them (friends, family and their teacher) perceived their mathematical ability. The pattern shows that $93 \%$ of respondents liked mathematics, with $40 \%$ of that group 'definitely' liking mathematics. Taking into account this data and cross checking the results of whether or not students perceived themselves to be good at mathematics, these results correlated well. There was a smaller percentage $(57 \%)$ of respondents that thought they were 'good' at mathematics, 33\% believed that they were 'definitely good' at mathematics. A small number of respondents $(10 \%)$ indicated that they were 'not good' at mathematics; again only a small number of respondents $(7 \%)$ identified that they did not like mathematics. A large majority of respondents indicated that they acknowledged that their friends, parents and teacher believed that they were 'good' or 'extremely good' at mathematics, with only a small number of respondents identifying that their parents $(3 \%)$ and friends $(7 \%)$ did not think them to be good at mathematics. Ten percent of respondents indicated that their teacher did not see them as being good as mathematics.

Table 5.1

Students' responses regarding how they and others perceive their mathematical ability (Questionnaire Questions 1, 5, 6, 7 and 8)

\begin{tabular}{|l|c|c|c|}
\hline \multicolumn{1}{|c|}{ Perceptions of Ability } & \multicolumn{2}{|c|}{ Frequency } \\
\cline { 2 - 4 } & $\begin{array}{c}\text { Rank 1 and 2 } \\
\text { (Not at all) }\end{array}$ & $\begin{array}{c}\text { Rank 3 and 4 } \\
\text { (Moderate) }\end{array}$ & $\begin{array}{c}\text { Rank 5 and 6 } \\
\text { (Yes definitely) }\end{array}$ \\
\hline Do you like maths? (1) & $2(7 \%)$ & $16(53 \%)$ & $12(40 \%)$ \\
\hline Are you good at maths? (5) & $3(10 \%)$ & $17(57 \%)$ & $10(33 \%)$ \\
\hline $\begin{array}{l}\text { Do you think your friends think you } \\
\text { are good at maths? (6) }\end{array}$ & $2(7 \%)$ & $19(63 \%)$ & $9(30 \%)$ \\
\hline $\begin{array}{l}\text { Do you think your parents think you } \\
\text { are good at maths? (7) }\end{array}$ & $1(3 \%)$ & $17(57 \%)$ & $12(40 \%)$ \\
\hline $\begin{array}{l}\text { Do you think your teacher thinks you } \\
\text { are good at maths? (8) }\end{array}$ & $3(10 \%)$ & $18(60 \%)$ & $9(30 \%)$ \\
\hline
\end{tabular}

However, as a group, the results show that the majority of students have a good perception of their mathematical ability, with a good perception of how others (friends 93\%, parents $97 \%$ and teacher 90\%) view their mathematical ability. Therefore, it was vital to create a further breakdown of the students' ability group, to identify the 
students' ability stage and to identify any correlation between the ability stage of the students and their mathematical perception.

As in Chapter 4 Section 4.1, the responses of students' perception of ability have been categorised using students' progress against the Numeracy stages from the New Zealand Numeracy Project in Table 1.1 (Section 1.2). Graphs were used to further understand if perceived ability was related to whether students liked or disliked mathematics and how good students think they are at mathematics (Figures 5.1 and 5.2).

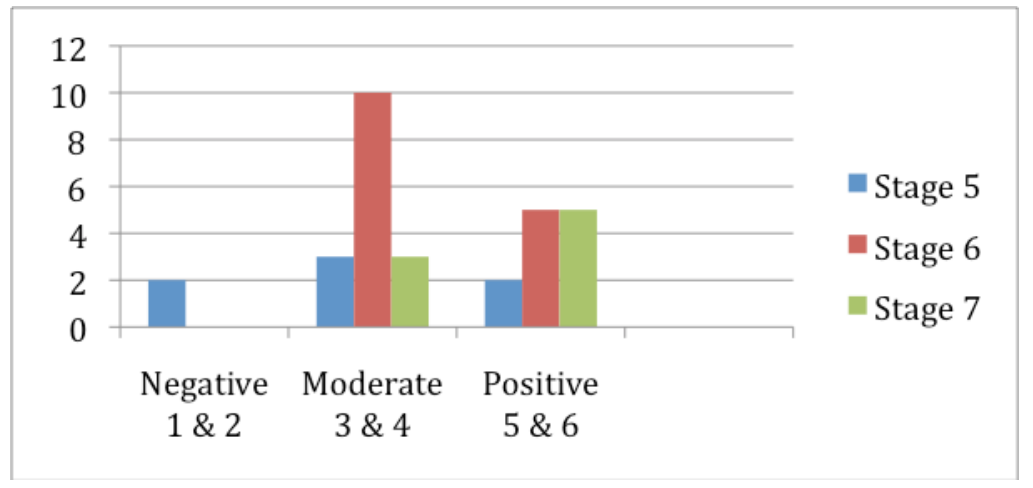

Figure 5.1. Students' responses in relation to how students like mathematics by Students' Numeracy Stage (Questionnaire Question 1)

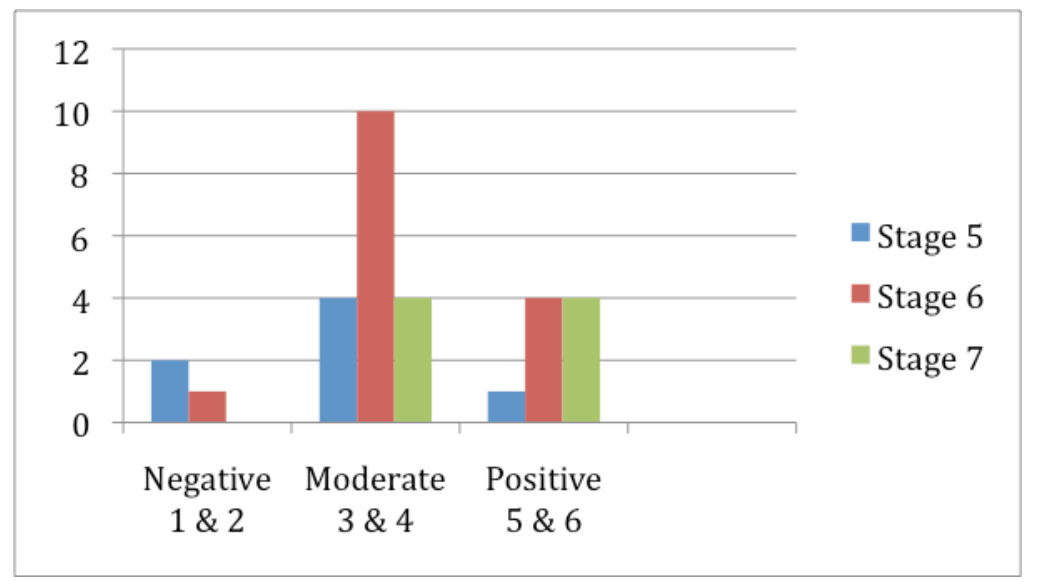

Figure 5.2. Students' responses in relation to how good students think they are at mathematics by Students' Numeracy Stage (Questionnaire Question 5)

For the Year 7 data 30 students completed the questionnaire. Further analysis of the data showed that all 15 students working at Stage 6 and all eight students working at Stage 7 responded that they 'liked' mathematics. Only the eight Stage 7 students perceived themselves as being good at mathematics. Fourteen out of fifteen Stage 6 students perceived themselves as being 'good' or 'extremely good' at mathematics. The seven students working at Stage 5 had mixed perceptions of mathematics: two were negative, 
three moderate and two positive. The perceptions of how good they are at mathematics showed two were negative, four moderate and one positive. Twenty-five out of 30 students 'liked' mathematics and perceived themselves to be 'good' or 'extremely good' at mathematics.

Analysis of the data from the semi-structured interviews showed that all nine students were aware of how they were grouped and the differences from Year 6 to Year 7. All nine students acknowledged that in Year 7 they were grouped as a whole class with one teacher that was not their form teacher, as opposed to small groups in Year 6:

We work as a class and don't get separated into groups. (Mia)

We don't have maths groups. We are one big group. (Hannah)

We are taught as a whole group. (Heidi)

Two students identified that three mathematics classes were mixed ability:

We are grouped as a class. There are two people out of the class in a different class (Michelle)

It's most of our class. There are people who aren't so good at maths. Some people who are and people in between. (Megan)

There are only a few people who are in a different group. (Helen)

Four students identified that one mathematics class was cross-ability grouped for students to work with others of the same ability:

There are four classes in total in year 7. In our class it's a mixture from all the classes. We have a small group, which is easier to learn. (Louise)

There is a group for people who need more help. (Megan)

People who are weak at maths are taken away. (Heidi)

One student saw this as a positive aspect to her learning:

You get to work with people who are around the same as you. It would feel pressured with people who are higher than you. (Lucy)

When asked how the students felt about the differences in grouping the students, seven out of the nine respondents were happy about the way in which they were grouped. Two students in the cross-class group identified that they liked the group they were in as it helped their learning:

I like the group because you aren't always with the really good people. Everyone can learn the same thing, because you're in a group that you all can do it. Not too easy or too hard. (Lucy) 
It's not much of a difference. If one person is stuck the teacher will help. In a smaller group you can discuss it more. (Louise)

Three students believed that it was good to work as a whole class, in order to hear different strategies, to work with people of the same level, and to do the same work as everyone else in the class:

I find it quite good having a big group of people at the same level. We are all doing the same thing and understanding it. (Helen)

Ifeel that it is a good way to hear people's strategies. To get people's different points of view. It's easier to learn. (Hannah)

However, one student did identify that all learning the same thing as a whole class could get boring if they already knew the strategies or mathematical concepts:

I think it is nice doing the same thing in a group. I can get a bit bored if I'm doing something I already know how to do. That can be a bit boring. (Heidi)

One student thought that whole class learning was better for students' self-concept of themselves and how well they do at mathematics. The student talked about being graded on ability, stating that students know who is good at mathematics and who is not, based on assessment scores and participation during class:

Mia: I feel that the whole class is better. You're graded on your ability. You know who's good at maths. In year 6 you could feel who was in which group. If you were in the bottom group you might feel bad about yourself.

Researcher: How do you know who's good at maths?

Mia: They get high grades in assessment and how many times they put up their hand in class.

Two students did not like the way in which they were grouped and identified that it would be better to have smaller groups to help with individual learning:

It would be better if there were smaller groups. It would be better to have groups that do different things from other groups. You would learn more and probably understand things a bit better. (Megan)

and that having small groups of mixed ability would benefit all students:

Lara: I don't really like it. The more advanced mathematicians should be with the least advanced. So you can learn off each other.

Researcher: In what way?

Lara: If one less advanced needed help, the higher person could explain it better. 
Researcher: In what way do you think that would be an advantage for the students?

Lara: They learn from the less advanced and they would be able to explain their process to the less advanced.

The data suggests that students' self-perception of their mathematical ability may be related to mathematical organisation for teaching. The students were aware of the way in which they were organised in their mathematics class. For the majority of students having a whole class teaching approach, with everyone working together on the same work was seen as a positive approach for mathematical self-perception and their learning. Students perceived their own mathematical ability as being good and positive. Students also saw that their friends, family and the teacher perceived their mathematical ability as being an able student.

The data suggests that students are aware of individuals' mathematical ability. This ability is shown through working with their peers from previous years and in Year 7, measured by grades, assessment and participation in class. The students identified that by having a whole class approach it is easier to be able to identify individual ability, as opposed to working in small groups where the students could not observe what other groups were working on. It was mentioned by some students that having a whole class approach allowed students to be able to hear questions and strategies as opposed to only working with a select few in a small group. However, some students did acknowledge that by adopting a whole class teaching approach it did hinder potential benefits of differentiation. By having leveled work aimed at different abilities it would help extend and support individuals within the classroom.

\subsubsection{Summary}

Students perceived themselves as being able mathematicians regardless of ability. Students were aware of the differences in grouping organisation in mathematics. The whole class teaching approach was viewed as a positive approach for mathematical selfperception and student learning. Students stated that they found it easier to be able to identify others' and their own individual abilities when working as a whole class as opposed to in small group organisation. Tools of assessing ability were used to identify individuals' level of ability, such as Progressive Achievement Testing (PAT), and pre and post testing before and after a unit has been taught. 


\subsection{Grouping and Students' Preferences for Organisation of Grouping}

Three open-ended questions from the questionnaire were identified in relation to how students felt about the organisation of grouping within mathematics. The three questions were:

Describe the group you are taught maths in.

Describe how you feel being taught in this group.

Are you happy to learn in this group? Give reasons for why or why not.

One open-ended question used in the semi-structured interview related to the category of organisation of grouping in mathematics was:

Have you noticed any differences in the way you are grouped?

In the category of perception of ability two themes emerged: grouping and learning (small group and whole class), and grouping versus perception of ability.

From the open-ended question, Question 10 (see appendix 1) within the questionnaire, respondents described the group they were taught in as being: 'form class', 'whole class', 'average class' and 'cross-class'. Ten students indicated that they were taught within their form class with a mathematics teacher, different to that of their form teacher. Nine respondents identified that there was a cross-class group that was made up of people from the three different form classes. Two respondents pointed out that by having a cross-class mathematics class it was a positive thing for individuals, as it allowed individuals to be able to work at their own level and to feel confident when working mathematically:

My group is cross-classed and is good for my level. (Year 7)

I think it is good to have a cross-class. So some girls who are not confident mathematicians can work at their level and not struggle. (Year 7)

Again, there was recognition from one student that the cross-class group was organised for ability purposes:

In my group people aren't as advanced as people in the whole class. (Year 7)

Five students out of ten who identified their class as being their form class also identified that one class had been organised by ability and therefore a cross-class group had been created:

Some people have been moved into the cross-class. (Year 7)

Four students recognised that the form classes had a mixture of ability:

There are some people who are really good at maths and there are some people who are ok at maths. (Year 7) 
There is a mixture of good and not so good at maths. (Year 7)

My maths class is a form class with some students moved depending on their ability.

(Year 7)

Twelve students identified that their form class was taught as a whole class with everyone doing the same work at the same time and indicating that there was little room for individual differentiation:

There is a big gap between people and their learning. (Year 7)

Twenty-six out of 30 students liked the way that they were taught mathematics in Year 7, either as a whole class or within the cross-class group. The students identified positive aspects of learning from each other as a whole class, working at the same level and hearing people's mathematical concepts within their group organisation:

I feel happy when I am taught in this group as I can learn from my peers. (Year 7)

I enjoy working in this class because we are all at the same level. (Year 7)

I like being taught sometimes as a whole class so I can hear everybody's ideas and then I see things from a different point of view. (Year 7)

However, two students did identify that 'yes' they were on the whole happy being taught in their group but recognised that whole class teaching does not always address individual needs or allow for differentiation:

I think I could do better if I had more one-on-one time with the teacher. (Year 7)

I like it, although it doesn't focus on people's individual strengths. (Year 7)

Even though the majority of the students were happy with the group they were taught within, four students responded that they were not happy with the way in which their mathematics class was organised, and may prefer differentiated learning:

Not happy because I know pretty much everything the teacher is teaching us. (Year 7)

I would prefer it if the classes were streamed. (Year 7)

Our teacher doesn't help us unless we need it. (Year 7)

I feel sad because I think that everybody should be in their form class for maths not in 'cross class' groups because then we could learn from the other people in the class. (Year 7)

Twenty-six out of 30 participants were happy to learn in the group they were organised within. The data showed mixed views with reasons such as working together as a whole class were appealing; students were taught at the same level, work was challenging. 
There was a different mixture of ability levels in the one group and a wide range of mathematical knowledge:

Most people are at the same level as me. (Year 7)

It's challenging. (Year 7)

There is a wider range of mathematical knowledge. (Year 7)

I also like it grouped as a whole class because then it is a good mixture of different levels in maths. (Year 7)

Working together to hear others' ideas and questions also were important to two of the respondents:

We hear each other's questions to give us a better understanding. (Year 7)

We can share our ideas and help each other. (Year 7)

One respondent did identify that by having been organised as a whole class there was no distinction between individual ability, which could give a student the feeling of not being very good at mathematics:

I don't feel like I am at the bottom of the class and I can talk to my classmates if I don't understand. (Year 7)

However, there were three participants who did identify that they did like the group they were organised within, but acknowledged that there were some negative aspects to whole class teaching such as being held back and needing extra time:

I am happy but I feel that I'm a bit held back by the class. (Year 7)

I need more time to complete some of the tasks. (Year 7)

One respondent felt that she was not good at mathematics when being taught in a whole class situation:

I feel I'm not very good compared to other girls in my class. (Year 7)

From the semi-structured interviews, nine participants were asked if they noticed any differences in the way in which they are grouped in Year 7 from their Year 6 groupings. Eight out of the nine participants agreed that 'yes' they had noticed differences in the way in which they were taught in Year 6 and Year 7, making comments such as: 'organisation of desks', 'facing the teacher and interactive whiteboard', not in groups facing each other, 'given more worksheets than working from a big book where they recorded their group's learning', the 'groups were based on results', 'no small groups' and the 'groups were not streamed, they were at the same level'. 
However, one respondent from the cross-class group who said 'no' commented that all the students within the group:

Are all at the same level. (Lara)

Therefore, this student felt that the mathematics classes were organised the same as in Year 6, by ability.

The biggest changes in their mathematics learning that the students saw from Year 6 to Year 7 were more worksheets and no small group work. The data suggests that students are aware of the way in which the classes are organised and how the grouping affects their mathematical learning and self-concept. The majority of students from all the Year 7 mathematics classes identified that having the cross-class group was positive for individuals, allowing for their confidence to grow and them being able to work at their own level. Some students see whole class organisation as a positive for their learning. It challenged them, gave opportunities to hear other people's mathematical concepts, and enhanced learning by having a wide range of abilities in one group. In contrast, there were students who saw whole class organisation being a problem, leaving little room for differentiation, less individual attention with the teacher, students being held back and feeling bored, students not getting extra time, feeling rushed, and having the feeling of not being as good as others in the class when working with a variety of abilities.

\subsubsection{Summary}

On the whole students saw whole class organisation as positive for their learning and found it challenging and an opportunity to work with a wide range of abilities. Students saw a cross-class approach as positive for individuals, allowing for their confidence to grow and for them to be able to work at their own level. In contrast, some students saw whole class organisation as providing little room for differentiation, less individual attention and increasing students' anxiety when dealing with mathematical strategies and concepts.

\subsection{Ways of Learning}

To examine how participants felt about learning and questioning in mathematics, questionnaire and interview questions were grouped into the category of: Questioning (within a whole class and small group situation, a one-on-one basis and whether or not 
students asked their teacher for help). Five questions from the questionnaire were identified in relation to if and when students ask questions in mathematics:

Do you ask questions in whole class discussions?

Do you ask questions in small group discussions?

Do you ask questions one-on-one with the teacher?

Do you ask your teacher for help when you need it?

Is there any way you would prefer to learn maths? If so please explain why and how. One open-ended question from the semi-structured interview related to the category of organisation of grouping in mathematics:

What are the differences in the way you are taught maths from Year 6 or Year 7?

The results for the questionnaire questions are presented in Table 5.3. The table in different ways shows the extent to which students asked questions when they were grouped in different ways: whole class, small group, one-on-one with the teacher, and asking the teacher for help. When asked about questions asking within a whole class situation, $13 \%$ responded they did this 'not at all', however $87 \%$ felt comfortable to do so. One student from the semi-structured interview commented:

If someone asks a question the teacher tells the whole class as opposed to one person.

The teacher writes the question on the board. (Helen)

That most students feel comfortable to ask questions could be due to more whole class teaching within Year 7 as opposed to Year 6 where there was small group organisation. The students seemed more likely to answer questions when students worked one-on-one with the teacher (77\%) than asking questions within a small group discussion (53\%). Ninety-three percent of students felt comfortable asking the teacher for help during the lesson. However, the data did show that $27 \%$ of the respondents mentioned that asking questions within a small group discussion did not apply within Year 7 and a high percentage chose 'not at all' for small group discussion (17\%) and one-on-one with the teacher (20\%). Again, this was likely to be due to the classes being taught as a whole class. This data links to the results from Question 2 (See Appendix 2) of the semistructured interview when students identified the differences in the way they are taught mathematics from Year 6 to Year 7. Three students commented:

You aren't taught in three little groups like in year 6. (Lucy)

Taught more as a whole class instead of focusing on one person. You all get taught as a whole class. (Michelle)

There aren't as many small groups as last year. You all do the same as everyone else. (Megan) 
Table 5.2

Students' responses to asking questions in mathematics (Questionnaire Questions 2, 3, 4 and 9)

\begin{tabular}{|l|c|c|c|c|}
\hline \multirow{2}{*}{ Ways of learning } & \multicolumn{4}{|c|}{ Frequency } \\
\cline { 2 - 5 } & $\begin{array}{c}\text { Rank 1 and 2 } \\
\text { (Not at all) }\end{array}$ & $\begin{array}{c}\text { Rank 3 and 4 } \\
\text { (Moderate) }\end{array}$ & $\begin{array}{c}\text { Rank 5 and 6 } \\
\text { (Yes definitely) }\end{array}$ & $\begin{array}{c}\text { Doesn't apply for } \\
\text { Year 7 }\end{array}$ \\
\hline $\begin{array}{l}\text { Do you ask questions in whole } \\
\text { class discussions? (2) }\end{array}$ & $4(13 \%)$ & $20(67 \%)$ & $6(20 \%)$ & - \\
\hline $\begin{array}{l}\text { Do you ask questions in small } \\
\text { group discussions? (3) }\end{array}$ & $5(17 \%)$ & $10(33 \%)$ & $7(23 \%)$ & $8(27 \%)$ \\
\hline $\begin{array}{l}\text { Do you ask questions one-on- } \\
\text { one with the teacher? (4) }\end{array}$ & $6(20 \%)$ & $15(50 \%)$ & $8(27 \%)$ & - \\
\hline $\begin{array}{l}\text { Do you ask your teacher for } \\
\text { help when you need it? (9) }\end{array}$ & $2(7 \%)$ & $7(23 \%)$ & $21(70 \%)$ & - \\
\hline
\end{tabular}

To aid the analysis process the categories were then analysed by students' strategy stages based on the New Zealand Numeracy Stages Table 1.1 (Section 1.2). The responses have been categorised into the Numeracy Stages to examine further whether ability grouping may be related to the way in which students learn and ask questions. These results are shown in Figures 5.3, 5.4, 5.5 and 5.6.

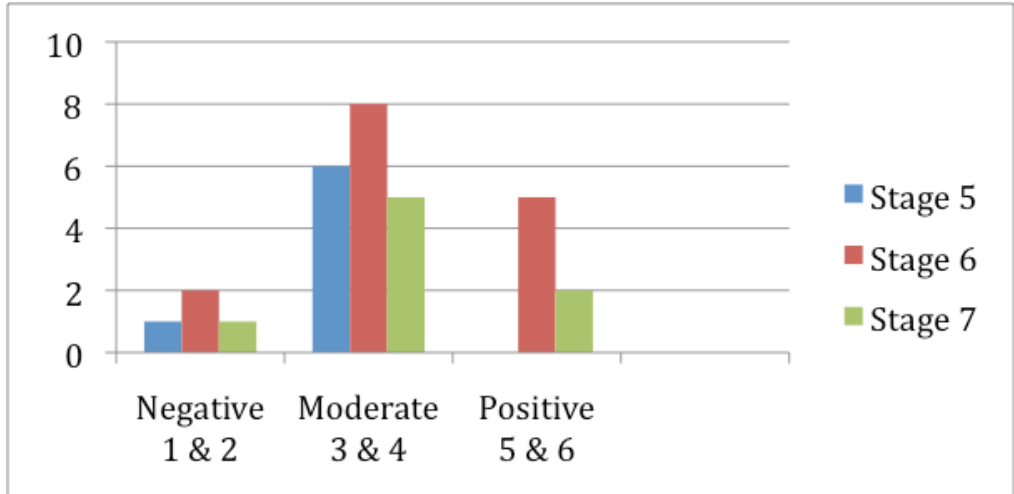

Figure 5.3. Students' responses in relation to asking questions in a whole class situation in mathematics by Numeracy Stage (Questionnaire Question 2)

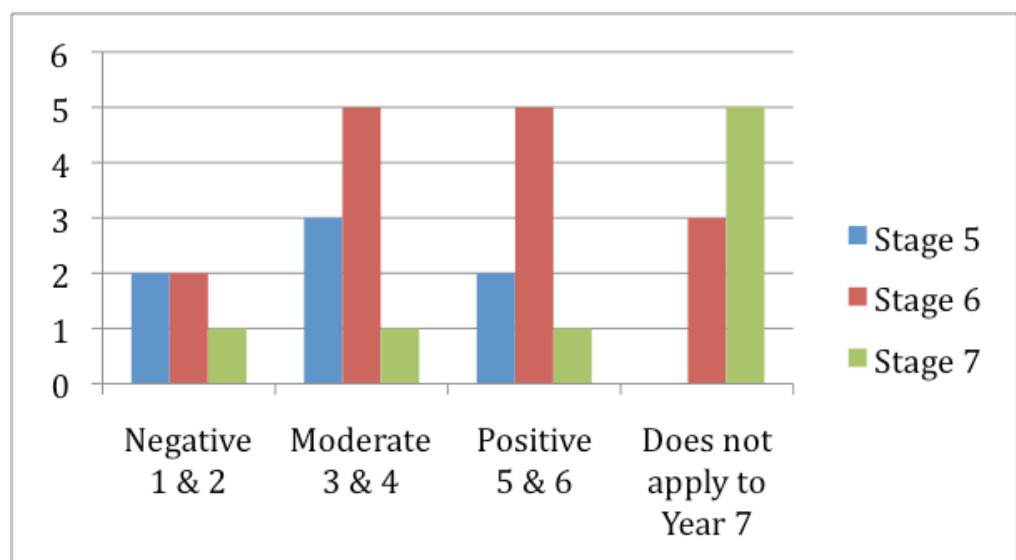

Figure 5.4. Students' responses in relation to asking questions in small groups in mathematics by Numeracy Stage (Questionnaire Question 3) 


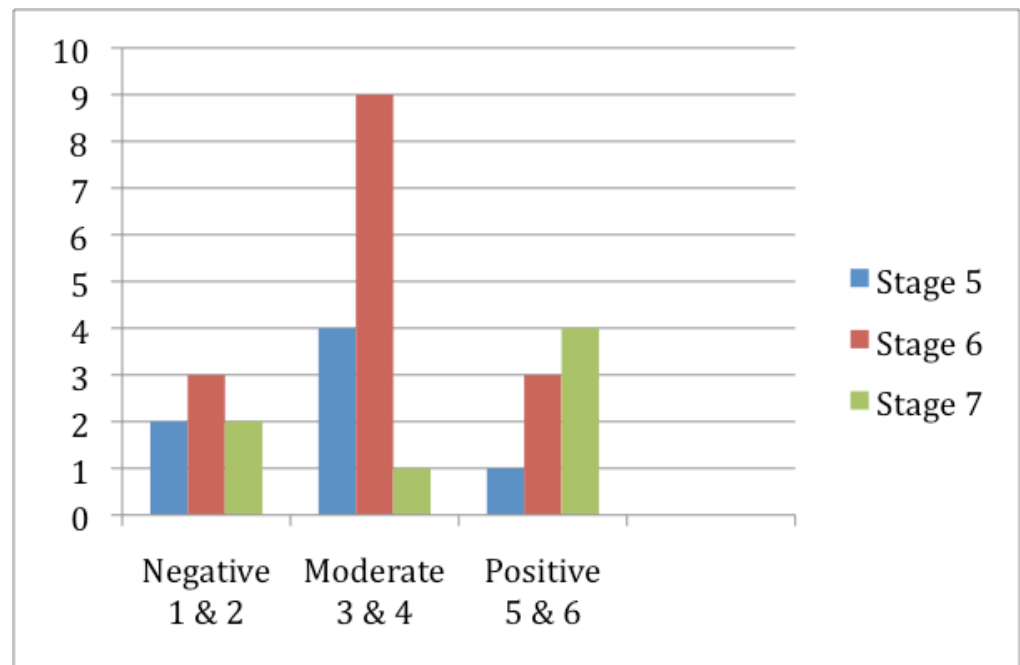

Figure 5.5. Students' responses in relation to asking the teacher questions one-on-one in mathematics by Numeracy Stage (Questionnaire Question 4)

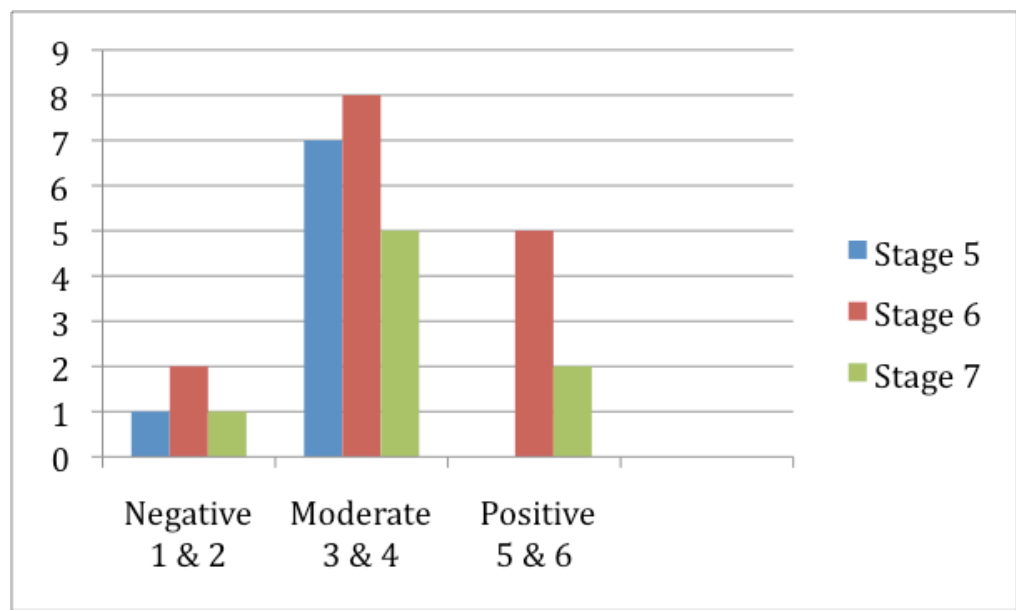

Figure 5.6. Students' responses in relation to asking the teacher for help in mathematics by Numeracy Stage (Questionnaire Question 9)

The results show that six out of seven students working at Stage 5 felt moderately positive and one student felt negatively about answering questions in a whole class situation. Students working at Stage 6 and Stage 7 were more positive in this area. This could be due to more whole class teaching and learning occurring. There were mixed results when it came to asking questions in a small group. Students working at Stage 6 and Stage 7 felt positive. However, five out of fifteen students working at Stage 6 and five out of eight students working at Stage 7 identified that small group organisation did not apply to Year 7. Five out of seven students working at Stage 5, nine out of fifteen students working at Stage 6 and five out of eight students working at Stage 7 felt positive when it came to asking the teacher questions in a one-on-one situation. There were low responses to the negative descriptors for each of Stage 5 (two out of seven), Stage 6 (three out of fifteen), and Stage 7 (two out of eight) students. Students working 
at Stage 5 felt less confident in asking the teacher for help (one out of seven 'negative' and six out of seven 'moderate'), whereas thirteen out of fifteen students working at Stage 6 and seven out of eight students working at Stage 7 felt positive about doing so. It is a concern that those who may need most help are least comfortable to ask for help.

The majority of students identified they were happy being taught as a whole class and gave no comment to any other preference on how they would prefer to learn. One student recognised that she preferred to learn from other people and share her ideas. Another student preferred to have the teacher explain the mathematical concepts, and four students indicated that they preferred to learn in smaller groups where there could be more one-on-one individual attention and differentiation:

Class should be spilt into smaller groups and focus more on students' individual strengths and weaknesses. (Year 7)

I would prefer to learn in smaller groups because I can learn more with the teacher. (Year 7)

I would prefer to learn with a small group of people at my level. (Year 7)

I would like work set for just you and set for your one-on-one needs. (Lucy)

In contrast, two students placed within the cross-class grouping indicated that they did not like learning within that class and would prefer to learn with peers they felt comfortable with and knew well, within a mixed class of different abilities:

I would prefer to learn with either my class or in a mixed class with people that are all the same level. (Year 7)

I would prefer to learn with my class because I get shy around people that I don't know. (Year 7)

I think that it would be nice to work in smaller groups to have your say. Not just putting your hand up and being picked by the teacher. (Megan)

\subsubsection{Summary}

There were mixed feelings about how students preferred to learn mathematics at Year 7. On the whole, students indicated that being in a cross-class group was less comfortable for them as they were not working with people they were comfortable with, and they would have preferred working with their form class in a mixed ability approach. However, some students felt positive about being taught as a whole class, learning from other people, sharing ideas, and having the teacher explain the mathematical concepts more. In contrast, some students preferred to learn in smaller groups with one-on-one individual attention and differentiation. 


\subsection{Summary}

In the research Year 7 students were aware of the differences in grouping organisation in mathematics and there were mixed feelings about how students preferred to learn. On the whole, students viewed whole class organisation as being positive for mathematical self-concept and student learning. They found this approach challenging and an opportunity to work with a wide range of abilities. The students felt that being taught as a whole class provided opportunities to learn from each other and to share ideas, and believed it to be easier for teacher explanation of mathematical concepts. Students felt that it was easier to be able to identify others' and their own individual ability when working as a whole class as opposed to small group organisation. However, some students saw whole class organisation as providing little room for differentiation, less individual attention and increasing students' anxiety when dealing with mathematical strategies and concepts. Some students in Year 7 preferred to learn in smaller groups with one-on-one individual attention and differentiation. Students saw a cross-class approach as positive for individuals, allowing for their confidence to grow and to be able to work at their own level. On the whole, students felt that being in a cross-class group was less comfortable when not working with people they were familiar with and they would have preferred working with their form class in a mixed ability approach. The comparison and implications of these results and the results of Chapter 4 will be discussed in Chapter 6. 


\section{Chapter 6: Comparison of Years 6 and 7 Results and Discussion/Conclusion}

This research set out to improve the understanding of what occurs in New Zealand classrooms (with special focus on Year 6 and Year 7) in relation to understanding effects of how classes are organised during mathematics instruction. The basis of the research is a comparative study between the views of the same group of students across two different year levels in order to examine two different approaches to classroom organisation in mathematics. In researching the questions, qualitative and quantitative methods were chosen in order to explore whether class organisation (cross-class or mixed ability grouping) affected students' self-concept in relation to their mathematical learning. This chapter provides a summary of the results from the previous two chapters with the purpose of showing how this research adds to the understanding of selfconcept, grouping and learning. Due to the small sample size used in this study, generalisations cannot be inferred to all Year 6 and Year 7 mathematics classrooms in New Zealand; however, this research provides a starting point for consideration of classroom organisation in mathematics and how it may affect female students' selfconcept. The study aimed to answer the following research question:

- To what extent does class organisation in mathematics affect female students' mathematical self-concept?

Perceptions of ability in relation to group organisation will be discussed in Section 6.1, preferences for organisation of grouping in Section 6.2, and ways of learning in Section 6.3. Section 6.4 concludes the findings and Section 6.5 presents the limitations that may have impacted on the reliability and validity on the findings of this research. Further questions and research ideas that arose from the study are noted in Section 6.6. Implications to be drawn from this research are specified in Section 6.7.

\subsection{Perceptions of ability}

Perceptions of ability in this study consisted of the comparison of views from Year 6 to Year 7 students in mathematics. This section explores the comparison of Strategy Stages (ability), how students from each Strategy Stage (Stage 5, 6 and 7) perceived their own ability over two years and if views of mathematical self-concept altered.

The Year 6 and Year 7 students from this study do have perceptions of their ability regardless of the Strategy Stage they are working within. As shown in Figure 6.1, the comparison of Strategy Stages from Year 6 to Year 7 shows students' responses to how good they felt they were at mathematics. The figures illustrate that students overall felt 
they were better at mathematics in Year 6 than Year 7. There were negative responses from students working within Stage 5 and Stage 6. However, more students responded positively within all Strategy Stages in Year 7.

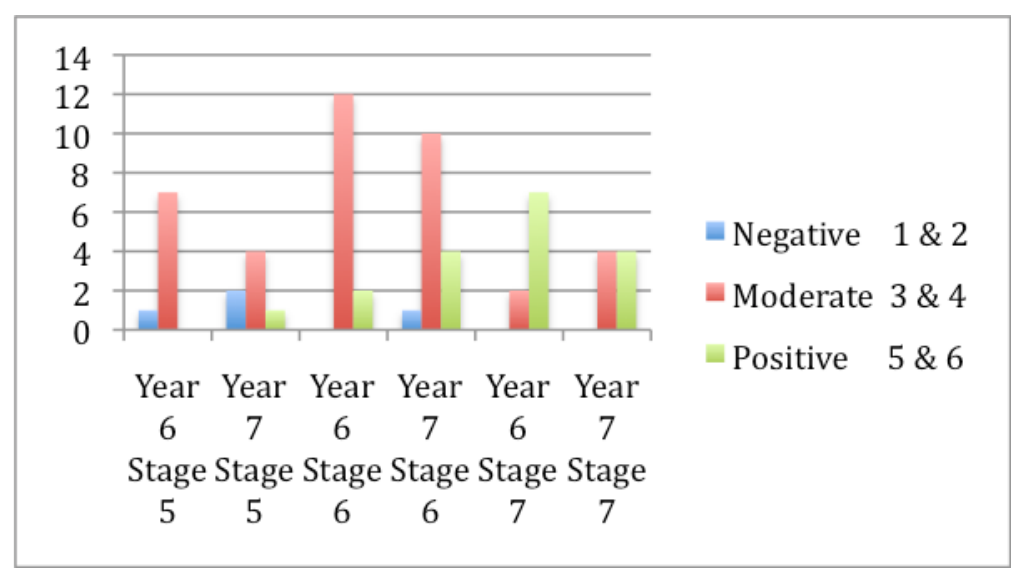

Figure 6.1. A comparison of students' Numeracy Stages from Year 6 to Year 7 student responses in relation to how good students think they are at mathematics (Questionnaire Question 5)

The data within this study shows that students are aware of their ability grouping and receive messages about their ability through classroom organisation, whether grouped in small ability groups, whole class mixed ability or cross-class organisation. These views may have impacted on both student self-concept and their feelings about their grouping through different factors, such as struggling with mathematical concepts and their own mathematical achievement over many years. It was clear that students do receive messages about their ability through the way in which a mathematics classroom is organised and are aware of the different abilities of other students, either in Year 6, small groups (naming of groups, e.g. circles, squares, triangles) or Year 7, whole class organisation, and through assessment, scores, grades and participation of individuals in class.

Figure 6.2 shows the comparison within each Numeracy Strategy Stage from Year 6 to Year 7, demonstrating how students 'liked' mathematics. Figure 6.2 shows that the students working within Stage 5 'liked' mathematics more in Year 6 than in Year 7. Eight students in Year 6 felt moderate or positive about mathematics, whereas in Year 7 there were two students who felt negatively towards mathematics and only two students felt positive as opposed to four in Year 6. The figures clearly show that students working within Stages 6 and 7 responded more positively towards liking mathematics in Year 7 than Year 6. Stage 6 students in Year 6 included two students feeling negatively 
about liking mathematics, and there was no feeling of negativity in Year 7. Grouping is one factor to consider but there are other factors to be taken into consideration that may have contributed to students 'liking' mathematics or not, such as the way their teacher portrayed maths or their own passion for it.

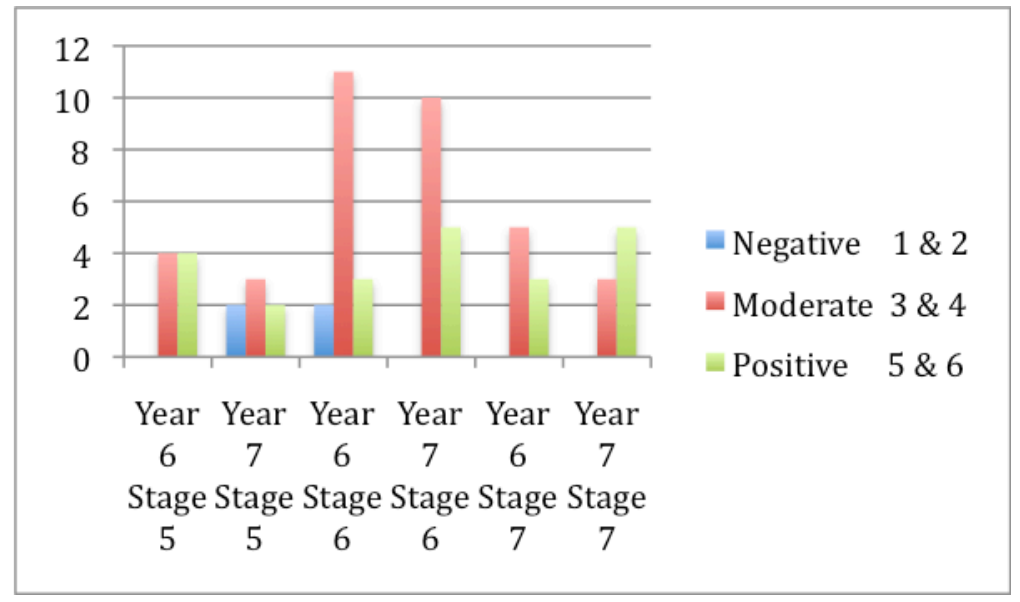

Figure 6.2. A comparison of students' Numeracy Stages from Year 6 to Year 7 student responses in relation to how students like mathematics (Questionnaire Question 1)

Year 6 students found being organised into small ability groups enabled individual attention from the teacher. The students felt that all students were included in the learning process and it facilitated their confidence with learning new concepts and strategies, creating positive mathematical self-concept. The Year 6 students in this study identified that being in small groups helped them learn from each other's mistakes and work co-operatively with their peers. The National Council Teachers of Mathematics (NCTM) (2000) acknowledge that mathematics is enhanced when students reflect on their own thinking, monitor their own progress, and learn from their mistakes, so in view of this, the results of this study indicate that organisation can provide students with the opportunity to explore diverse and sometimes more advanced mathematics and therefore lead to students having a positive perception of their ability.

In contrast, the results from the Year 7 students showed that they felt a whole class teaching approach in mathematics was for them a positive way in which to organise the class and was constructive in developing their mathematical self-concept. The students acknowledged that with all students working at the same level and working on the same mathematical concepts, students are able to observe each other's strengths and weaknesses and therefore evaluate individual ability. However, not all Year 7 students 
found the whole class approach a positive experience. Some found this way of organisation boring and limiting for student differentiation. Many problems have been experienced from the lack of teacher differentiation, expecting students to learn at the same pace as each other (Boaler et al., 2000 and Boaler \& William, 2001).

\subsection{Grouping and Students' Preferences for Organisation of Grouping}

This section looks at the organisation of grouping in mathematics and the preferences of students from Year 6 to Year 7. These preferences are identified from each year group to show similarities or differences in student views over two years.

The Year 6 students preferred learning within a small group as they felt that it allowed for discussions, being able to hear different number strategies being used, and being able to learn at an individual's ability level. Heterogeneous groups are formed to accommodate the opinions of others, engage in problem solving and take different perspectives (Bossert, 1988); collaboration of working together came through strongly in how the Year 6 students felt that they learnt best. Even though the groups were arranged by Strategy Stages there was still a range of abilities within each group. Significant benefits for learning can arise from students collaborating with others. Students learn to take on other people's perspectives, help their peers, and develop their own understanding and the understanding of others in their group (Steel, 2005). The students commented on small groups promoting camaraderie and having less pressure to get things right than when taught as a whole class, as everyone works together to help each other. Students giving and receiving help can be effective when it is in the form of elaborated explanations and not just answers (Webb, 1991). Working and learning within a small group allows for individuals to have more opportunities to be able to explain things, and to work and learn at their own pace in ways that are congruent with real-world tasks (Lampert, 1986; Schoenfeld, 1983). The Year 6 students from all strategy stages identified small group organisation as a positive experience for their learning and for their mathematical self-concept. Students felt confident in their learning and were not worried about getting things wrong in front of their peers. Students felt supported by others and liked being taught with students of a similar ability.

What was evident from the results was that when working within a small group, there is no hiding for individuals. Each individual is part of the group and therefore it is more 
transparent and easier for the students and the teacher to identify the ability of individual students, even though they are at a similar level. As suggested by Slavin (1990), there are positive effects of small group work on students' attitudes towards school. The Year 6 students working within a small group identified that they learnt new concepts and strategies all the time. The co-operative learning methods that can occur in small group organisation are known to improve student achievement and therefore are likely to lead to higher self-concept. On the whole, the Year 6 students found working at the same level gave individuals confidence in their own ability. However there were some students who did not like the fact that you could feel scared or uncomfortable about being at the bottom of a small group.

As suggested by Cocklin (1999, sited in Matheson, 2009), the transition from a primary school setting to the secondary school setting may decrease student motivation due to less individual decision making happening in a whole class situation (Matheson, 2009). In this study, the Year 7 students saw the transition from small group organisation in mathematics, being organised in form classes in a mixed ability approach, to whole class and cross-class ability grouping, positively. With all students doing the same work at the same level, students saw this as positive for their learning, as they were able to hear everyone's questions, strategies, ideas and points of view. When in Year 6, however, students perceived learning within a whole class situation as a pressurised learning situation, with their peers racing ahead and finishing work, students being left behind, the work being too challenging for individuals, and not being able to get enough teacher attention.

However, not all students viewed whole class organisation positively in Year 7. Some students viewed whole class organisation to have no room for individual differentiation, no allowance for individual strengths and weaknesses, and there was a lack of teacher attention and one-on-one support. Straker (1999) says that all students benefit from direct contact with their teacher. This approach of organisation gave students the feeling of being left behind and not being very good at mathematics. Students identified that they all had to work at the same pace and move onto new concepts even if they had not yet grasped them. The whole class approach has the potential for limited monitoring of concept understanding and contributions each student is likely to make to the class discussion. Furthermore, students who fail to grasp concepts are even less likely to 
contribute to such discussions for fear of disapproval and rejection by peers (Straker, 1999).

The Year 7 students identified that students who were slower than others and needed extra time could hold the class back, and some students found this frustrating. Students' mathematical self-concept could be affected significantly more if students work in a more traditional way, for example whole class teaching all of the time. However, students viewed the selected Year 7 students working in the cross-class group as a positive aspect for an individual's learning, allowing individuals to work at their own level and to feel confident at the pace at which they were working. The students in this group working at Stage 5 appeared to be happy and confident learning this way.

\subsection{Ways of learning}

The Year 7 students of the study identified major differences in the ways they were taught from Year 6 to Year 7. The students were clear about the different ways of organisation, and agreed that whole class organisation and learning was prevalent in Year 7 in contrast to small ability groups, as in Year 6. This section looks at the ways in which students learn and their preferred way of learning and questioning in mathematics: questioning within a small group, whole class situation, one-on-one with the teacher and asking the teacher for help. This section compares the Strategy Stages of Year 6 and Year 7 students to understand if there are differences in a student's mathematical self-concept in relation to learning through classroom organisation.

The study showed that students were more likely to answer questions in a small group situation, as shown in Figure 6.3. The figures show that students working at Stage 5 were more confident about asking questions when in Year 6, as opposed to Year 7, although in Year 7, small group work did not apply to all mathematics classes. The students noted that in Year 7 there was limited small group organisation occurring within all four classes. Overall, Stage 6 and Stage 7 students were more positive in Year 6 than Year 7. Year 6 students identified a preference for working in a small group to help with their learning. The students acknowledged that small group work helps individuals to feel more confident to ask and answer questions, while allowing students to stay focused on particular tasks, share their strategy knowledge and observe how other students operate mathematically, which all benefit students' progress and 
confidence. The NDP in Year 6 scaffolds the use of strategic questioning. The questions are responsive, allowing the teacher to respond to teachable moments, often using phrases offered by students to previous questions. This allows students to retain a sense of ownership of developing ideas and to negotiate meaning (Ministry of Education, 2003b). The dialogue with the teacher and small groups was viewed as being important in order to allow for the interaction of multiple voices to form new mathematical understanding. This type of dialogue provides a context within which students are able to develop their own dialogical thought processes in which competing voices are internalised (Straker, 1999), by encouraging discussion.

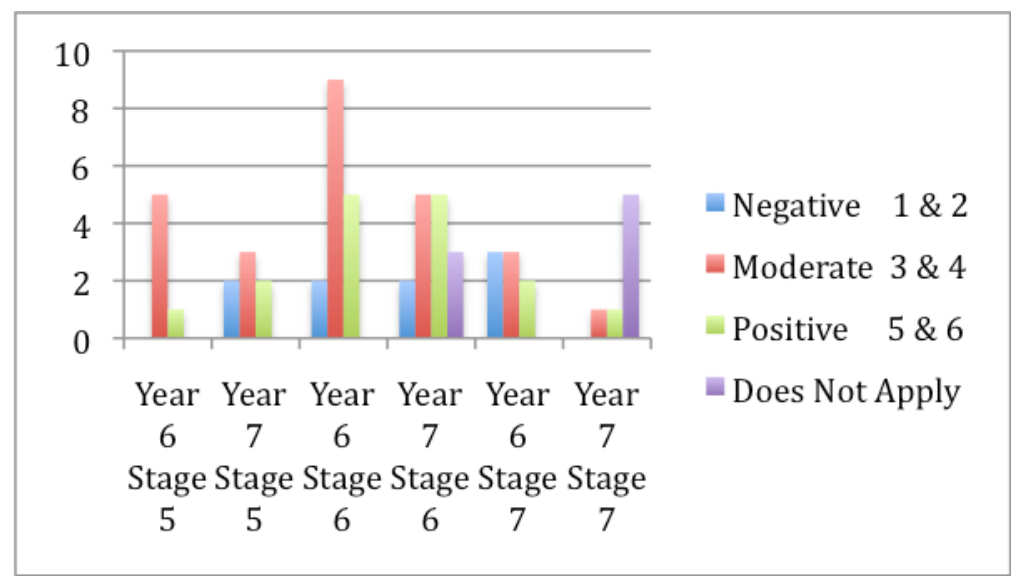

Figure 6.3. A comparison of students Numeracy Stages from Year 6 to Year 7 student responses in relation to asking questions in small groups in mathematics (Questionnaire Question 3)

There were mixed views from the students in Year 6 when putting up their hand in a whole class situation. The data clearly shows that all Strategy Stages overall in Year 6 were more negative towards asking questions in a whole class situation, as shown in Figure 6.4. This could be because there was more whole class learning occurring than when in Year 6, but could be seen as students asking the teacher in a more private situation as opposed to in front of their peers where they may feel less confident, potentially resulting in a lower self-concept. Some students in Year 6 indicated that whole class organisation gave the option to work with new people of different abilities. This way of organisation the students felt could help assist with students blending into the class as a whole group and it wouldn't matter about an individual's ability as they felt no one would know the strengths or weaknesses of individuals. However, some students in Year 6 felt that having mixed ability teaching in a whole class situation could make individuals feel pressurised if the work was too hard. However, the Year 7 
data identified that students were more than happy to learn within a whole class situation and gave no preference to any other way of learning.

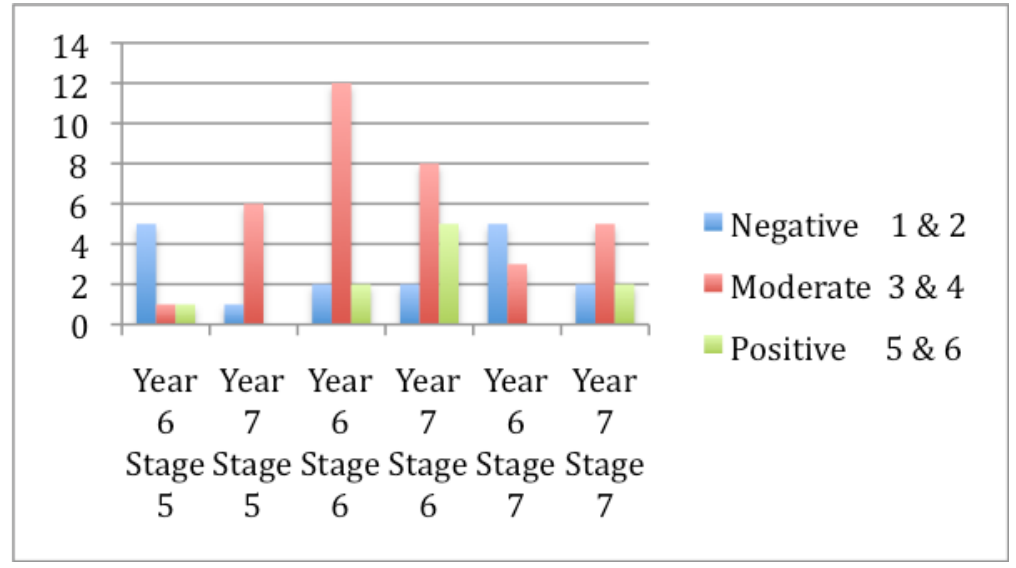

Figure 6.4. A comparison of students' Numeracy Stages from Year 6 to Year 7 student responses in relation to if they ask question in a whole class situation in mathematics (Questionnaire Question 2)

As shown in Figures 6.5 the Year 7 students were more likely to answer questions oneon-one with the teacher. Year 6 Stage 5 students all felt positive and confident enough to ask the teacher questions in a one-on-one situation. This could be due to the small group organisation and not being taught as a whole class where individuals can be heard by everyone which could be seen as daunting for some students. However, students working at Stage 6 and Stage 7 showed an improved confidence in Year 7 overall, with less negativity.

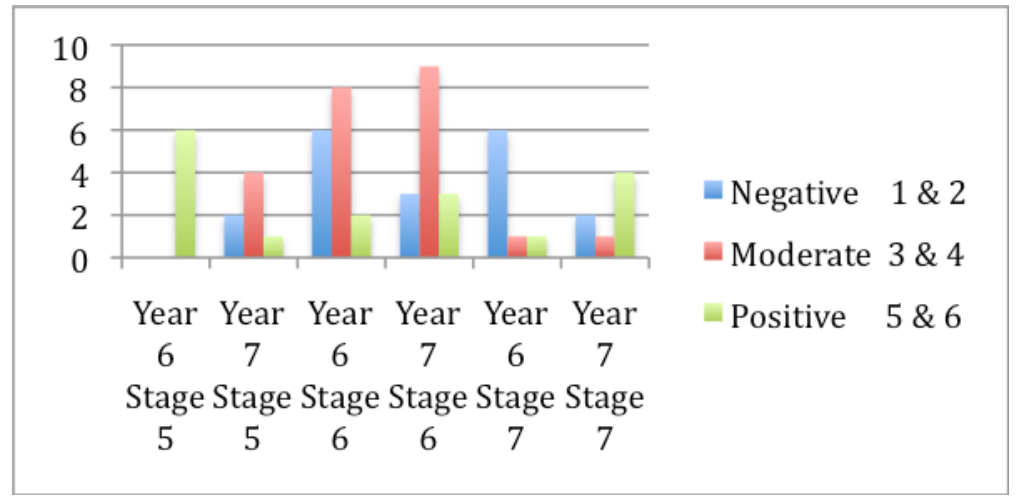

Figure 6.5. A comparison of students' Numeracy Stages from Year 6 to Year 7 student responses in relation to if they ask the teacher questions one-on-one in mathematics (Questionnaire Question 4)

When asking the teacher for help Stage 5 students were more confident overall in Year 6 than Year 7, as shown in Figure 6.6. There was the same negative response for Stage 6 students within both year groups, with a higher positive response in Year 6. Stage 7 
students showed overall a lower negative and positive response in Year 7, with a higher moderate response.

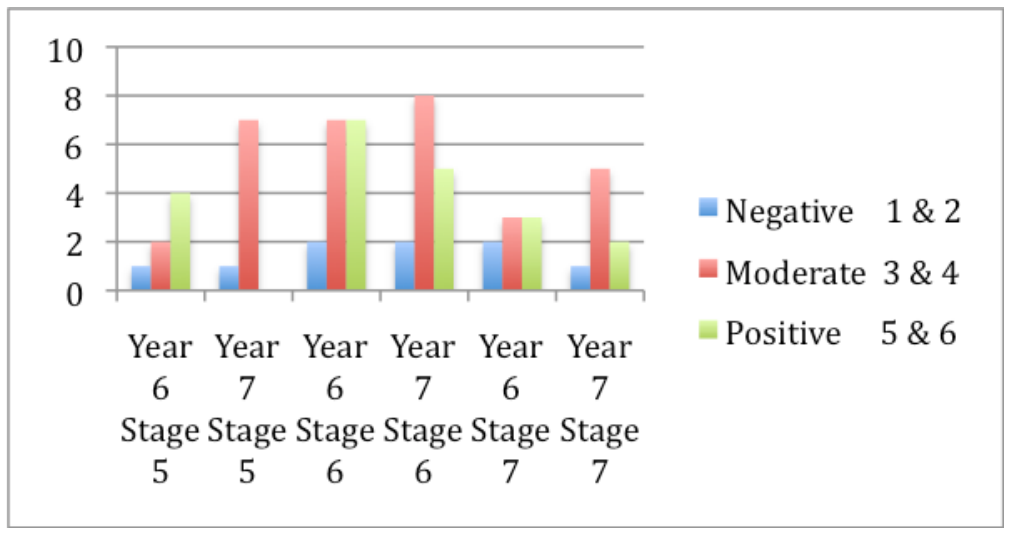

Figure 6.6. A comparison of students' Numeracy Stages from Year 6 to Year 7 student responses in relation to if they ask the teacher for help in mathematics (Questionnaire Question 9)

The data from the questionnaires and semi-structured interviews showed that some students were scared to answer questions in case they got the question wrong and worried that their peers would judge them. This tells us that students can feel anxious about risk taking and putting themselves forward in a situation, and therefore it is important for teachers to create an environment where it encourages students to take risks, and be more involved in discussions and questioning when working in a small group (Ministry of Education, 2007). During small group work all students are accountable for their learning and this way of organisation does not suit all students' learning, which in turn affects mathematical self-concept, positively and negatively.

\subsection{Conclusion}

It is evident from the study that students do receive messages about their ability from friends, parents and the teacher, which includes the way in which their mathematics class is organised, whether in small groups based on ability as stipulated in the NDP or whole class based on mixed ability. The students could see the benefits of all ways to organise to assist with their mathematical learning and developing positive mathematical self-concept.

The Year 6 students felt that working and learning in small groups based on ability created an environment which gave opportunities for risk taking, collaboration, helping others, creating discussion (dialogue), working with the teacher and allowing for more attention, and being able to articulate mathematical strategies and concepts at an 
individual level. The students found that by working together it helped their learning and mathematical self-concept. The Year 6 students viewed whole class organisation as being more pressurised, having to perform in front of their peers and feeling failure or being judged for being wrong. The students viewed small group organisation as a safe environment to facilitate their learning and mathematical self-concept, through camaraderie, being able to work at their own pace in a co-operative setting and feeling less pressure to get things correct. However, some Year 6 students viewed small group organisation based on ability negatively and saw themselves as being transparent, worrying that they would be at the bottom of the group and not feeling very good about their mathematical ability. In addition, the results showed that students were more likely to ask and answer more questions in a small group where students are less anxious about risk taking and are more involved in discussions and questioning.

The Year 7 students' perception of their ability was influenced by individuals' contributions to class discussions, scores, and assessment. The majority of students viewed whole class organisation positively, allowing for everyone to hear questions, strategies, points of view, and with everyone doing the same work. The students largely felt confident to ask and answer questions within a whole class and one-on-one with the teacher. However, students did identify negative aspects of whole class organisation and noted that it provided limited room for individual differentiation. The students found that within whole class organisation there was a lack of individual distinction with less room for teacher monitoring of students' contributions to class discussions. This lack of contribution could leave students not fully grasping mathematical concepts and lagging behind the rest of the class. Students felt less likely to contribute for fear of disapproval of peers for holding the class back from moving onto the next concept.

The comparison of data shows that schools and teachers need to allow for opportunities for students to develop a positive attitude towards mathematics. A positive attitude raises students' comfort levels and gives students greater confidence in their capacity to learn and to make sense of mathematics. (Anthony \& Walshaw, 2007). Class organisation needs to support students to be able to work in a variety of ways: small group, whole class, with a partner and individually. For mathematical self-concept to be developed and nurtured students need a variety of ways to learn in order to feel 
confident, to take ownership of their learning and to develop their mathematical thinking in a positive way.

\subsection{Limitations of the study}

The data collected for this research was carried out over a two-year span. There were time restraints to carrying out this piece of research and having to work within the set timeframe, both of which were imposed by the size of a masterate study. The data was collected in term 3 of the first year and term 2 of the second year. The timing may have impacted on the students' perceptions of comparing the two years, as the timing in each year was not the same. This timing could also have an impact on the students' attitudes towards the teacher. In Year 6 the students had their form teacher and therefore may have a closer relationship than they did with their Year 7 Teacher who they saw only for five periods a week. Therefore, there could be different feelings towards the teachers that may have impacted on the data.

Limitations to studies in general include that the sample size could be perceived as too small (Seidman, 1998) and an unrepresentative sample can be seen as biased if it contains too many of one kind of people and not enough of another (Katzer, Cook \& Crouch, 1998). The research in this study was limited in scope to only one school and the students who participated in the study may not be representative of all Year 6 and Year 7 girls throughout New Zealand.

The use of the different curriculums in the comparison years could be seen as a limitation. The Numeracy Development Project and the Primary Years Programme (PYP) were implemented in Year 6, with Year 7 focusing on the Middle Years Programme (MYP). These differences could reflect different teaching styles and mathematical skills, topics studied, or tests or other events around the times of the questionnaires and interviews, and could have influenced when mathematics was taught during the day as well as what topics were being taught.

Furthermore, assumptions could have been made by participants regarding the researcher's view, for example, they may have decided the researcher thought that ability grouping is negative and that homogenous grouping is not the way forward 
for teachers to be organising lessons. All attempts were made to portray the researcher's view as unbiased, however it is possible that the questionnaires or semistructured interviews may have been perceived by participants as conveying the researcher's personal assumptions (Katzer et al., 1998). The study focused on students' self-perception and students had opportunities to express different viewpoints.

All research has some error (Katzer et al., 1998) and it is the job of the evaluator to identify these errors and understand that their research needs to work towards being objective and unhindered from the external influence of bias. To do so, the researcher reviewed the data multiple times, and used as large a sample as possible for the questionnaire and interview data.

Some limitations may be alleviated in a similar study if the research was extended in the following ways:

- other schools with the Year 6 to Year 7 transition of small group and whole class organisation could be included;

- the research could be conducted at same the time of the year when the teachers are teaching the same topic, for example Number, allowing for a more fair comparison of teaching strategies and class organisation; and

- observation of the differences in the curriculum being implemented in Year 6 and Year 7 and of students participation could be incorporated.

\subsection{Further questions promoted by the study}

This research indicates a variation of class organisation in mathematics occurred for the study students across Year 6 and Year 7 classes. This research raises further questions about the impact of these different ways of organising classes for mathematical learning. Questions that could be explored in other studies are:

- How do teaching strategies influence students' perception of their ability?

- What impact does the Numeracy Development Project have on primary schools and intermediate schools that are based in a secondary school setting? and

- How does class organisation in mathematics affect student achievement? 


\subsection{Implications}

Despite the limitations discussed above, this study indicates there is a need to look closely at class organisation in mathematics and how the classroom environment is being presented to students in New Zealand schools. More communication is needed about the effects of class organisation being managed in New Zealand schools, which may help to reduce negative self-concept in mathematics for girls in particular. Year 7 students would still benefit from teachers building communities of small group learning in their classrooms. These communities would then promote questioning and dialogue between students and teachers to create confident learners who are willing to take risks and discuss their learning.

Students have claimed that within a whole class teaching approach there can be limited differentiation. If many New Zealand schools secondary schools exhibit the lack of differentiation in mathematics then this may be a serious concern for New Zealand students. The Ministry of Education (1992) stipulated that students of all abilities need to have the opportunity to experience a range of mathematics that is suitable for their age, interests and capabilities. Straker (1999) says that one aim for the teacher in the whole class approach is making sure that all students keep up. This struggle to keep up can be a problem as students can give up. This may affect an individual's perception of their own ability and motivation for learning.

Webb (1989) and Webb and Farivar, (1994) identified several key variables for consideration when planning groupwork in the classroom. One of these variables is the teacher and instructional teaching (teacher's perceptions and expectations, classroom characteristics, teacher role, classroom management, preparation of teachers, assessment and accountability) and individual student and group variables (age/grade, achievement). Research has shown that teachers can struggle with the complexity of teaching heterogeneous classes, and can find it easier to teach ability-grouped classes. Since teachers often opt to teach to the 'average' child in the class, ability grouping achieves a better match between learning tasks and student aptitudes (Koshy, 2001). Researcher advocates of mixed ability schooling recommend a differentiated teaching approach for all students, and emphasise the need for teachers to have time for professional development and collaborative planning in preparation for lessons (Renzulli, 1994; Wheelock, 1992). 
Students in this study have claimed that collaborative group work can benefit an individual's mathematical self-concept and therefore it is vital that teachers are able to encourage and organise students using a variety of approaches: small group work, whole class, working with a partner and having an opportunity to work individually. Student perceptions are formed from the environment that the individual is working within, and therefore it is important to provide a variety of ways for students to learn as, according to Wong (1992), mathematical achievement is closely related to self-concept and attitudes towards mathematics. Findings clearly suggest that mathematical selfconcept is closely related to students' perceptions of their mathematical achievement, which implies that actual changes in mathematical education are likely to help address the student's self-concept as well (Davis, 1994). This organisation can prove to be difficult for teachers because whole class teaching can be viewed as being an easier way to group students as it cuts down on preparation time, and provides teachers with a consistent method to assess student development.

There may need to be more of a focus on secondary school teachers being trained with the Numeracy Development Project (NPD), which embraces cooperation and collaboration of students (Ministry of Education, 2003b). The Numeracy Development Project (NPD) groups' students close in ability (Strategy Stages), taking into consideration ability to work collaboratively, friendships and heterogeneous grouping (Ministry of Education, 2003b). Within an ability-grouped class, students are able to contribute more equally to group work (Mills \& Durden, 1992), and discuss ideas together more easily (Koshy, 2001).

Teachers often do not have the choice about teaching organisation, streamed or unstreamed classes. They need to fit into the system of the school at which they teach. Teachers need to take into consideration that every class is different and has different needs and abilities. It is best practice to teach to those needs and cater for the strengths and weaknesses of the students.

This study indicates that there is a need for education professionals to have more direction about which method of organisation is most beneficial for New Zealand students in promoting a positive mathematical self-concept. There is much debate about whether to ability group or not. The debate can now be stretched to looking at 
motivation, self-concept and learning expectations, and how students work together and the experiences they get from those discussions, whether in small group or whole class situations. This research will enable a better understanding of the effective way to organise mathematics by providing tools teachers could use to examine their own students' views. Such data will allow these teachers to stand back and assess their programme of delivery and evaluate the methods they use in their classroom and how their students feel about it.

In summary, this research has found that students are well aware of their mathematical ability and that it is important for teachers to have an awareness of the positive and negative aspects of the way they organise a mathematics classroom, as this knowledge will assist in maximising the learning of New Zealand students. It is important that these effects are investigated further. Focusing on enhancing students' mathematical selfconcept in all mathematical classes whether in a primary school or secondary school setting is vital in order to help teachers have a clear understanding that class organisation does play a role in developing this, and in turn in enhancing students' learning. 


\section{REFERENCES}

Adams, D., Carlson, H., \& Hamm, M. (1990). Cooperative learning and educational media: Collaborating with technology and each other. Englewood Cliffs, NJ: Educational Technology Publications.

Anthony, G., \& Walshaw, M. (2007). Effective Pedagogy in Pāngarau/Mathematics: Best Evidence Synthesis Iteration (BES). Wellington: Ministry of Education.

Bankston, C. L. III., \& Zhou, M. (2002). Being well vs. doing well: Self-esteem and school performance among immigrant and non-immigrant racial and ethnic groups. International Migration Review, 36, 389-415.

Bartholomew, H. (2003). Ability grouping and the construction of different types of learner in mathematics classrooms. In L. Bragg, C. Campbell, G. Herbert, \& J. Mousley (Eds.), Mathematics education research: Innovation, networking, opportunity. Proceedings of the $26^{\text {th }}$ annual conference of the Mathematics Education Research Group of Australasia, Vol. 1, pp. 128-135. Sydney, NSW: MERGA.

Baxter, J.A., Woodward, J., \& Olson, D. (2001). Effects of reform-based mathematics instruction on low achievers in five third-grade classrooms. Elementary School Journal, 101(5), 529-47.

Becker, J. \& Foletta, G. (2003). Ability Grouping Is Not Just Tracking Anymore. Roeper Review, 26(1), 29-36.

Bennett, N. \& Cass, A. (1998). The effects of group composition on group interactive process and pupil understanding. British Educational Research Journal, 15 (1), $19-32$.

Boaler, J. (1999). Participation, Knowledge and Beliefs: A Community Perspective on Mathematics Learning. Educational Studies in Mathematics, 40, 259-281.

Boaler, J. William, D., \& Brown, M. (2000). Students' experiences of ability grouping disaffection, polarisation and the construction of failure. British Educational Research Journal, 26(5), 631-648.

Boaler, J., \& William, D. (2001). 'We've still got to learn!': Students' perspectives on ability grouping and mathematics achievement. In Gates, P. (Ed.), Issues in mathematics teaching (pp. 77-92). London, England: Routledge Falmer.

Bogdan, R. \& Biklen, S.K. (1998). Qualitative research for Education: An introduction to theory and methods ( $3^{\text {rd }}$ ed.). Boston, MA: Allyn \& Bacon.

Booker, G., Bond, D., Sparrow, L., \& Swan, P. (2004). Teaching Primary Mathematics ( $3^{\text {rd }}$ ed.). Australia: Pearson Education.

Bong, M., \& Clark, R.E. (1999). Comparison between self-concept and self-efficacy in academic motivation research. Educational Psychologist, 34(3), 139-153. 
Bossert, S.T. (1979). Tasks and social relationships in classrooms: A study of instructional organization and its consequences. New York, NY: Cambridge University Press.

Bossert, S. T. (1988). Cooperative activities in the classroom. Review of Research in Education, 15(1988-1989), 225-250.

Braddock, J., \& Slavin, R. (1995). Why ability grouping must end: Achieving excellence and equity in American education. In Pool, H., \& Page, J. (Eds.), Beyond tracking: finding success in inclusive schools (pp. 7-20). Bloomington, IN: Phi Delta Kappa Educational Foundation.

Burns, R.B. (1994). Introduction to research methods in education. Cheshire, England: Longman.

Campbell, D., \& Fiske, D.W. (1957). Convergent and discriminant validation by multitrait-multimethod matrix. Psychological Bulletin, 54, 291-32.

Cohen, E. (1994). Restructuring the classroom: Conditions for productive small groups. Review of Educational Research, 64(1), 1-35.

Cohen, L., Manion, L., \& Morrison, K. (2000). Research Methods in Education $\left(5^{\text {th }}\right.$ ed.), Validity and Reliability (pp. 106-117). London, England: Routledge.

Coms, A. W., \& Snygg, D. (1959). Individual behavior (2nd ed.). New York, NY: Harper \& Row.

Creswell, J.W., \& Clark, V.P. (2007). Designing and conducting mixed methods research. Thousand Oaks, CA: Sage.

Davis, R.B. (1994). What mathematics should students learn? The Journal of Mathematic Behaviour, 13, 3-33.

Denscombe, M. (2007). Good Research Guide. Buckingham, England: Open University Press.

Diezmann, C.M., \& Watters, J.J. (2001). The collaboration of mathematically gifted students on challenging tasks. Journal for the Education of the Gifted, 25(1), 731 .

Dickhauser, O., \& Meyer, W.U. (2006). Gender differences in young children's math ability attributions. Psychology Science, 48, 2006(1), 3-16.

Education Review Office (2000). In Time for the Future. A Comparative Study of Mathematics and Science Education. Wellington, New Zealand: Author.

Education Review Office (2007) The Quality of Teaching: Good Practice. Wellington, New Zealand: Author. 
Education Review Office (2008). Schools' Provision for Gifted and Talented Students: Good Practice. Wellington, New Zealand: Author.

Fennema, E., \& Sherman, J.A. (1978). Sex-related differences in mathematics achievement and related factors: A further study. Journal for Research in Mathematics Education, 9, 189-203.

Foote, N.J. (2006). The Impact of Grouping in Mathematics in Elementary Schools. Retrieved on February 15, 2009, from http://etd.ohiolink.edu/sendpdf.cgi/Foote\%20Nancy.pdf?marietta1144375834

Fouad, N. (2008). Tracking The Reasons Many Girls Avoid Science And Math. Retrieved on May 4, 2010, from http://www.sciencedaily.com/releases/2008/09/080905153807.htm

Grouws, D. A., \& Cebulla, K. J. (2000). Improving student achievement in mathematics (Vol. 4). Genf, Switzerland: International Academy of Education/International Bureau of Education.

Hall, T., Strangman, N., \& Meyer, A. (2003). Differentiated instruction and implications for UDL implementation. National Center on Accessing the General Curriculum. Retrieved on July 9, 2004 from http://www.k8accesscenter.org/training_resources/udl/diffinstruction.asp

Hamachek, D. (1995). Self-concept and school achievement: Interaction dynamics and a tool for assessing the self-concept component. Journal of Counseling and Development, 73, 419-425.

Hollifield, J. (2000). Is Ability Grouping the Way to Go - Or Should it Go Away? Retrieved on September 20 2008, from http://www.educationworld.com/a issues/Issues002.shtml

Holloway, J. H. (2001). Grouping Students for Increased Achievement. Educational Leadership, 59(3), 84-85.

Holloway, J. H. (2003). Grouping Gifted Students. Educational Leadership, 61(2), 89-91.

International Baccalaureate Organization (2009). Primary Years Programme Making the PYP happen. Cardiff, Wales: Author.

International Baccalaureate Organization (2010). The Middle Years Programme Preparing students for university in the 21st century. Retrieved on October 5, 2010 from

https://www.ibo.org/myp/documents/MYP_PreparingstudentsUKrecognition.pdf

Ireson, J., \& Hallam, S. (2005). Pupils' liking for school: Ability grouping, self-concept and perceptions of teaching. British Journal of Educational Psychology, 75, 297311. 
Ireson, J., Hallam, S., \& Hurley, C. (2002, September). Ability grouping in the secondary school: effects on GCSE attainment in English, Mathematics and Science. Paper presented at the British Educational Research Association Annual Conference, Exeter University, Exeter.

Ireson, J., Hallam, S., \& Plewis, I. (2001). Ability grouping in secondary schools:

Effects on pupils' self-concepts. British Journal of Educational Psychology, 71, 315-326.

Jackson, B. (1964). Streaming: An Education System in Minature. London, England: Routedge \& Kegan.

Katzer, J., \& Cook, K., \& Crouch, W. (1998). Evaluating Information: A Guide for Users of Social Science Research ( $4^{\text {th }}$ ed.). New York, NY: McGraw Hill.

Koshy, V. (2001). Teaching mathematics to able children. London, England: David Fulton.

Kulik, C.L., \& Kulik, J.A. (1982). Effects of ability grouping on Secondary School Students: A meta-analysis of evaluation findings. American Educational Research Journal, 19, 415-428.

Kutnich, P. (1994). Use and effectiveness of groups in the classrooms: Towards pedagogy. In P. Kutnick \& C. Rogers (Eds.), Groups in Schools (pp. 1333). London, England: Cassell Education.

Kvale, S. (1996). Interview: An Introduction to Qualitative Research Interviewing. Thousand Oaks, California: Sage.

Lampert, M. (1986). Knowing, doing and teaching multiplication. Cognition and Instruction, 3(4), 305-342.

Lockett, C. T., \& Harrell, J. P. (2003). Racial identity, self-esteem, and academic achievement: Too much interpretation, too little supporting data. Journal of Black Psychology, 29, 325-336.

Loveless, T. (1998). The tracking and ability grouping debate. Thomas B. Fordham Foundation. Retrieved on January 27, 2012 from http://www.edexcellence.net

MacIntyre, H., \& Ireson, J. (2002). Within-class Ability Grouping: placement of pupils in groups and self-concept. British Educational Research Journal, 28(2), 249-263.

Manger, T., \& Eikeland, O. (1998). The Effect of Mathematics Self-Concept on Girls' and Boys' Mathematical Achievement. School Psychology International, 19(1), 518 .

Marsh, H. W., \& Yeung, A. S. (1998). Longitudinal structural models of academic selfconcept and achievement: Gender differences in the development of Math and English constructs. American Educational Research Journal, 35, 705-738. 
Martin, A., \& Debus, R. L. (1998). Self-reports of mathematics self-concept and educational outcomes: The roles of ego-dimensions and self-consciousness. British Journal of Educational Psychology, 68 (4), 517-535.

Matheson, J.K. (2009). The predominant teaching strategies in Year 8 and Year 9 Mathematics classrooms. Wellington, New Zealand: Victoria University Press.

Mills, C., \& Durden, W. (1992). Co-operative learning and ability grouping: an issue of choice. The gifted Child Quarterly, 36(1), 11-15.

Ministry of Education. (1992). The New Zealand Curriculum. Wellington, New Zealand: Author.

Ministry of Education. (2002). The School and Classroom Context for Year 9 Students' Mathematics and Science Achievement. Results from New Zealand's participation in the repeat of the Third International Mathematics and Science Study. Wellington, New Zealand: Author.

Ministry of Education. (2003a). Book 1, The Number Framework. Numeracy Professional Development Projects. Wellington, New Zealand: Author.

Ministry of Education. (2003b). Book 3, Getting Started. Numeracy Professional Development Projects. Wellington, New Zealand: Author.

Ministry of Education. (2003c). Transition to Secondary School: A Literature Review. Wellington, New Zealand: Author.

Ministry of Education. (2007). The New Zealand Curriculum. Wellington, New Zealand: Author.

Ministry of Education. (2008). Relevant Legislation. NEGs and NAGs. Retrieved on October 20, 2011, from http://www.minedu.govt.nz/NZEducation/EducationPolicies/Schools/Polic yAndStrategy/PlanningReportingRelevantLegislationNEGSAndNAGS.asp $\underline{\mathrm{x}}$

Ministry of Education (2009a). Student Learning Approaches for Tomorrow's World. Results of New Zealand 15 year olds in the 2003 PISA Survey. Wellington, New Zealand: Author.

Ministry of Education (2009b). The New Zealand Curriculum. Mathematical Standards for Years 1-8. Wellington, New Zealand: Author.

Nagy, G., Trautwein, U., Koller, O., Baumert, J., \& Garrett, J. (2006). Gender and course selection in upper secondary education: Effects of academic self-concept and intrinsic value. Educational Research and Evaluation, 12, 323-345. 
Nagy, G., Garrett, J., Trautwein, U., Cortina, K. S., Baumert, J., \& Eccles, J. (2008). Gendered high school course selection as a precursor of gendered occupational careers: The mediating role of self-concept and intrinsic value. In H. M. G. Watt \& J. S. Eccles (Eds.), Gendered occupational outcomes: Longitudinal assessments of individual, social, and cultural influences (pp. 115-143). Washington, DC: American Psychological Association.

National Council of Teachers of Mathematics (NCTM). (2000). Principles and Standards for School Mathematics. Reston, VA: Author.

New Zealand Association for Research in Education. (1998). Ethical Guidelines. Retrieved on April 25, 2010, from http://www.nzare.org.nz/pdfs/NZARE_ethical_guidelines.pdf

Oakes, J. (1995). More than meets the eye: Links between tracking and the culture of schools. In Pool, H., \& Page, J. (Eds.) Beyond tracking: Finding success in inclusive schools (pp. 59-70) Bloomington, IN: Phi Delta Kappa Educational Foundation.

Pajares, F., \& Schunk, D.H. (2001). Self-beliefs and School Success: Self-efficacy, Self-concept and School Achievement. In R. Riding and S. Rayner (Eds). Perception (pp. 239-266). London, England: Ablex.

Piaget, J. (1928). The language and thought of the child. New York, NY: Harcourt Brace.

Pintrich, P.R., \& De Groot, E.V. (1990). Motivational and self-regulated learning components of classroom academic performance. Journal of Educational Psychology, 82, 33-40.

Renzulli, J. (1994). Schools for talent development: a practical plan for total school improvement. Mansfield Center, CT: Creative Learning Press.

Reyes, L.H. (1984). Affective variables and mathematics education. Elementary School Journal, 84, 558-581.

Rogers, C. (1982). Freedom to learn in the eighties. Columbus, OH: Merill.

Rogers, K. (1991). The relationship of grouping practices to the education of the gifted and talented learner. Storrs, CT: NRC/GT.

Ross, C. E., and Broh. B.A. (2000). The Roles of Self-Esteem and the Sense of Personal Control in the Academic Achievement Process. Sociology of Education, 73(4), 270-284.

Schmidt, J. A., \& Padilla, B. (2003). Self-esteem and family challenge: An investigation of their effects on achievement. Journal of Youth and Adolescence, 32, 37-46. 
Schoenfeld, A. (1983). Problem solving in the mathematics curriculum: A report, recommendations, and an annotated bibliography. Washington, D.C.: Mathematical Association of America.

Seidman, I. (1998). Interviewing as Qualitative Research: A Guide for researchers in Education and the Social Sciences. New York, NY: Teachers College Press.

Shavelson, R. J., \& Bolus, R. (1981). Self-concept: The interplay of theory and methods. Journal of Educational Psychology, 74(1), 3-17.

Silverman, D. (1993). Interpreting Qualitative Data: Methods for Analysing Talk, Text and Interaction. London, England: Sage.

Silverman, D. (2005). Doing Qualitative Research (2 ${ }^{\text {nd }}$ ed.) London, England: Sage.

Slavin, R.E. (1990). Student team learning in mathematics. In: Davidson, N., (Ed.) Cooperative learning in math: a hand-book for teachers, pp. 69-102. Boston, MA, Allyn \& Bacon.

Smith, C.M., \& Sutherland, M.J. (2003). Setting or mixed ability? Teachers' views of the organisation of pupils for learning. Journal of Research in Special Educational Needs, 3 (3), 141-146.

Steel, M. (2005). Ability Grouping and Mathematics Education. ACE Papers. March Issue 15.

Stipek, D., \& Granlinski, H. (1991). Gender Differences in Children's AchievementRelated Beliefs and Emotional Responses to Success and Failure in Mathematics. Journal of Educational Psychology , 83(3), 361-71.

Straker, A. (1999). The National Numeracy Project 1996-1999. In I. Thompson (Ed.), Issues in teaching numeracy in primary schools. (pp. 39-47). Buckingham, England: Open University Press.

Tomlinson, C.A. (1999). How to differentiate instruction in mixed-ability classrooms. Alexandria, VA: ASCD.

Verkuyten, M., \& Brug, P. (2002). Ethnic identity achievement, self-esteem, and discrimination among Surinamese adolescents in the Netherlands. Journal of Black Psychology, 28, 122-141.

Vygotsky, L. (1978). Mind and Society. Cambridge: Cambridge University Press.

Walker, R., \& Debus, R. (1991). Subject-specific components of academic selfconcept and self-efficacy. Contemporary Educational Psychology, 16 (4), 331-345.

Wang, J. (2007). A Trend Study of Self-Concept and Mathematics Achievement in a Cross-Cultural Context. Mathematics Education Research Journal, 19(3), 33-47. 
Ward, R. (2000). Transfer from middle to secondary school: A New Zealand study. International Journal of Educational Research, 33, 365-374.

Webb, N. M. (1989). 'Peer Interaction and Learning in Small Groups'. International Journal of Educational Research, 13, 21-39.

Webb, N. M. (1991). Task-related verbal interaction and mathematics learning in small groups. Journal for Research in Mathematics Education, 22, 366-389.

Webb, N., \& Farivar, S. (1994). 'Promoting Helping Behavior in Cooperative Small Groups in Middle School Mathematics'. American Educational Research Journal, 31, 369-395.

Wheelock, A. (1992). Crossing the Tracks: How "Untracking” Can Save America's Schools. New York, NY: New Press.

Wong, N. (1992). The Relationship among Mathematics Achievement, Affective Variables and Home Background. Mathematics Education Research Journal, 4, 32-42.

Yates, L. (1999). Transitions and the year 7 experience: A report from the 12 to 18 project. Australian Journal of Education, 43(1), 24-41 


\section{Appendix 1: Questionnaire}

VICTORIA UNIVERSITY OF WELLINGTON

Te Whare Wananga o te Upoko o te Ika a Maui

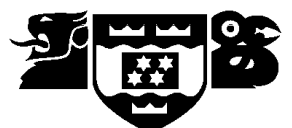

Name:

Teacher for Mathematics:

\section{Grouping Code:}

Purpose: The purpose of this questionnaire will assist in finding out how you feel about how the class is organised into groups for mathematics. The meaning of 'group' is inclass organisation and small group teaching.

\section{Questionnaire Instructions:}

- For each question/statement circle one number only (1-6).

- Please answer every question

Does your class/form teacher teach you maths? Yes No

1. Do you like maths?

$\begin{array}{cccccc}\begin{array}{c}\text { Not at } \\ \text { all }\end{array} & & & & & \begin{array}{c}\text { Yes } \\ \text { definitely }\end{array} \\ 1 & 2 & 3 & 4 & 5 & 6\end{array}$

2. Do you ask questions in whole class discussions?

$\begin{array}{cccccc}\begin{array}{c}\text { Not at } \\ \text { all }\end{array} & & & & & \begin{array}{c}\text { Yes } \\ \text { definitely }\end{array} \\ 1 & 2 & 3 & 4 & 5 & 6\end{array}$

3. Do you ask questions in small group discussions?
Not at
Yes
all
1
$2 \quad 3$
4
definitely
6

4. Do you ask questions one-on-one with the teacher?

Not at

all

1

2

3

4

Yes

definitely

6

5. Are you are good at maths?

Not at

Yes

all

2

3

4

5

definitely

6 
6. Do you think your friends think you are good at maths?

$\begin{array}{cccccc}\begin{array}{c}\text { Not at } \\ \text { all }\end{array} & & & & & \begin{array}{c}\text { Yes } \\ \text { definitely }\end{array} \\ 1 & 2 & 3 & 4 & 5 & 6\end{array}$

7. Do you think your parents think you are good at maths?

$\begin{array}{cccccc}\begin{array}{c}\text { Not at } \\ \text { all }\end{array} & & & & & \begin{array}{c}\text { Yes } \\ \text { definitely }\end{array} \\ 1 & 2 & 3 & 4 & 5 & 6\end{array}$

8. Do you think your teacher thinks you are good at maths?

Not at

all

1
2
4
Yes

definitely

6

Yes

definitely

6

10. Describe the group you are taught maths in (The meaning of 'group' is in-class organisation and small group teaching)

11. Describe how you feel being taught in this group

12. Are you happy to learn in this group? Give reasons for why or why not

13. Is there a way you would prefer to learn? Explain why and how? 


\title{
Appendix 2: Semi-Structured Interviews
}

\author{
VICTORIA UNIVERSITY OF WELLINGTON \\ Te Whare Wananga o te Upoko o te Ika a Maui
}

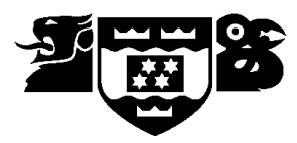

\section{Interview Questions (Year 6)}

Purpose: The purpose of this interview will assist in delving deeper into how individuals from different abilities feel about mathematics and how the classroom is organised in a mixed ability with the teaching structured in small groups.

1. Is maths a favourite subject of yours? Explain why or why not?

2. Describe how you feel about maths?

3. Do you like the maths group you are in? Explain why/why not?

4. Do you think that you are good at maths? Explain why/why not?

5. Do you answer questions during class? Explain why/why not?

6. Do you ask your teacher for help when you need it? Explain why/why not?

7. Have you heard about how students learn maths here in Year 7?

8. Do you think the way you have been grouped has affected how good you think you are at maths? 


\section{VICTORIA UNIVERSITY OF WELLINGTON \\ Te Whare Wananga o te Upoko o te Ika a Maui}

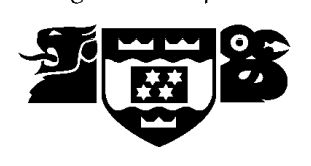

\section{Interview Questions (Year 7)}

Purpose: The purpose of this interview will assist in delving deeper into how individuals from different abilities feel about mathematics and how the classroom is organised in a cross-class ability grouping with whole class teaching.

1. What are the main differences students see from Year 6 to Year 7?

2. What are the differences in the way you are taught maths from Year 6 or Year 7?

3. Have you noticed any differences in the way you are grouped?

4. How do you feel about the differences in grouping for maths?

5. Do you think the way you have been grouped has affected how good you think you are at maths? 


\title{
Appendix 3: Information Letters
}

\author{
VICTORIA UNIVERSITY OF WELLINGTON \\ Te Whare Wananga o te Upoko o te Ika a Maui
}

\begin{abstract}
50
Project Title:

Class Organisation and its effects on the mathematical self-concept of Year 6 and 7 female students: PRINCIPAL/TEACHER

I am doing research as part of my Masters of Education at Victoria University, Wellington. The study will be conducted over two years. The purpose of the study is to investigate if class organisation in regards to grouping affects female students' mathematical self-concept. My research question is: To what extent does class organisation in mathematics affect female student's mathematical self-concept?
\end{abstract}

The study is voluntary and will involve students of Year 6 and Year 7 completing a questionnaire and from those answers 9 students from different strategy groups will be interviewed in more depth. The questionnaires with students will take up to 40 minutes and the Interviews with students will take up to half an hour in both years of study. All questionnaires and interviews will take place at a pre-arranged time that will be negotiated with the teacher and will be administered by the researcher.. All participating teachers will be interviewed about their grouping decisions in mathematics and will take up to 10 minutes. All data will be collected at school. All written material (questionnaires, interview notes, etc) will be kept in a locked file. All electronic information will be kept in a password-protected file. Any audio or video recordings will be electronically wiped. Access to the research data will be restricted to the researcher and the supervisor, Dr Robin Averill.

The information from the study may be used to inform conference presentations and/or journal articles. Information that is collected will remain confidential. A summarised version of the findings will be written up and given for you to read. The findings will be written up in a thesis that will be graded by Victoria University in order for me to complete my MEd in 2012. The study school and participating individuals will not be able to be identified and all material gathered will be confidential to the researchers.

If you agree to take part, you can withdraw your consent at any time by informing me via email, telephone or by letter. An ethics application has been approved to begin the study. If you have any queries, please contact me or my supervisor Dr Robin Averill from the School of Education (contact details below).

Yours sincerely

Rebecca Blackwood

Masters Student, Faculty of Education, Victoria University

Dr Robin Averill

School of Educational Policy and Implementation, Faculty of Education

Contact Details

DDI: 0275461145

DDI: (04) 4639714

email: beckyblackwood@gmail.com email: robin.averill@vuw.ac.nz

Mailing Address

Victoria University

Faculty of Education

PO Box 17-310

Karori

Wellington 


\section{VICTORIA UNIVERSITY OF WELLINGTON \\ Te Whare Wananga o te Upoko o te Ika a Maui}

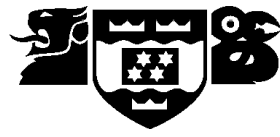

Project Title:

Class Organisation and its effects on the mathematical self-concept of Year 6 and 7 female students: PARENTS

I am doing research as part of my Masters of Education at Victoria University, Wellington. The study will be conducted over two years. The purpose of the study is to investigate if class organisation in regards to grouping affects female students' mathematical self-concept. My research question is: To what extent does class organisation in mathematics affect female student's mathematical self-concept?

The study is voluntary and will involve students of Year 6 in 2010 and Year 7 in 2011 completing a questionnaire and from those answers students will be interviewed in more depth. The questionnaires with students will take up to 40 minutes and the Interviews with students will take up to half an hour in both years of study. All questionnaires and interviews will take place at a pre-arranged time, which will be negotiated with the class teacher. All data will be collected at school. All written material (questionnaires, interview notes, etc) will be kept in a locked file. All electronic information will be kept in a passwordprotected file. Any audio or video recordings will be electronically wiped. Access to the research data will be restricted to the researcher and the supervisor, Dr Robin Averill.

The information from the study may be used to inform conference presentations and/or journal articles. Information that is collected will remain confidential. A summarised version of the findings will be written up and given for you to read. The findings will be written up in a thesis that will be graded by Victoria University in order for me to complete my MEd in 2012. The study school and participating individuals will not be able to be identified and all material gathered will be confidential to the researcher.

If you agree for your child to take part, you can withdraw your consent at any time by informing me via email, telephone or by letter. An ethics application has been approved to begin the study. If you have any queries, please contact me or my supervisor Dr Robin Averill from the School of Education (contact details below).

Yours sincerely

Miss Rebecca Blackwood

Masters Student, Faculty of Education, Victoria University

Dr Robin Averill

School of Educational Policy and Implementation, Faculty of Education

\section{Contact Details}

DDI: 0275461145

DDI: (04) 4639714

\section{Mailing Address}

Victoria University

Faculty of Education

PO Box 17-310

Karori

Wellington email: beckyblackwood@gmail.com

email: robin.averill@vuw.ac.nz 


\section{VICTORIA UNIVERSITY OF WELLINGTON \\ Te Whare Wananga o te Upoko o te Ika a Maui}

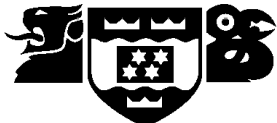 \\ Project Title: \\ Class Organisation and its effects on the mathematical self-concept of Year 6 and 7 female students: STUDENTS}

I am doing research into good ways of teaching and learning mathematics. The study will be conducted over two years.

I will be asking students to complete a questionnaire to tell me about how they feel in mathematics. I will be asking 9 students from different strategy groups to answer some questions. I might need to ask you some questions and I might also use a tape recorder so I can listen to people's answers again. If you decided to participate you will have 40 minutes to answer the questionnaire and if you are chosen for the interview that will take up to 30 minutes.

All data will be collected at school. All written material (questionnaires, interview notes, etc) will be kept in a locked file. All electronic information will be kept in a password-protected file. Any audio or video recordings will be electronically wiped. Access to the research data will be restricted to the researcher and the supervisor, Dr Robin Averill.

I would really like it if you could help me with this research. You can say no as your participation is voluntary. The research is being done so that teachers can find out really good ways of organising and teaching mathematics. The research is confidential. This means that no one apart from the people in the research will know who has participated.

The findings will be written up in a thesis that will be graded by Victoria University in order for me to complete my MEd in 2012. The information from the study may be used to inform conference presentations and/or journal articles. The ideas collected are confidential. This means no one will know which ideas came from each person.

If you agree to be part of the project, you can stop being part of it any time by telling your teacher, your parent/guardian, or me that you want to stop.

If you have any questions, please ask your teacher at school or myself, through email, telephone or a letter. An ethics application has been approved to begin the study.

Thank you very much

Rebecca Blackwood

Masters Student, Faculty of Education, Victoria University

Robin Averill

School of Educational Policy and Implementation, Faculty of Education

\section{Contact Details}

DDI: 0275461145

DDI: (04) 4639714

email: beckyblackwood@gmail.com

email: robin.averill@vuw.ac.nz

Mailing Address

Victoria University

Faculty of Education

PO Box 17-310

Karori

Wellington 


\title{
Appendix 4: Consent Forms
}

\author{
VICTORIA UNIVERSITY OF WELLINGTON \\ Te Whare Wananga o te Upoko o te Ika a Maui
}

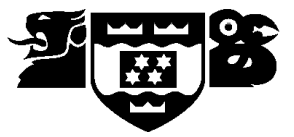

Informed Consent Form for Participants: Principal

\section{Project Title: Class Organisation and its effects on the mathematical self-concept of Year 6 and 7 female students.}

I agree for the school to take part in the above research project. I have had the project explained to all involved. I have read the Explanatory Statement, which I will keep for my records.

I understand that agreeing for the school to take part means that up to 40 students from Year 6, 2010 and their parents/guardians will be given information about the study. The students for who consent is given will be involved in answering questionnaires in 2010 and 2011 and 9 students will be interviewed. The questionnaire will be administered and collected by the researcher. I also understand that participating teachers will be interviewed about their grouping decisions in mathematics.

The schools participation will be for 2 years and that participating students will be re-interviewed.

any information is confidential and no information that could lead to the identification of any individual will be disclosed in any reports on the project

\section{I understand that:}

the schools participation is voluntary and that the school can choose not to participate in the project

the school can withdraw at any stage of the project without being penalised or disadvantaged in any way

$\square$ the information the school provides cannot be used except for this project and the dissemination of the project results eg. through conference presentations or journal articles

the materials will be destroyed 1 year after the completion of the study

(please tick each box)

I consent to the school being involved in this research project.

Name:

Signature:

Date:

I would like written feedback about the outcomes of this research.

Address to which the research findings should be sent: 
VICTORIA UNIVERSITY OF WELLINGTON

Te Whare Wananga o te Upoko o te Ika a Maui

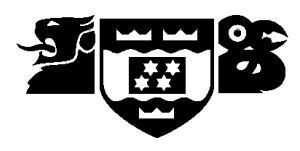

Informed Consent Form for Participants: Teachers

\section{Project Title: Class Organisation and its effects on the mathematical self-concept of Year 6 and 7 female students.}

I agree to take part in the above research project. I will have the project explained and I will have read the Explanatory Statement, which I will keep for my records. I understand that agreeing to take part means that I am willing:

to be interviewed by the researcher to explain how I group my students for mathematics

\section{I understand that:}

participation will be for 2 years and that participating students will be re-interviewed.

any information is confidential and no information that could lead to the identification of any individual will be disclosed in any reports on the project

my participation is voluntary and that I can choose not to participate in the project

I can withdraw at any stage of the project without being penalised or disadvantaged in any way

the information I provide cannot be used except for this project and the dissemination of the project results eg. through conference presentations or journal articles

the materials will be destroyed 1 year after the completion of the study

(please tick each box)

I consent to be involved in this research project.

Name:

Signature:

Date:

I would like written feedback about the outcomes of this research.

Address to which the research findings should be sent: 


\section{VICTORIA UNIVERSITY OF WELLINGTON \\ Te Whare Wananga o te Upoko o te Ika a Maui}

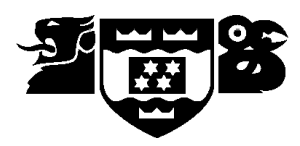

\section{Informed Consent Form for Participants: Teachers \\ Project Title: Class Organisation and its effects on the mathematical self-concept of Year 6 and 7 female students.}

I agree to take part in the above research project. I will have the project explained and I will have read the Explanatory Statement, which I will keep for my records. I understand that agreeing to take part means that I am willing:

to be interviewed by the researcher to explain how I group my students for mathematics

participation will be for 2 years and that participating students will be re-interviewed.

\section{I understand that:}

any information is confidential and no information that could lead to the identification of any individual will be disclosed in any reports on the project

my participation is voluntary and that I can choose not to participate in the project

I can withdraw at any stage of the project without being penalised or disadvantaged in any way

$\square$ the information I provide cannot be used except for this project and the dissemination of the project results eg. through conference presentations or journal articles

the materials will be destroyed 1 year after the completion of the study

(please tick each box)

I consent to be involved in this research project.

Name:

Signature:

Date:

I would like written feedback about the outcomes of this research.

Address to which the research findings should be sent: 


\section{VICTORIA UNIVERSITY OF WELLINGTON \\ Te Whare Wananga o te Upoko o te Ika a Maui}

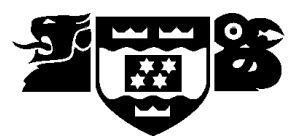

Informed Consent Form for Participants:

Parents of Children involved in the Study

\section{Project Title: Class Organisation and its effects on the mathematical self-concept of Year 6 and 7 female students.}

I agree that my child may take part in the research project. I have had the project explained to me and I have read the Explanatory Statement, which I keep for my records. I understand that agreeing to take part means that I am willing for my child to:

answer questions in a questionnaire

be interviewed by the researcher

\section{I understand that:}

any information is confidential and no information that could lead to the identification of any individual will be disclosed in any reports on the project

participation will be for 2 years and that participating students will be re-interviewed.

my child's participation is voluntary and that we can choose not to participate in the project

$\square$ I can withdraw my child at any stage of the project without being penalised or disadvantaged in any way

$\square$ the information my child provides cannot be used except for this project and the dissemination of the project results eg. through conference presentations or journal articles

$\square$ the data will be destroyed 1 year after the conclusion of the research

(Please tick each box)

I consent to my child's involvement in this research.

Student's Name:

Name:

Signature:

Date:

I would like written feedback about the outcomes of this research.

Address to which the research findings should be sent: 